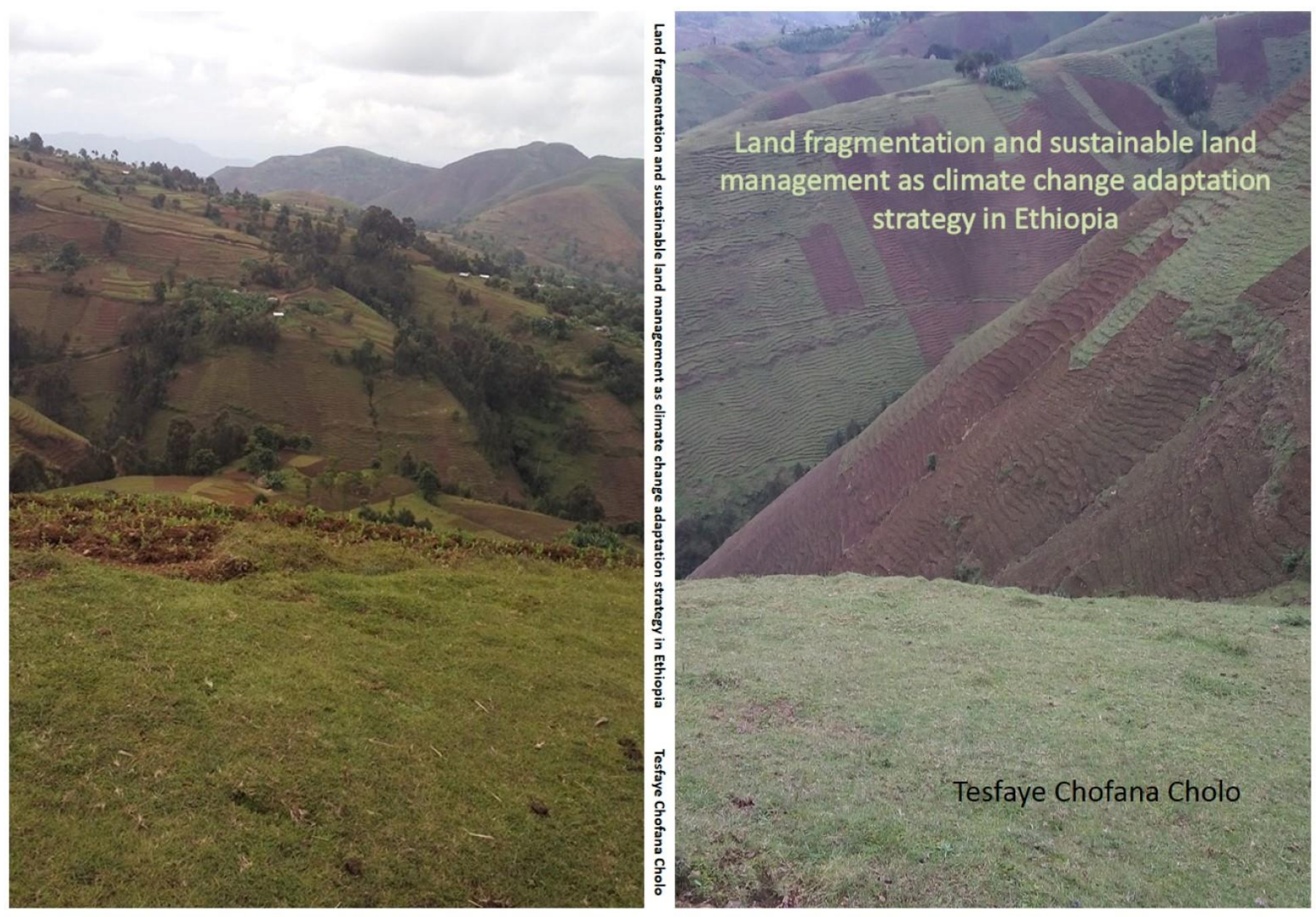




\section{Land fragmentation and sustainable land management as climate change adaptation strategy in Ethiopia}

Tesfaye Chofana Cholo 


\section{Thesis committee}

\section{Promotor}

Prof. Dr Coen J. Ritsema

Professor of Soil Physics and Land Management

Wageningen University \& Research

\section{Co-promotors}

Dr Luuk Fleskens

Associate professor, Soil Physics and Land Management Group

Wageningen University \& Research

Dr Jack H.M. Peerlings

Associate professor, Agricultural Economics and Rural Policy Group

Wageningen University \& Research

\section{Other members}

Prof. Dr F. Ludwig, Wageningen University \& Research

$\operatorname{Dr}$ A.A. Taye, Addis Ababa University, Ethiopia

Dr M.M. Bakker, Wageningen University \& Research

Dr Y. de Mey, Wageningen University \& Research

This research was conducted under the auspices of the Research School for SocioEconomic and Natural Sciences of the Environment (SENSE) 


\section{Land fragmentation and sustainable land management as climate change adaptation strategy in Ethiopia}

\section{Tesfaye Chofana Cholo}

\section{Thesis}

submitted in fulfilment of the requirements for the degree of doctor at Wageningen University by the authority of the Rector Magnificus,

Prof. Dr A.P.J. Mol, in the presence of the

Thesis Committee appointed by the Academic Board to be defended in public on Wednesday 5 September 2018 at 11 a.m. in the Aula. 


\section{Propositions}

1. Land fragmentation increases food security of subsistence agricultural households in the Gamo Highlands of Ethiopia.

(this thesis)

2. Technical efficiency not only differs between farmers, but also between plots of one farm.

(this thesis)

3. For an individual country, climate change adaptation is less costly than climate change mitigation.

4. The job creation effects of technological progress are significantly greater than the job destruction effects.

5. Through short term training a society can get rid of the immediate causes of poverty.

6. Increasing military defense expenditure increases insecurity.

Propositions belonging to the thesis entitled "Land fragmentation and sustainable land management as climate adaptation strategy in Ethiopia"

Tesfaye Chofana Cholo

Wageningen, 5 September 2018 
Tesfaye Chofana Cholo

Land fragmentation and sustainable land management as climate change adaptation strategy in Ethiopia, 134 pages.

PhD thesis, Wageningen University, Wageningen, the Netherlands (2018)

With references, with summary in English

DOI: https://doi.org/10.18174/456352

ISBN: 978-94-6343-323-5 


\section{Table of contents}

1. General introduction $\quad 7$

2. Is land fragmentation facilitating or obstructing adoption of climate adaptation measures in Ethiopia?

3. Land fragmentation, climate change adaptation, and food security in the Gamo Highlands of Ethiopia

4. Land fragmentation, technical efficiency, and adaptation to climate change by farmers in Ethiopia

5. Gendered climate change adaptation practices in fragmented farm fields of Gamo Highlands, Ethiopia

6. Synthesis

Literature cited 107

English summary 123

Acknowledgements 127

About the author 



\section{General introduction}




\subsection{Climate change impacts}

Although the entire world faces climate change impacts, the nature of such impacts varies spatially (Parry et al., 1999; Olesen and Bindi, 2002; Mendelsohn et al., 2006; Parry et al., 2007). Climate change impacts are most challenging to low income countries (Tol, 2011) and people living in poverty (Reilly and Schimmelpfennig, 1999). Agriculture is the sector most affected by climate change in developing countries (Houghton, 1996; Mendelsohn and Dinar, 1999; Mendelsohn et al., 2006; Knox et al., 2012; IPCC, 2014). In Sub-Saharan Africa (SSA) agriculture is vulnerable to increasing temperature and precipitation (Kabubo and Karanja, 2007; Parry et al., 2007; Kurukulasuriya and Mendelsohn, 2008; Seo and Mendelsohn, 2008b), specifically, rain-fed agriculture (Parry et al., 2007). For instance, net revenue elasticities with respect to temperature and precipitation for African farms are estimated to be -1.3 and 0.4 respectively, and are the highest for dryland agriculture (Kurukulasuriya and Mendelsohn, 2008).

Climate change has an important impact on the food security of agricultural household, as climate change increases yield loss (Jones and Philip, 2003; Schlenker and Roberts, 2009; Schlenker and Lobell, 2010), decreases access to food in many African countries (Parry et al., 2007), and therefore, leads to hunger risk which will affect an estimated additional 5 to 170 million people in 2080 (Schmidhuber and Tubiello, 2007). Harvey et al. (2014) found that climate change causes significant crop and income shortfalls that worsen food insecurity of smallholders in Madagascar. Similar reductions in crop yields have been witnessed in Kenya (Kabubo and Karanja, 2007) and Ethiopia (Deressa, 2007).

Furthermore, Africa is confronted by significant environmental problems, including soil degradation (Lal, 1998; Drechsel et al., 2001; Ehui and Pender, 2005). These lead to low productivity in agriculture (Ehui and Pender, 2005). The interaction of climate change impacts with ongoing land degradation make achieving the United Nations Sustainable Development Goals in 2030 a big challenge for SSA.

\subsection{Climate change adaptation}

To cope with climate change adaptation is needed (Parry et al., 2007:19; Reidsma et al., 2010), where climate change adaptation is defined as "adjustment in natural or human systems in response to actual or expected climatic stimuli or their effects, which moderates harm or exploits beneficial opportunities" (Parry et al., 2007:869). Farmers' adaptation to climate change has two stages (Maddison, 2007; Silvestri et al., 2012). In stage one, farmers perceive climate change and its impacts; in stage two, farmers apply adaptation strategies. 
The majority of farmers in SSA countries perceive temperature and decreasing precipitation as increasing (Maddison, 2007; Di Falco et al., 2011) making their perceptions of climate change consistent with meteorological data. This also holds true for Ethiopia (Bryan et al., 2009). Although most farmers perceive climate change and its impacts as occurring, a significant proportion of farmers (37\% in Ethiopia and 62\% South Africa) do not adjust their farming practices (Bryan et al., 2009).

Farmers adapting their agricultural practices employ a portfolio of adaptation measures to deal with climate change (Parry et al., 2007). For instance, farmers deploy sustainable land management (SLM) practices, which increase yield and soil quality at the same time such as tree planting, soil and water conservation, irrigation and the adoption of new crop varieties (Bryan et al., 2009; Deressa et al., 2009; Sietz and Van Dijk, 2015). Other adaptation practices include altering planting time (Bryan et al., 2009), changing animal breeds to suit climatic conditions (Seo and Mendelsohn, 2008a), diversifying livestock feed (Silvestri et al., 2012) and diversifying income generating activities (Mersha and Van Laerhoven, 2016). SLM practices deliver several benefits. For instance, in a warmer climate SLM practices improve the eco-environment, increase crop yields and farmers' incomes, and reduce the possibility of drought (Lei et al., 2016). Moreover, SLM practices that reduce soil erosion result in economic benefits (Mizina et al., 1999), increase resilience (Edwards et al., 2011), increase crop productivity (Di Falco et al., 2011) and improve food security (Jerneck, 2018). However, farmers' adaptation decisions are influenced by access to information, extension services, credit, and market and policy incentives and farm size (Cramb et al., 1999; Bryan et al., 2009; Deressa et al., 2009; Silvestri et al., 2012; Kibue et al., 2015), and social norms (Bryan et al., 2009; Kibue et al., 2015). Furthermore, adopting SLM practices is not gender neutral (Jerneck, 2018), as knowledge of SLM practices are gendered (Smucker and Wangui, 2016) and constraints on the adoption of SLM practices differ between men and women (Jin et al., 2015; Mersha and Van Laerhoven, 2016). In addition, the endeavor to implement SLM practices could have an uneven impact on men and women (Tatlonghari and Paris, 2013).

Given the above challenges to adapt, adaptation policies need to consider social, economic and environmental impacts of adaptation efforts. For this, sustainable adaptation is preferred over adaptation in general (Eriksen et al., 2011; Eriksen and Brown, 2011). O'Brien and Leichenko (2007) defined sustainable adaptation as a combination of both sustainability and adaptation. It includes measures that minimize vulnerability to climate change and encourage long term resilience. The core assumption behind sustainable adaptation is that we have imperfect information about the short and long term impacts of current adaptation practices on economic growth, social equity and environmental sustainability (Eriksen and Brown, 2011). Overall, sustainable adaptation adds two extra requirements to conventional adaptation approaches: i) enhance the adaptive capacity of 
those living in poverty by reducing poverty, and ii) to solve the causes of vulnerability among those living in poverty (Eriksen and O'Brien, 2007; Brown, 2011). Adaptation through SLM practices needs to pay attention to both social equity and environmental sustainability (Brown, 2011; Eriksen et al., 2011). However, current adaptation experiences might not be sustainable (Brown, 2011), and evidence shows that the ongoing SLM practices in Africa may be inadequate to cope with future climate changes (Parry et al., 2007). For instance, collecting plant gum and resins as an alternative to livestock production for livelihood diversification in Kenya's drylands is not sustainable unless the causes of the marginalization of local livelihoods are removed (Gachathi and Eriksen, 2011).

\subsection{Sustainable land management}

Fernandes and Burcroff (2006:2) define SLM as "a knowledge-based procedure that helps to integrate land, water, biodiversity, and environmental management (including input and output externalities) to meet rising food and fiber demand while sustaining ecosystem services and livelihoods". According to the reports of the Ministry of Agriculture and Rural Development (MARD) the Government of Ethiopia and its development partners have introduced an SLM program since 2008 with the intention of restoring land quality, addressing climate change and variability related risks, and enhancing yield (MARD, 2013; Schmidt and Tadesse, 2014). Employing SLM as an adaptation measure to climate change in agriculture is expected to increase food security and productivity (Lei et al., 2016) albeit the results vary according to the specific practices and agro-climatic conditions (Branca et al., 2013). A meta-analysis of the application of biochar, a charcoal, to soils showed that the average land productivity increases by $10 \%$ when biochar is practiced, although the productivity effect varies from $-28 \%$ to $39 \%$ (Jeffery et al., 2011).

Evidence from Ethiopia shows that SLM practices (i.e., investing in stone terraces, reduced tillage and reduced burning) are profitable (Pendera and Gebremedhin, 2007). Teshome et al. (2013) conducted a cost-benefit analysis and found that soil bunds, stone bunds and fanya juu (i.e. a specific kind of terrace) are lucrative under normal conditions. Minimum tillage results in a larger increase in productivity than chemical fertilizer does in areas with a low agricultural potential (Kassie et al., 2010). Plots on which sustainable land and watershed management practices (such as terraces, bunds, and check dams) are applied have a higher yield than plots without such interventions (Schmidt and Tadesse, 2014). Stone bunds applied to semi-arid plots increase yield (Kassie et al., 2007), and Tesfaye et al. (2008) showed that adoption of small-scale irrigation is improving food security as it reduces dependency on rainfall and increases the production frequency per year. 
In contrast, the adoption of SLM practices may not enhance the livelihoods of adopters compared to non-adopters, because of contamination problems, long repayment periods of SLM practices, and externalities (Araya et al., 2012; Fanaye, 2017). Damte et al. (2017) found both positive and negative effects of adoption of SLM practices on crop net revenue, and Kassie et al. (2009a) found that plots with bunds have lower yields than plots without bunds. Moreover, effective use of SLM practices is constrained by several factors, such as the socioeconomic characteristics of farm households and plot characteristics (Anley et al., 2007; Nigussie et al., 2017). Furthermore, the maintenance of SLM structures in the short and long term is often ignored in Ethiopia (Shiferaw and Holden, 1998; Anley et al., 2007). To enhance sustainability and productivity earlier studies have suggested that SLM practices should be tailored to fit various agro-ecological zones, rather than a one-size-fits-all approach (Kassie et al., 2009b).

\subsection{Land fragmentation}

Land fragmentation or parcelization is defined as ownership or use of separated multiple plots per farm that are potentially far away from each other and at a distance from the home (Bentley, 1987; Nguyen et al., 1996; Demetriou et al., 2013). Land fragmentation (LF) is increasing in SSA countries, because of high population growth and lack of off-farm employment opportunities. Population growth has led to high LF in countries like Kenya (King, 1977) and Nigeria (Udo, 1965). Additionally, Gashaw (2017) observed in Ethiopia that population growth, the inheritance system and land redistribution have led to fragmented farm holdings. In 2001, the average farm size in Ethiopia equaled 1.01 hectares fragmented into 2.4 plots (Deininger and Jin, 2006), comparable to the average operated land size of 1.5 hectares divided into 3.1 plots in densely populated Rwanda (Bizimana et al., 2004).

The increasing LF has costs for smallholders. Earlier studies showed that LF increased the cost of production (Jabarin and Epplin, 1994; Kawasaki, 2010), and the time of commuting to fulfil domestic needs like collecting firewood (McCall, 1985; Bentley, 1987; Nguyen et al., 1996) particularly for women in developing countries. Moreover, LF decreases land productivity and profit (Blaikie and Sadeque, 2000; Hung et al., 2007; Rahmana and Rahman, 2008; Manjunatha et al., 2013) and reduces efficiency (Wadud and White, 2000; Manjunatha et al., 2013). Furthermore, LF increases border demarcation, which can result in land abandonment and border conflicts. Crop loss increases as many detached plots per farm bordering roads leads to crops being stolen or attacked by livestock (McCall, 1985). Crops growing along the roadside are commonly stunted. LF also decreases access routes to plots (Bentley, 1987). 
Furthermore, LF hampers the deployment of SLM practices such as irrigation and soil conservation (Blarel et al., 1992; Zhang et al., 1996), the application of organic fertilizer (Teshome et al., 2014; Asfaw et al., 2016), stone-faced soil bunds, and agroforestry (Nigussie et al., 2017). LF also decreases the possible number of crops grown or SLM practices applied on a plot, for example, farmers are reluctant to grow cash crops, fruits and vegetables on remote plots in Nepal (De Lisle, 1982; Thapa and Paudel, 2002).

However, LF may also have benefits. The plots per farm could be heterogeneous in terms of soil type, soil fertility, capacity to retain water, slope, altitude and agro-ecological zone. These heterogeneities benefit farmers by decreasing production risks and, therefore, are substitutes for risk reduction strategies, like insurance, credit, storage and off-farm income, when farmers lack access to these risk reduction means (Charlesworth, 1983; Ilbery, 1984; Bentley, 1987; Di Falco et al., 2010). Moreover, scattered parcels with differences in agroecological diversity allow farmers to diversify crops and optimize labor allocation to resolve seasonal labor shortages and hence reduce food insecurity (Fenoaltea, 1976; Bonner, 1987; Blarel et al., 1992). In addition, fragmentation increases the use of certain SLM practices, for instance, crop diversity (Tana et al., 2006; Di Falco et al., 2010) and soil bunds (Nigussie et al., 2017).

Studies also uncovered the challenge of measuring and finding a comprehensive indicator for LF (Bentley, 1987; Demetriou et al., 2013) since different indices capture different features of LF (Bentley, 1987). Earlier studies have used the following indicators for LF: number of plots (Bizimana et al., 2004; Tan et al., 2010), the Simpson index (Kawasaki, 2010), distance from home to farm fields (Bizimana et al., 2004), farm size (Hung et al., 2007), average farm size (Rahmana and Rahman, 2008), shape of plots, and a combination of these indicators (Di Falco et al., 2010; Demetriou et al., 2013). Employing multiple indicators is more powerful than using a single indicator, because LF has various dimensions (Demetriou et al., 2013). Therefore, this thesis employs several indicators to capture various characteristics of LF. The indicators that are used are: number of plots, Simpson index, sum of non-overlapping distance from home to various plots, the number of multiple separate homes owned, and number of soil types per farm, and whether or not the plots are located in different agro-ecological zones. There are different agro-ecological zones when a farmer uses multiple plots in the midlands and the highlands that have a distinct altitude and production season.

\subsection{Problem statement}

Ethiopia is among the most drought-prone countries in the world: it also has with the lowest adaptive capacity of all the countries in Africa (Orindi et al., 2006; Stige et al., 2006). Ethiopia 
is facing an extreme poverty level, which was at 33\% in 2011 (World Bank, 2016) and a fast growing population. The United Nations (2018) 'low-variant' scenario population projections indicate that the population size of Ethiopia is 107.5 million in 2018 and is expected to rise to 134 million in 2030. Despite significant recent achievements, the prevalence of extreme poverty (i.e., the percentage of the population not able to meet basic needs) and low adaptive capacity make Ethiopia vulnerable to climate change impacts. Moreover, development challenges facing the country, including food insecurity and natural resource degradation (World Bank, 2016) are exacerbating its vulnerability to climate change impacts. Although agriculture is rain-fed, dominated by smallholders and vulnerable to climate change impacts, it has a significant contribution to the national economy: agriculture accounted for $40 \%$ of gross domestic product (World Bank, 2016), employed $72.7 \%$ of the population (Schmidt and Bekele, 2016), and accounted for $83.9 \%$ of the total exports in 2013 (Matouš et al., 2013).

Ethiopia has five main agro-ecological zones with different altitudes, ranging from below 500 meters to more than 3700 meters above sea level (Hurni, 1998), and variable conditions in terms of temperature, rainfall and soil types. Having different agro-ecological zones provides an opportunity for production diversification and risk reduction. Climate change impacts and vulnerability vary between agro-ecological zones and are also expected to vary for the same agro-ecological zone over the seasons. Thus, the agro-ecological diversities and LF together offer opportunities and challenges for agricultural production and climate change adaptation. Although LF increases access to different agro-ecological zones and microclimates, creating opportunities for crop diversification across seasons and spatially, it increases production costs and decreases productivity, profit and efficiency. In other words, despite some beneficial effects, plot dispersion across distinct agro-ecological zones and microclimates involves higher production and adaptation costs, which includes for SLM practices deployed as adaptation options. LF affects the SLM practices applied and, hence, affects the sustainability of Ethiopian agriculture.

Agro-ecological diversity and microclimate heterogeneity are particularly important in the Gamo Highlands of Ethiopia. Temperature and rainfall variability are important determinants of persistent food insecurity and vulnerability in the Gamo Highlands, and in Ethiopia as a whole (Demeke et al., 2011). Moreover, smallholder agriculture is vulnerable to climate change in Ethiopia (Deressa and Hassan, 2009). The level of LF in the Gamo Highlands is larger than the national average, as the average farm size of 1.7 hectares is divided into 21 plots, ranging from 1 to 80 plots per farm. This remarkable level of LF in the Gamo Highlands is expected to increase due to population pressure and the equitable apportionment of land by inheritors. Moreover, smallholder farmers in the Gamo Highlands have limited and costly access to credit, insurance, agricultural technologies and off-farm 
employment. This leads to challenges in absorbing the risk associated with crop and livestock production failure due to climate change. However, the mountainous topography of the Gamo Highlands also creates an opportunity for smallholders to exploit various agroecological niches and seasons. Farmers can adapt to climate change by diversifying crops spatially and over seasons. The two main seasons are Belg and Meher respectively, i.e., the short rainy season versus the long rainy season (Di Falco et al., 2011).

LF allows farmers to access different agro-ecological zones, however, it also affects the use of SLM practices and outcomes of investments in soil improvements. Therefore, it is worthy to investigate what challenges and opportunities LF has on climate change adaptation in the Gamo Highlands. To do this, it is necessary need to consider a number of issues not addressed in earlier studies.

First, the influence of various dimensions of LF on farmers' decisions to adopt SLM practices is unknown. LF could influence the adoption of SLM practices in several ways. For example, it is hypothesized that LF holds farmers back from applying manure on plots at a distance from home, as manure application on multiple faraway plots is effort-intensive (Asfaw et al., 2016). Moreover, when farm fields are fragmented farmers are less likely to invest in tree planting and waterways to avoid conflicts with neighbouring farmers (Bentley, 1987). Farmers are also expected to invest less frequently in soil improvements on distant plots (Nigussie et al., 2017). Crop production far away from home is more likely to be unsustainable, because it is expected that fewer farmers invest in SLM practices (such as manure) and that chemical fertilizer is more often applied. Even if plots close to and far away from home are equally suitable for crop production, farmers are expected to be reluctant to produce effort-intensive crops (such as potatoes) at a distance from home (De Lisle, 1982). This implies that LF reduces the alternative uses of plots and limits the possibilities for crop diversification to adapt to climate change.

Second, while LF has both costs and benefits, its benefits have been mostly ignored. The important contribution of this thesis in this regards is to provide new evidence that LF can be beneficial in maintaining food security. To my knowledge, this thesis is the first that investigates the effect of LF on food security and the combined effect of LF and SLM practices on food security explicitly. As LF constrains investment in land improvement (Teshome et al., 2014; Nigussie et al., 2017), it affects the productivity of farm fields and the technical efficiency of farms across multiple plots and across farms (Rahmana and Rahman, 2008). Moreover, LF leads to lengthy commuting costs, and therefore, increases working hours and reduces the number of working hours devoted to income generation. On the other hand, LF could enhance food security through its positive effects on the adoption of SLM practices. Crop diversification across plots and seasons has risk reduction benefits and 
enhances year-round access to food. For instance, pests that affect barley yield in one agroecological zone may not occur in another, crops produced in one zone may not be able to be produced in another and production seasons can be different across agro-ecological zones.

Third, SLM practices and LF can have differentiated effects on the length of working hours of men and women, because of the gendered division of farm and domestic work. However, this has not been addressed in earlier studies. This thesis examines whether or not the hours worked by men and women are differently influenced by SLM practices and LF.

\subsection{Objective and research questions}

The objective of the thesis is to explain how land fragmentation and sustainable land management practices influence the outcomes of sustainable adaptation to climate change in the Gamo Highlands of Ethiopia. The outcomes of sustainable adaptation can be expressed using environmental, social, and economic targets. More specifically, the outcomes of sustainable adaptation examined in this thesis include the application of SLM practices, food security, technical efficiency, and the working hours of men and women in the Gamo Highlands. The following specific research questions were examined to address the objective.

Is land fragmentation facilitating or obstructing the adoption of climate change adaptation measures in Ethiopia?

What are the effects of land fragmentation and sustainable land management practices on food security?

What are the effects of land fragmentation and sustainable land management practices on technical inefficiency?

Do land fragmentation and sustainable land management practices have differential effects on the working hours of men and women? 


\subsection{Data and Methodology}

This study was conducted in the Gamo Highlands of southwest Ethiopia. Primary and secondary data were collected. Primary data were collected using a household survey. The first round of primary data collection was from June to September 2015 in three kebeles ${ }^{1}$. The kebeles Done, Haila and Ocholo-Badiga, were selected from the woreda ${ }^{2}$ Dita (see Figure 1.1 for location within Ethiopia). The study is limited to three kebeles because in 2015 the local government's geographic information system (GIS) data inventory had only been fully completed for these kebeles in 2015. This was relevant as it is difficult to measure the land size of a farm having an average 21 plots, the number of plots ranging from 1 to 80 plots per farm, and plots that are apart from each other and from the home of the owner. A stratified random sampling technique was used to select farm households from the kebeles, which jointly had a total of 1,009 farm households. The number of plots per farm and the agro-ecological zones that these plots were in were used to form 10 strata. Then, using a simple random sampling approach, 300 households were selected proportionately from each stratum.

For each household, the household head (husband) and his wife were interviewed. For female-headed households, women were interviewed using both questionnaires. Single male-headed households were not observed. The survey questionnaire for wives was limited to food security questions (as women are responsible for household welfare in Gamo communities) and her socioeconomic characteristics. Data were collected from 297 households, comprising 297 men and 297 women. To complement the quantitative analysis, qualitative information was gathered through focus group discussions and keyinformant interviews with farmers $(n=30)$, experts and extension workers $(n=15)$. GIS data collected by experts employed by the local government using global positioning system (GPS) devices to register land use rights were used as to assess LF.

\footnotetext{
${ }^{1} \mathrm{~A}$ 'kebele' is the lowest level administrative unit in Ethiopia.

${ }^{2} \mathrm{~A}$ 'woreda' is an administrative unit in Ethiopia comparable to a province.
} 


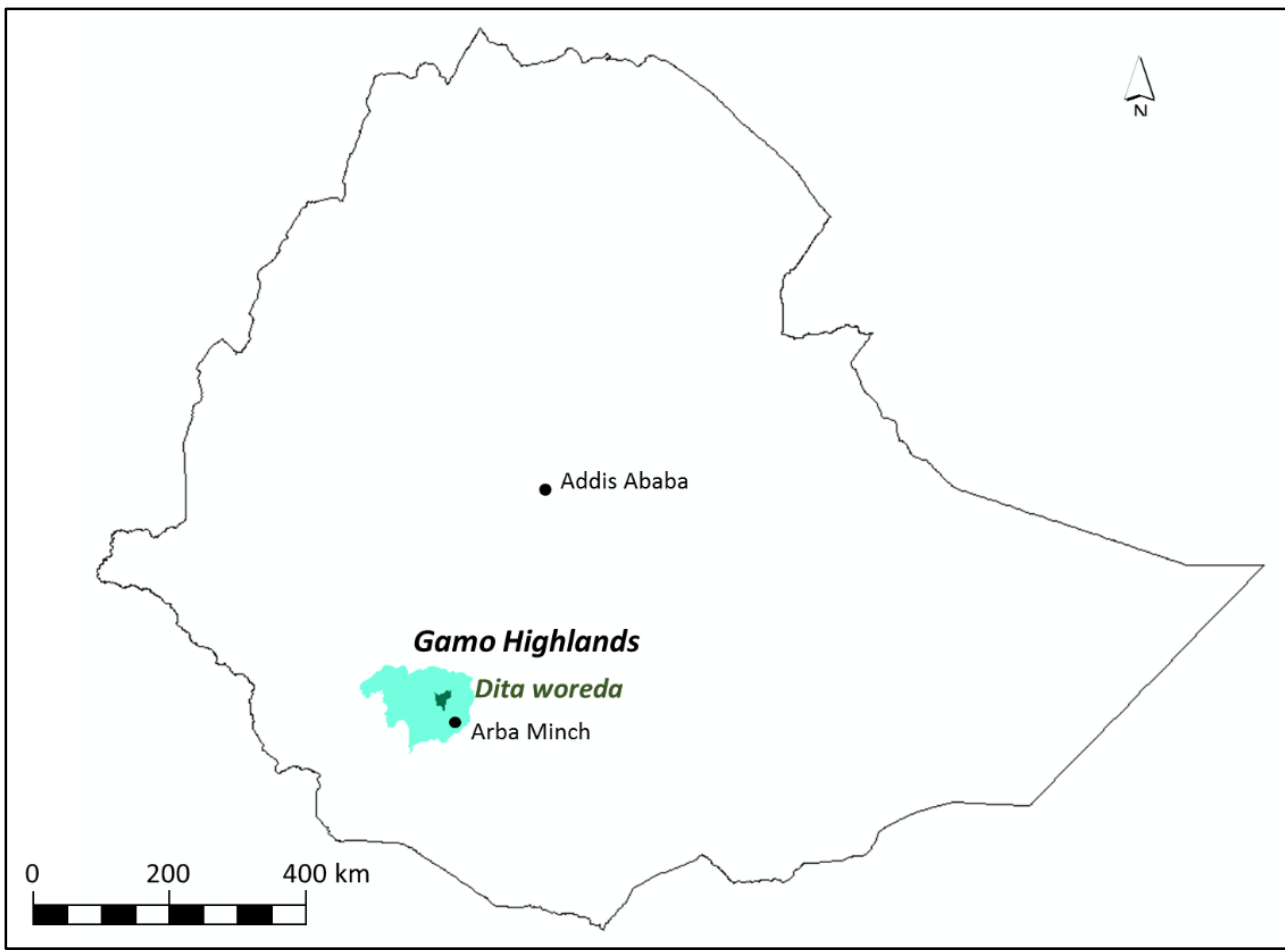

Figure 1.1 Location of the study area in Ethiopia.

In addition to these data, plot-level data were collected from 100 households in Done during the meher season (the main barley production season)- from June to September 2016. These households had previously been surveyed in 2015. Plot-level data collection was limited to a single kebele, because gathering information on land management practices (e.g., the amount of manure applied and the number and age of native trees planted) for multiple plots per owner is demanding. A stratified random sampling technique was used to select barley plots. Moreover, the two plots selected per farm were far from each other and included: a homestead plot close to home and a remote plot (the furthest from home). Farms that had only either a homestead or a remote plot were dropped. The resulting plotlevel data comprised 184 plots belonging to 92 farm households.

Mainly econometric techniques were applied to analyze the data. The econometric techniques applied will be discussed next for each research question separately.

To answer research question 1 on the effect of LF on the use of SLM practices as climate change adaptation measure, eight SLM practices were considered. The multivariate probit (MVP) method was used for this purpose. MVP is an extension of the binary probit model applied to estimate various correlated binary outcomes jointly. For example, a decision to 
apply manure and use legume-barley rotation are correlated binary decisions. An MVP model allows to estimate the multiple choices of farmers jointly, whereas a binary probit model ignores these correlations. Kassie et al. (2015), Asfaw et al. (2016) and Nigussie et al. (2017) employed the same model, for instance, to explain the adoption of sustainable intensification practices, agricultural technology and SLM practices, respectively.

To determine the effects of LF and SLM practices on food security (i.e. research question 2) I applied probit and Poisson models. The combined effects of LF and SLM practices on food security are also assessed with these models. This thesis uses subjective perception measures of food security because they can capture more dimensions of food security than objective measures (Maxwell, 1996; Feleke et al., 2005). The probit model is used to deal with binary food security variables while the Poisson model is applied when food security is expressed by the household dietary diversity score (which is count data). The study applies likelihood ratio tests to assess the joint effect of LF indicators, SLM practices, or a combination of these variables on food security. Moreover, the marginal effects of SLM practices at the representative values of LF indicators are calculated to assess how the food security effects of each SLM practice change with different levels of LF. For example, how the effect on food security of a specific SLM measure (such as indigenous tree planting) changes when LF is increased. Earlier studies also applied probit models to identify factors affecting food security (Feleke et al., 2005) and the adoption of climate change adaptation practices (Bryan et al., 2009).

To answer research question 3, two stochastic frontier models were formulated and estimated. First, the true fixed effect stochastic frontier model developed by Greene (2005) was applied to identify factors that affect efficiency. The following hypotheses were tested with the model: i) LF indicators jointly affect technical efficiency; ii) SLM practices jointly affect technical efficiency, and iii) LF and SLM practices have a combined effect on technical efficiency. Second, the Kumbhakar et al. (2014) multi-step approach of formulating and estimating a random effects stochastic frontier model was used to estimate the two sources of inefficiency: persistent technical efficiency and residual technical efficiency. Persistent efficiency refers to efficiency differences across farms while residual efficiency refers to efficiency differences across plots per farm. To estimate the models, the panel data adapted has two dimensions: i) the different farms, and ii) the two plots observed per farm.

To evaluate the existence of gendered climate change adaptation practices (i.e., research question 4) hours allocated to work across three seasons by the farmer (man) and his wife (woman) was investigated. In order to do so, joint estimation of six equations was applied. That is, the dependent variables of six equations (i.e., three seasons, times two gender types) were considered to estimate a linear system of equations where SLM practices and 
LF are explanatory variables. The model was estimated using Seemingly Unrelated Regression (SUR). The SUR estimator is preferred over the Ordinary Least Square (OLS) estimator, which estimates equation-by-equation the six linear equations (Cameron and Trivedi, 2005). The main motivation for using SUR is that OLS is consistent, but inefficient when the error terms across the equations are correlated (Zellner, 1962; Cameron and Trivedi, 2009). Likelihood ratio tests were also applied by imposing constraints on estimated coefficients to test for the existence of gendered adaptation practices.

\subsection{Thesis outline}

The thesis is divided into six chapters. This chapter, Chapter 1 , provides the general introduction of the thesis. It provides a brief review of climate change adaptation and LF literature followed by the problem statement, objective of the study and a discussion of data and methodology. Chapter 2 proposes SLM practices as a sustainable adaptation strategy and examines the effect of LF on the decision to adopt selected SLM practices. Chapter 3 evaluates the food security effects of LF, SLM practices used and the combined effects of both. Chapter 4 evaluates the effect of LF, SLM practices used and their combined effects on technical efficiency. Chapter 4 also presents persistent and residual technical efficiencies. Chapter 5 evaluates the differential effects of LF and SLM practices on the working hours of men and women. Chapter 6 synthesizes and discusses the major findings to provide an answer to the research questions formulated and explains the implications of the findings for sustainable climate change adaptation. Chapter 6 also outlines the caveats of the study and makes suggestions for future research. 


\section{Is land fragmentation facilitating or obstructing adoption of climate adaptation measures in Ethiopia?}

Land fragmentation is high and increasing in the Gamo Highlands of southwest Ethiopia. We postulate that this substantial land fragmentation is obstructing the adoption of sustainable land management practices as climate adaptation measures. To explore this, a mixed method study was conducted with emphasis on a multivariate probit model. The results indicate that farmers adapt to climate change and variability they perceived. While according to the probit model, there is no clear answer to the question whether land fragmentation facilitates or obstructs adoption of sustainable land management practices, a qualitative analysis found that farmers perceive land fragmentation as an obstacle to land improvement as adaptation strategy. Moreover, farmers invest more in land improvement on plots close to their homestead than in remote plots. However, the higher land fragmentation also promoted crop diversification, manure application and terracing. Although exogenous to farmers, we therefore suggest that land fragmentation can be deployed in climate change adaptation planning. This can be done through voluntary assembling of small neighbouring plots in clusters of different microclimates to encourage investment in remote fields and to collectively optimise the benefits of fragmentation to adaptation.

Published as:

Cholo, T.C., Fleskens, L., Sietz, D. and Peerlings, J., 2018. Is Land Fragmentation Facilitating or Obstructing Adoption of Climate Adaptation Measures in Ethiopia?. Sustainability, 10(7), p.2120. 


\subsection{Introduction}

Agriculture in developing countries is vulnerable to the increasing impacts of climate change, which are exacerbating food and livelihood insecurities (Kurukulasuriya and Mendelsohn, 2008; Kok et al., 2016). Adaptation to climate change is the only strategy available for farmers. Adaptation is defined as "adjustment in natural or human systems in response to actual or expected climatic stimuli or their effects, which moderates harm or exploits beneficial opportunities" (Parry et al., 2007:869). Farmers in developing countries apply different adaptation measures. For example, they diversify crops and plant crops that are more suited to the changing local conditions (Kjellstrom and Weaver, 2009; Wang et al., 2010). Moreover, they change planting dates, combine crops and trees, and use soil and water conservation measures such as terracing and irrigation (Bryan et al., 2009; Deressa et al., 2009; Sietz and Van Dijk, 2015). Some of these adaptation measures fall into the category of sustainable land management (SLM) practices. SLM is defined as "a knowledgebased procedure that helps integrate land, water, biodiversity, and environmental management (including input and output externalities) to meet rising food and fibre demands while sustaining ecosystem services and livelihoods" (Fernandes and Burcroff, 2006:2). SLM, as a strategy to adapt to climate change and variability, can result in increased food productivity and better output (Roco et al., 2017), although the results vary according to the specific practice used and the agro-climatic conditions (Branca et al., 2013). Consequently, the use of SLM can build resilience to climate change (Edwards et al., 2011; Sietz and Van Dijk, 2015).

The main barriers to adaptation in Africa are lack of access to technology, information, credit and incentives (Bryan et al., 2009; Deressa et al., 2009; Silvestri et al., 2012). However, land fragmentation also affects the use and effectiveness of SLM practices as a strategy for adaptation to climate change and variability. Land fragmentation (LF) is defined as the spatial disintegration of plots into separate and different parcels (McPherson, 1982; Kawasaki, 2010). LF results in the ownership of multiple scattered plots, which can be faraway from the main homestead and from each other (Niroula and Thapa, 2005).

LF can potentially constrain SLM for several reasons. First, LF means higher commuting costs (Clay et al., 1998; Niroula and Thapa, 2005), which leads to efficiency losses (Rahman and Rahman, 2008; Tan et al., 2010). Second, LF can potentially increase border disputes and lead to loss of land for plot demarcation purposes and access routes (Van Dijk, 2003). Third, LF restricts investment in land in the form of soil fertility enhancement and erosion control (Niroula and Thapa, 2005; Teshome et al., 2014). Fourth, LF decreases the number of alternative uses of remote plots, for example, remote plots are not used to plant 
'demanding' crops, i.e., crops that require intensive care (De Lisle, 1982; Niroula and Thapa, 2005). These reasons imply that LF limits choice of climate adaptation measures.

However, LF may also enhance the use of SLM practices to adapt to climate change and variability. Plots scattered across diversified agro-ecological zones enhance crop diversification (Blarel et al., 1992; Di Falco et al., 2010), smoothening labour requirements throughout the year (Fenoaltea, 1976; Bentley, 1987; Blarel et al., 1992) and freeing up time to invest in SLM. Moreover, heterogeneous scattered plots spread (climate-related) risk of production failure (Bentley, 1987; Blarel et al., 1992; Sikor et al., 2009).

The Gamo Highland is a mountainous area in southwest Ethiopia where there is significant LF. The subsistence farmers in this area are exposed to the adverse impacts of increasing climate change (Mendelsohn et al., 2006; Pachauri et al., 2014). The effect of LF on adoption of SLM as a strategy to deal with the adverse effects of climate change has not yet been studied in this region. LF is exogenous to farmers, i.e., it is not an adaptation strategy that they choose because sons inherit fragmented land from their parents. The purpose of this paper is to analyse the conditions under which LF is either facilitating or obstructing climate change adaptation in subsistence agriculture in the Gamo Highlands and to inform the debate on the pros and cons of LF by providing additional empirical evidence.

The next section of the paper describes the study area, data and methodology; this is followed by a section on results and discussion. A final section concludes with whether LF promotes or hinders the adoption of SLM measures to adapt to a changing climate.

\subsection{Materials and Methods}

\subsubsection{Study area}

This study was carried out in Dita district in the Gamo Highlands. According to Dita Woreda Statistics Bureau (DWSB) the district lies at an elevation of between 1,250 and 3,568 metres above sea level and is located at 6 $6^{\circ} 12^{\prime} 19^{\prime \prime} \mathrm{N}, 37^{\circ} 36^{\prime} 37^{\prime \prime} \mathrm{E}$ (DWSB, 2015). The area has a long agricultural history and is largely dominated by smallholder subsistence agriculture. The district has a high population density and high topography. Due to its rugged character, the land covers two distinct agro-ecological zones (AEZs) with different opportunities for cropping: the highland area constitutes $60 \%$ and the midland area $40 \%$. The annual rainfall of the district is bimodal and is between $2,500 \mathrm{~mm}$ and $3,500 \mathrm{~mm}$. The temperature ranges between $10^{\circ} \mathrm{C}$ and $23^{\circ} \mathrm{C}$. 
According to Niroula and Thapa (2005), LF in South Asia is caused by population growth, customary land division among sons, and lack of land markets and off-farm employment opportunities. These factors also play a role in the Gamo Highlands and will inevitably lead to an increase in LF in the future. In the north-western highlands, farmers manage four to five parcels of land on average (Teshome et al., 2014), and in the south-central part of Ethiopia farms are fragmented into two to three parcels (Tolossa, 2003). However, in the Gamo Highlands the average number of plots per farm is 21 . Projected climate change is expected to hold back agricultural progress in Ethiopia if no adaptation practices are adopted (Deressa and Hassan, 2009). Farmers in the Gamo Highlands recognise the existence of climate change and use various measures to cope with climate change and variability. However, lack of access to credit and climate change information constrain their efforts to adapt (Bryan et al., 2009; Deressa et al., 2009).

\subsubsection{Study set-up and data}

An econometric technique was used to analyse whether plot dispersion hinders or promotes the adoption of SLM as an adaptive strategy to climate change. A qualitative method was also used to explain quantitative results by examining farmers' opinions on how fragmentation influences the use of adaptation measures.

For this, both primary and secondary data were collected. Primary data were collected using a household survey. Three kebeles (the lowest level administrative unit in Ethiopia) were selected from 24 kebeles in Dita district, because the local government's geographic information system (GIS) data inventory had been fully completed for these 3 kebeles. A stratified random sampling technique was used to select farmers from the kebeles that were home for 1009 households. The number of plots per farm and the AEZs that these plots were in were used to form 10 strata. Then, using a simple random sampling approach, 300 households were selected proportionately from each stratum. From each household, the household head was interviewed. Quantitative data were collected from 297 households. To complement the quantitative analysis, qualitative information was gathered through focus group discussions and key-informant interviews with farmers $(n=30)$, experts and extension workers $(n=15)$. GIS data collected by experts employed by the local government using Global Positioning System (GPS) devices to register land use rights were used as secondary data to assess plot scattering. 


\subsubsection{Model specification}

For the quantitative analysis, this study uses a multivariate probit (MVP) model. A MVP model is the generalisation of a probit model used to jointly estimate correlated binary outcomes. The MVP model is particularly suitable when the decision to adopt a particular measure is expected to be conditional on the adoption of another complementary measure (direct relationship between the error terms of adoption equations) or may be influenced by other available substitutes (negative correlation). In contrast, the application of a binary probit, or logit model in this case, ignores the correlation in error terms of adoption equations and would lead to biased or inefficient estimation (Kassie et al., 2015; Asfaw et al., 2016; Nigussie et al., 2017).

The dependent variable of the MVP model reflects the choice of $m$ distinct SLM practices and is given by:

$y_{i m}^{*}=\beta x_{i m}+\gamma L F I_{i m}+\theta w_{i m}+\varepsilon_{i m} \quad i=1, \ldots, I \& m=1, \ldots, M$

Where $y_{i m}^{*}$ is the latent dependent variable which represents the level of household $i^{\prime} s$ benefits from adaptation, and the distinct binary choice of a household is given by:

$y_{i m}=\left\{\begin{array}{l}1, \text { if } y_{i m}^{*}>0 \\ 0, \text { if } y_{i m}^{*} \leq 0\end{array}\right.$

Specifically, $y_{i m}$ denotes the $m^{\text {th }}$ observed response of the $i^{\text {th }}$ household; $y_{i m}$ equals 1 if the farmer $i$ adopts SLM practice $m$ and zero otherwise. Vectors of explanatory variables that are expected to determine $y_{i m}$ comprise the socioeconomic characteristics of households, $x_{i m}$ LF indicators, $L F I_{i m}$ and $w_{i m}$ denoting farmer $i^{\prime} s$ perception about climate variability and its impacts in the last 25 years. Error terms $\varepsilon_{i m}$ are distributed as multivariate normal, each with a mean of zero and a variance covariance matrix $v$, where $v$ has a value of one on the leading diagonal and correlations $\rho_{k j}=\rho_{j k}$ as off-diagonal elements (Cappellari and Jenkins, 2003). In our case, $\rho_{j k}$ is the correlation coefficient of the error terms corresponding to any two adaptation equations to be estimated in the model. $A$ positive value of $\rho_{j k}$ denotes that any two measures used are complementary while a negative correlation is interpreted as measures used being substitutes (Kassie et al., 2015). Stata software version 13.1 was used for model estimation. 


\subsection{Results}

This section describes the dependent variables and explains the measurement of explanatory variables. It also presents and discusses the results of the study. Dependent variables were identified as a subset of 13 surveyed SLM practices used as climate adaptation measures, i.e., only those SLM practices that could be associated with perceived climate change and variability were included; the latter is hence presented first.

\subsubsection{Descriptive statistics}

\section{Climate change and variability perception}

Farmers were asked about their perception of climate change and variability for the long rainy season (called the 'meher') in the last 25 years. Most farmers perceived temperatures as increasing (90\%) and precipitation as decreasing (83.8\%) (see Table 2.1). For the same period, $61.7 \%$ of farmers perceived soil erosion impacts to be decreasing and $58.3 \%$ perceived crop productivity to be increasing. Even though we lacked measured climatic data for the study area, farmers' perceptions of long-term climate change and variability were consistent with meteorological data (Bryan et al., 2009) and with previous studies in Ethiopia and Sub-Saharan Africa (Maddison, 2007; Deressa and Hassan, 2009; Conway and Schipper, 2011; Bryan et al., 2013).

The focus group discussions with farmers and experts revealed that farmers perceive precipitation to be decreasing and more variable. The farmers reported rain shortages and unseasonable rain to be prevalent, resulting in low productivity and the destruction of harvests. They also mentioned that temperatures have been rising in the last 25 years in both cropping seasons. Moreover, because of the changing climate, crops endemic to the midlands are currently also being grown in highland areas and the productivity of some trees (e.g., bamboo) and crops is decreasing.

This study hypothesises that farmers respond to perceived climate change variability and impacts so that they can cope with hazards and take advantage of opportunities. The frequent observation of shocks (both climatic and non-climatic) by farmers in the last five years is expected to favour adaptation. Almost $95 \%$ of farmers reported adjusting their land management practices in response to increased perceived climate variability and change, while others reported practising autonomous adaptation through the continued use of customary practices. 
Table 2.1 Summary statistics of variables.

\begin{tabular}{|c|c|c|c|c|c|c|}
\hline Variable & Description & $\%$ & Mean & $S D$ & Min & $\operatorname{Max}$ \\
\hline \multicolumn{7}{|l|}{$\overline{S L M}$ practices } \\
\hline seed & 1 if a farmer alters quality seed use & 76.1 & & & & \\
\hline manure & 1 if a farmer alters manure use & 93.9 & & & & \\
\hline indigenous & 1 if a farmer alters indigenous tree planting & 73.7 & & & & \\
\hline terrace & 1 if a farmer alters stone terrace or soil bund & 83.8 & & & & \\
\hline diversification & 1 if a farmer alters crop diversification & 84.5 & & & & \\
\hline enset & 1 if a farmer alters planting more enset & 84.5 & & & & \\
\hline legume & 1 if a farmer alters legume-barley rotation & 85.5 & & & & \\
\hline new-crop & 1 if a farmer introduced new crops & 58.9 & & & & \\
\hline \multicolumn{7}{|c|}{ Perceived climate change and variability } \\
\hline rainfall & $\begin{array}{l}1 \text { if meher rainfall has been increasing for the last } 25 \\
\text { years }\end{array}$ & 16.2 & & & & \\
\hline Temp & $\begin{array}{l}1 \text { if meher temperature has been increasing for the last } \\
25 \text { years }\end{array}$ & 90.2 & & & & \\
\hline productivity & $\begin{array}{l}1 \text { if meher crop productivity has been increasing for the } \\
\text { last } 25 \text { years }\end{array}$ & 58.3 & & & & \\
\hline shock2 & Sum of all shock damages observed in the last 5 years & & 7.2 & 3.6 & 0 & 14 \\
\hline \multicolumn{7}{|c|}{ Land fragmentation indicators } \\
\hline homes & Number of separate homes & & 1.5 & 0.7 & 1 & 4 \\
\hline soil & Number of soil types an owner cultivates & & 3.9 & 1.2 & 1 & 5 \\
\hline plots & Total number of plots per farm & & 20.6 & 13.8 & 1 & 80 \\
\hline farm & Total farm size, ha & & 1.7 & 1.7 & 0.1 & 15.3 \\
\hline sfi & Simpson index for $L F$ & & 0.85 & 0.1 & 0 & 0.97 \\
\hline distance 2 & $\begin{array}{l}\text { Sum of non-overlapping distance from home to plots } \\
(\mathrm{km})\end{array}$ & & 2.6 & 1.6 & 0.1 & 8.7 \\
\hline aez & 1 if a farmer cultivates both in midland and highlands & 35.7 & & & & \\
\hline landqual & Land quality index & & 0.4 & 0.2 & 0 & 1 \\
\hline \multicolumn{7}{|c|}{ Socioeconomic characteristics } \\
\hline gender & 1 if gender of household head is male & 90.6 & & & & \\
\hline literacy & 1 if household head can read and write & 21.6 & & & & \\
\hline experience & Farming experience (years) & & 33.9 & 15.6 & 0 & 76 \\
\hline labour & Family labour size & & 3.5 & 2.3 & 0 & 15 \\
\hline tlu & Number of tropical livestock units & & 2.5 & 2.7 & 0 & 22.9 \\
\hline asset & Number of assets & & 3.6 & 2.2 & 0 & 17 \\
\hline remittance & 1 if a household has remittance & 11.5 & & & & \\
\hline income & Amount of off-farm income (thousands) & & 1.6 & 2.7 & 0 & 20 \\
\hline \multicolumn{7}{|c|}{ Social network, market access and extension services } \\
\hline network1 & Participation in 5 social networks per month & & 5.8 & 5.3 & 0 & 54 \\
\hline network2 & No. of trusted social networks & & 2.2 & 1.4 & 0 & 5 \\
\hline credit & 1 if access to credit without constraint & 58.9 & & & & \\
\hline market & Walking distance to market (hour) & & 1.93 & 1.2 & 0.3 & 6 \\
\hline training1 & 1 if training on modern input use & 82.5 & & & & \\
\hline training2 & 1 if training on soil fertility & 81.5 & & & & \\
\hline training3 & $\begin{array}{l}1 \text { if training on soil erosion control } \\
\text { Number of observations }\end{array}$ & 84.5 & & & & 297 \\
\hline
\end{tabular}

Source: survey data

\section{SLM practices}

A total of 13 SLM measures potentially used as climate adaptation measure was surveyed. A chi-square test was conducted to test whether these measures could de facto be 
associated with perceived climate change and variability. SLM measures that were correlated with at least one indicator of climate change or variability perceived by farmers at less than $10 \%$ significance level were considered as climate adaptation measures in the study. Some SLM practices, such as conservation tillage and changing the sowing period, were not significantly correlated with farmers' perception. Eucalyptus tree planting and fertilizer use to adapt to climate change and variability were also not considered in the MVP analysis, as the government forces farmers to apply fertilizer and, hence, only eight farmers reported not using fertilizer. Eucalyptus trees are replacing indigenous trees and are not eco-friendly.

Finally, eight SLM measures were considered as adaptation practices: i) expansion of manure use on a plot, ii) use of a quality seed, iii) introduction of a new crop, iv) plant more enset (Ensete ventricosum), a perennial crop in the banana family, v) plant indigenous trees, vi) barley-legume rotation, vii) crop diversification, and viii) terracing (i.e., use of stone bunds or terrace steps on hilly plots). The use of these SLM practices ranged between 59 and $97 \%$ (Table 2.1).

\section{$L F$ indicators}

Seven LF indicators were used: number of plots and number of soil types across the noncontiguous plots, an agro-ecological zone dummy for growing crops in either a single agroecological zone or both the midlands and highlands, sum of non-overlapping distance from the homestead to owner's plots in km, Simpson index, total farm size, and number of separate homes (see Table 2.1). The non-overlapping distance to plots from the homestead was measured using GPS to avoid the overlap of distances. Where the owner had multiple homes in separate plots, the distance was measured from the closest homestead to each plot.

The Simpson index, which was used to measure $\mathrm{LF}$, is defined as $\left[1-\left(\sum_{i=1}^{n} a_{i}^{2} / A^{2}\right)\right]$ where $a_{i}$ is the area of the $i^{\text {th }}$ plot in hectares, and $A$ is the farm size in hectares, which equals the sum of the area of all $n$ plots of the farm, $A=\sum_{i=1}^{n} a_{i}$ The value of the index ranges from zero to one. A value of zero refers to the situation where a household has a single parcel, i.e., perfect land consolidation, whereas a value close to one implies that a landholder has many plots and the farm is severely fragmented (Hung et al., 2007). Ownership of multiple homes is a customary practice in Gamo communities to avoid commuting costs, and is expected to enhance the use of adaptation measures. Land quality is measured as the ratio of the number of plots with vigorous barley growth to the sum of all plots that have stunted and vigorous barley growth, and quality land is assumed to increase adaptation decisions. 
The level of LF in the Gamo Highlands is substantially higher than the national average landholding of 1.01 hectares fragmented into 2.4 plots (Deininger and Jin, 2006). In our sample, the mean farm size of households was 1.7 hectares and was fragmented into 21 parcels (Table 2.1). Farm-level LF varied significantly, ranging from a single consolidated plot to a maximum of 80 plots per farm. The average Simpson index was 0.85 and ranges from zero, perfect consolidation, to 0.97 . The mean non-overlapping distance between parcels and the homestead was $2.6 \mathrm{~km}$. We argue that higher LF is expected to decrease the use of most SLM practices.

\section{Socioeconomic characteristics of households}

These variables include gender, the farming experience and education of the household head, family labour size (i.e. family members aged between 14 and 65 years), off-farm income, and wealth indicators such as assets, farm implements and the number of tropical livestock units (TLUs). The number of TLUs is calculated as the weighted ${ }^{3}$ sum of individual livestock units owned. Off-farm employment opportunities were inaccessible to $72 \%$. Farmers who had access to off-farm employment earned a mean annual off-farm income of 700 birr (approximately €28), making access to land essential for survival. We hypothesise that either wealth or human capital indicators will promote the use of adaptation measures.

\section{Social capital, market access and extension services}

We considered two forms of social capital: i) social network (defined as the average number of household members participating in five important types of local networks, namely, 'idir' ${ }^{4}$, 'iquib' ${ }^{5}$, 'mahiber' ${ }^{6}$, 'debo' $^{7}$, and farmers' clubs ${ }^{8}$ per month) and ii) perceived support (which is the number of these networks a household member participates in and trusts to support him in case of misfortune). These social networks are expected to have either a positive or negative effect on the use of adaptation measures. Market access refers to the walking distance to market in hours. Limited market access results in a lengthy mean round trip of 3.9 hours for the surveyed farmers. Goods were expensive in these markets, hence, $41 \%$ of farmers said that they abstained from making purchases. Sufficient access to market is assumed to increase the use of adaptation measures. Access to credit is defined as unconstrained access to credit by farmers when they need credit. Credit per annum was accessible to most farmers (59\%) when required. Access to microcredit was limited to $13 \%$ with a mean loan size of 510 birr (€20.4) in the last five years. More common was informal

\footnotetext{
${ }_{3} \mathrm{TLU}=0.5 \times$ calf $+1 \times$ cow $+1.1 \times$ ox $+0.80 \times$ horse $+0.5 \times$ donkey $+0.7 \times$ mule $+0.1 \times$ sheep $+0.1 \times$ goat $+0.01 \times$ chicken

${ }^{4}$ Informal insurance to support each other during misfortune and is financed by members contribution

${ }^{5} \mathrm{~A}$ saving and credit association that operates by pooling money from members.

${ }^{6} \mathrm{~A}$ religious or cultural interest group that has parties/social gatherings and whose members help each other when needed.

${ }^{7}$ A group of people who work together to achieve common goals.

${ }^{8}$ Group of five farmers organised by local government to exchange good farming practices.
} 
credit with an average loan of $€ 18$ and accessibility of $57 \%$ per year. Loan access was mainly constrained by the fear of being unable to repay the loan $(28.9 \%)$ and high interest rates (13\%). Unconstrained credit access is expected to improve the use of adaptation measures.

\subsubsection{Factors affecting the use of SLM practices}

Table 2.2 presents the estimation results. The MVP model fits the data well because the Wald test of the null hypothesis that all regression coefficients in each equation are jointly equal to zero was rejected at the $1 \%$ significance level. The MVP model is also superior to the binary probit model as the likelihood ratio test rejected the absence of correlation between the error terms at the 1\% significance level (see Table 2.2) and 15 of the 28 pairs of error terms had a significant positive correlation. For instance, indigenous tree planting was positively correlated with most measures at the $1 \%$ significance level, except for quality seed and manure use, implying that these measures are complementary.

\section{The role of climate change and variation}

Farmers were responding to their perception of climate variability and climate change impacts. For example, the likelihood ratio test indicates that three climate change and variability indicators jointly affected the use of SLM practices at the $1 \%$ significance level. More specifically, increases in rainfall were likely to decrease the use of certain adaptation measures, such as the use of quality seed and planting of indigenous trees, but increase enset planting. The first group of adaptation practices are mostly perceived as being able to endure shortages of rainfall, whereas enset is more productive when rainfall is high. Hence, by planting more enset farmers aim to take advantage of this perceived opportunity. Farmers who perceived increased temperature were more likely to increase legume-barley rotation and new crop introduction, probably as higher temperature enables growing a wider range of crops. Moreover, anticipating increased crop productivity is generally a strong incentive for applying adaptation measures. Seo and Mendelsohn (2008) found that farmers switch crops to adjust to their local climatic conditions, and pastoralists in southern Ethiopia are changing their choice of adaptation practices to adapt to rising temperature (Berhanu and Beyene, 2015). However, Hassan and Nhemachena (2008) found no clear effect of rising temperatures and precipitation on the use of various agricultural adaptation practices. 
Table 2.2 Factors affecting the use of SLM practices.

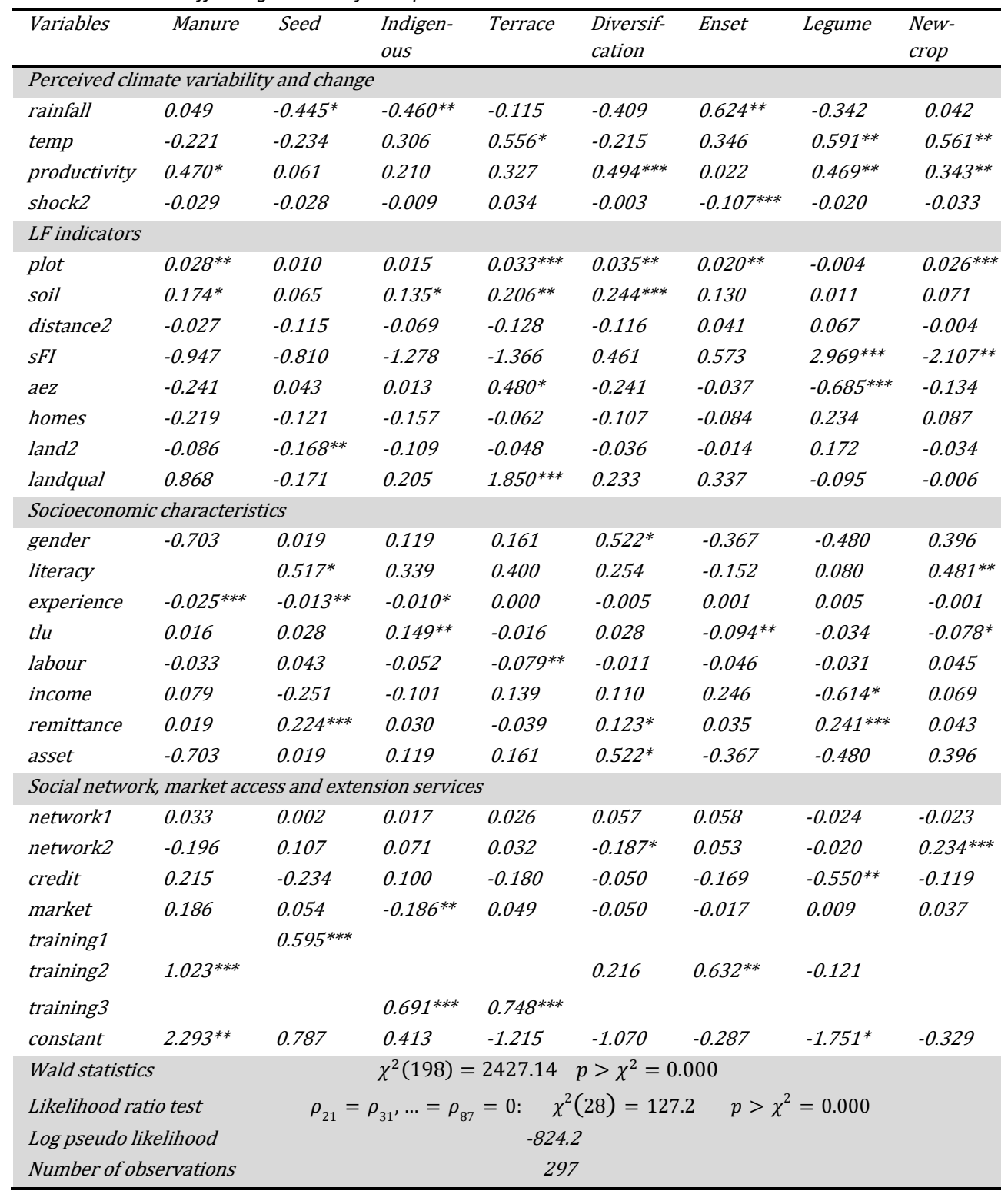

\section{The role of $L F$ indicators}

Fragmentation indicators jointly had a significant effect on the use of SLM practices at the $1 \%$ significance level. Contrary to expectations, Table 2.2 shows that most LF indicators had positive effects on the use of various SLM measures. For instance, higher fragmentation is expected to inhibit terracing, but some LF indicators, such as the production of crops in both the midlands and highlands, cultivation of a higher number of plots, and different soil types 
were found to increase terracing. This is probably because the terracing of plots is imperative to prevent rainfall run-off from sloping land by diminishing the degree of slope in order to maintain at least status quo production and consumption. Farmers commonly construct terraces from the soil itself, rather than from stone, due to stone and labour shortages. Unlike constructing a stone terrace, gradual terracing through soil bunds is not labour intensive, hence, farmers continue to terrace although fields are fragmented. Moreover, a higher number of plots and different soil types cultivated were found to be positively associated with crop diversification, probably to fit the different soil types and stabilise production.

Additionally, the cultivation of a larger number of plots and soil types was found to increase manure application and the cultivation of a larger number of plots also increased planting of perennials, although these practices require much effort. Three-quarters of farmers said that fragmentation posed a challenge when applying manure. However, these econometric results are in contrast to the results of a study by Teshome et al. (2014) in northern Ethiopia. The contrasting results are perhaps associated with the customary practices of Gamo communities, which aim to ease the application of demanding land management practices. For instance, to overcome the challenges involved in carrying and applying manure to remote fields, $57 \%$ of farmers raised horses or mules to transport the manure and $45 \%$ constructed multiple homes in separate plots to stock manure to simplify application in remote plots. Moreover, traditionally, operators' homes are ringed by enset. A Spearman correlation test shows that the construction of multiple separate huts and the number of horses owned had a significant positive correlation with the number of plots on which sufficient manure was applied. Hence, in this study, only $29 \%$ of farmers reported abstaining from manure application because their plots were too fragmented.

Terracing by farmers across hillsides was not labour intensive; as a result, production in multiple agro-ecological zones promoted terracing, but unexpectedly decreased legumebarley rotation. Half of smallholders contended that plot dispersion restricted the cultivation of legumes to increase soil fertility (see Table 2.3). Farmers who live in midland areas, but own plots both in the midlands and the highlands decreased legume-barley rotation as highland plots suitable for legume production are fara way from home and are being thieved. A larger number of plots increased the introduction of new crops, perhaps because having many plots tends to increase access to different soil types and microclimates suitable for new crops. However, a higher Simpson index discouraged the introduction of new crops.

Non-overlapping distance to plots had no significant effect on SLM practices used as climate adaptation strategy. Clay et al. (1998) and Asfaw et al. (2016) found a negative association 
between distance and investment in land improvement, while distance has a two-way effect on SLM practices in studies by Nigussie et al. (2017). However, farmers opined that distanceinduced investment and productivity gaps between plots close to homesteads and remote plots were significant. For instance, $79 \%$ of landholders judged homestead plots to be more fertile and most producers often fallow faraway plots. Three-quarters (75\%) and $90 \%$ of producers respectively applied more manure and planted more enset on nearby plots to improve soil fertility. Farmers (61\%) perceived that erosion was more frequent on faraway plots and they terraced infields more (57\%). Farmers (87\%) also planted vegetables on nearby plots, and over half of them planted trees on homestead plots; $73 \%$ of farmers said they visited nearby plots more than distant ones. More frequent plot visits increase the chance of detecting land management problems (e.g., blocked drainage channels). Experts and extension agents also agreed that farmers tend to invest more in nearby plots to minimise effort and avoid wasting time. As a result infields were more fertile and productive than faraway plots. For instance, barley yield per hectare was higher in proximate plots for the majority of the producers (58\%). Farmers said remote plots were commonly sharecropped or chemical fertilizers were applied instead of manure, which may result in relatively low soil fertility. These fertility and productivity differences translated into investment differentials. Other studies have also found that farmers often cultivate remote plots less intensively; Van Dijk (2003) and Richardson (1974) found that rice output and labour input decrease with the distance of a plot from the homestead.

Table 2.3 Land fragmentation constrains adoption of SLM practices.

\begin{tabular}{lcc}
\hline Selected SLM practices ( $n=279$ ) & Yes & $\%$ \\
\hline Does land fragmentation increase loss of your labour time by increasing commuting time? & 179 & 60 \\
Does land fragmentation impede manure application? & 223 & 75 \\
Does land fragmentation prohibit you from planting a crop you want? & 174 & 59 \\
Does land fragmentation impede use of legume-barley rotation? & 149 & 50 \\
Does land fragmentation impede use of crop rotation? & 159 & 54 \\
Have you abstained from manure application because some of your plots are too small? & 87 \\
Is land fragmentation a challenge to apply terracing on your plots? & 29 \\
Does land fragmentation impede use of modern inputs (fertilizer and quality seeds)? & 135 \\
Does land fragmentation decrease indigenous tree planting as you want to avoid conflicts with & 162 \\
neighbouring farmers? & 55 \\
Does land fragmentation decrease eucalyptus tree planting as you want to avoid conflicts with & 47 \\
adjacent farmers? & 175 \\
\hline Source: survey data & 59
\end{tabular}

The implication is that LF increases the distance to multiple plots, resulting in loss of labour time and limiting the effective use of SLM practices as adaptation measures. The majority of farmers $(60 \%)$ asserted that having scattered plots increases their commuting time, resulting in loss of labour time that can be allocated elsewhere. Labour is an important resource, particularly for the poor, to earn income and to be able to finance adaptation strategies. For example, farmers who applied quality seed have a higher off-farm income 
than farmers who did not. Blarel et al. (1992) and Thapa and Niroula (2008) also reported on the costly commuting consequences of fragmentation.

A remote plot may in theory have as many alternative uses as a nearby plot, but in practice remote fields tend to be at higher elevations and underutilised, implying that LF constrains the adoption of available adaptation measures. For instance, in the Gamo Highlands $87 \%$ of producers exclusively used nearby plots to grow staple vegetables (e.g., potatoes and cabbages). Vegetables are bulky to transport, labour intensive to cultivate, fence, and manure, and outlive other crops, increasing their exposure to livestock attacks and theft in open outfields without fences; this constrains their production on remote plots. Likewise for Mennonite farmers in Canada, their cropping patterns are constrained by land dispersion, so they prefer infields for growing heavy crops (such as potatoes), but light crops (such as wheat) are grown both in infields and outfields (De Lisle, 1982).

Large farm size decreased the use of quality seed, implying that land scarcity can induce agricultural intensification in the form of the use of quality seed (Kassie et al., 2015) and plot size has inconsistent effect on the adoption of SLM measures (Nigussie et al., 2017). Large farm size also decreased the planting of indigenous trees. This is not confirmed by Teklewold et al. (2013) who observed that large farm size increases tree planting. However, $47 \%$ of the farmers in the present study abstained from planting aboriginal trees to avoid conflict (see Table 2.3). The contrast between inferential and descriptive results may be attributed to the planting of eucalyptus trees, which compete for limited land and are preferred over local trees because they grow faster and have higher economic benefits. Despite its externality effects, farmers planted eucalyptuses more than twice as frequently as native trees, such as bamboo. Planting combinations of eucalyptus and local trees is impossible as eucalyptus hinder the growth of crops and local trees. Moreover, eucalyptus effects continue for some years even after they are harvested.

\section{The role of socioeconomic characteristics}

Household head literacy was found to be significant in the choice to use quality seeds and introduce new crops. Previous studies have also found that better education improves access to information on improved technologies and climate variation, and enhances adoption of adaptation measures (Silvestri et al., 2012; Asfaw et al., 2016). The farming experience of the household head was inversely correlated with the use of manure and quality seed and native tree planting. Older farmers are unable to manage huts in separate parcels to stock manure; they also lack the money to buy quality seed. Moreover, older farmers are less likely to invest in trees which have a long payback period. In the literature, the effect of farming experience is controversial, with instances of experience discouraging the adoption of climate change adaptation measures (Shiferaw and Holden, 1998; Wu and 
Babcock, 1998; Nigussie et al., 2017) and instances where age increases adoption (Hassan and Nhemachena, 2008).

The number of assets and livestock owned are wealth indicators and enhanced the use of legume-barley rotation and quality seed, as well as the planting of indigenous trees, but had contrasting effects on the planting of enset. However, in a study by Bryan et al. (2009), better-off families have a significantly enlarged choice of measures for offsetting climate risks. In addition, a positive effect of TLU ownership was found by Silvestri et al. (2012).

The availability of family labour increased the likelihood of growing new crops. However, the size of off-farm income discouraged terracing as less time is left for such an adaptation measure after off-farm activities - and perhaps undertaking these activities results in a high opportunity cost for farmers who can earn higher income off-farm.

The role of social networks, market access and extension services

Participation in networks did not have a significant effect on SLM practices, but the number of trusted social networks a farmer had increased the introduction of new crops. In the literature, social capital has both a positive and negative correlation with the adoption of sustainable intensification practices (Kassie et al., 2015) and adaptation methods (Deressa et al., 2009). However, social networks are vital to the exchange of information among farmers constrained by market imperfections, as argued by Teklewold et al. (2013). Moreover, we observed that the number of trusted social networks from which support is expected during misfortune discouraged crop diversification. Perceived trust in support from networks acts as a risk-avoidance strategy and inhibits the adoption of measures that hold some risk, such as introducing new crops.

Lengthy market access decreased indigenous tree planting and had no effect on the use of other measures. Studies by Bryan et al. (2009) found that proximity to the output market discourages the uptake of adaptation measures. However, Hassan and Nhemachena (2008) found that remoteness from markets has both desirable and undesirable effects. Access to credit decreased legume-barley rotation. However, other studies have shown instances of both positive and negative associations. Some studies found that credit discourages adaptation (Deressa et al., 2009; Falco, 2014; Kibue et al., 2015).

Access to focused extension trainings was found to enhance quality seed use, manure use and enset planting to boost soil fertility, as well as terracing and the planting of native trees for erosion control purposes. The findings of this study on the effect of training agree with those of Seo (2010) and Zamasiya et al. (2017). More importantly, Di Falco and Veronesi (2011) and Sietz and Van Dijk (2015) demonstrate that information provided by extension workers increases the probability of farmers deciding to adapt. In addition, Teklewold et al. 
(2013) explain that highly-skilled extension workers enhance the adoption of sustainable agricultural packages, implying that upgrading the skills of extension workers could enhance uptake.

\subsection{Concluding remarks}

Considering LF in the context of key environmental, socio-economic and perceptual factors, this study delivers integrated insights into the conditions under which farmers use SLM practices as climate adaptation strategies. We present empirical evidence that agricultural land across the Gamo Highlands in Ethiopia is highly fragmented, exceeding the national average land fragmentation levels. Land fragmentation poses a challenge to the application of effective SLM practices and hence can exacerbate land degradation and vulnerability to food insecurity and other climate change impacts in the already food insecure Gamo Highlands.

The study found that farmers in the Gamo Highlands altered the use of SLM practices to adapt to perceived climate change and variation. MVP model results indicate that LF created both opportunities and challenges for the application of SLM practices as a means of climate change adaptation. The magnitude and direction of the effects depend on the type of index used to capture LF and the adaptation methods employed. The qualitative analysis of farmers' perceptions found that fragmentation was a challenge for adaptation by obstructing choice and effective use of available adaptation measures. For instance, in more fragmented landscapes, farmers used less SLM strategies in remote fields than in fields close to their homestead due to increased commuting costs. In addition, farmers invest in homestead plots more frequently, such that nearby plots were less eroded and more productive than remote plots. Moreover, farmers perceived nearby plots as having more alternative uses than faraway fields. Contrasts between econometric results and farmers' perceptions may be attributed to the fact that farmers construct separated multiple homes and use horses and mules for transportation to ease the application of demanding SLM practices.

This analysis demonstrates that LF is not necessarily detrimental to adaptation, as it promotes the use of some climate change adaptation practices. For instance, higher fragmentation promoted crop diversification (to fit different soil types and to stabilise yield), manure application (to increase soil fertility), and terracing (to prevent erosion on mountainous farm fields). Therefore, although LF is exogenous to farmers, it could be deployed in climate change adaption planning. For example, the assembling of nearby small plots in different microclimates could be an important strategy to maximise the benefits of 
fragmentation to climate adaptation, while at the same time increasing the magnitude and quality of investment in remote fields. Land assembling can be done either by promoting the voluntary exchange of plots between farmers or through cooperatives. Moreover, increasing farmers' access to focused training in SLM practices is vital to promote adaptation.

This study examined whether LF is facilitating or obstructing the use of SLM practices to adapt to climate change and variability at the farm level. However, farmers make adaptation decisions at the plot level. At the same time, the underlying conditions for the adoption and maintenance of adaptation measures may change over time. Future studies would, therefore, be useful to explore the effects of land fragmentation in relation to the plot-level dynamics of sustainable land management and climate adaptation including the intensification, modification, abandonment and replacement of particular strategies. 


\section{Land fragmentation, climate change adaptation, and food security in the Gamo Highlands of Ethiopia}

Household food security among smallholder farmers is sensitive to a variable and changing climate, requiring farmers in the Gamo Highlands of Ethiopia to adopt new land management practices to improve food security. Agricultural land in the Gamo Highlands is highly fragmented. The extent to which land fragmentation moderates the food security effects of sustainable land management practices is unknown. This study used probit and Poisson models to explain this relationship. The study found that food insecurity was severe during the food shortfall season. Land fragmentation provides more potential opportunities for improving food security than challenges and, furthermore, that sustainable land management practices had both positive and negative effects on food security and their effects were also conditioned by the magnitude of land fragmentation. Reducing severe land fragmentation through the assembly of small parcels into larger heterogeneous plot clusters could enhance food security by exploiting synergies between adaptation practices and land fragmentation.

Based on:

Cholo, T., Fleskens, L., Sietz, D., and Peerlings, J. Land fragmentation, climate change adaptation, and food security in the Gamo Highlands of Ethiopia. Agricultural Economics, second revised version under review 


\subsection{Introduction}

Climate change and variability are delaying the achievement of global food security (Schmidhuber and Tubiello, 2007), and the changing climate affects all components of food security (Kotir, 2011). According to the United Nations Food and Agricultural Organization (FAO), food security "exists when all people, at all times, have physical, social and economic access to sufficient, safe and nutritious food that meets their dietary needs and food preferences for an active and healthy life" (FAO et al., 2015). The adverse effects of climate change and variability on food security are most noticeable in less developed countries (Parrya et al., 2004). The agricultural sector (Mendelsohn et al., 2006; Kok et al., 2016) and the poor (Schmidhuber and Tubiello, 2007) are most vulnerable to climate change impacts in Sub-Saharan Africa. Although progress has been made, in the years 2014-2016 the majority of the people still undernourished were in Sub-Saharan Africa (FAO et al., 2015).

It is difficult to overcome the impacts of climate change and variability on agriculture, especially in less developed countries like Ethiopia (Conway and Schipper, 2011). Farmers in Ethiopia are unable to produce sufficient food for consumption, even during good rainfall years (Devereux and Sussex, 2000). This makes Ethiopia, particularly vulnerable to climate change impacts (Stige et al., 2006) and famine (Von Braun, 2009). Furthermore, climate change is projected to reduce net revenue per hectare in Ethiopia in the long term (Deressa and Hassan, 2009). Adapting agriculture to adverse climate impacts is a possible way out for farmers (Parry et al., 2007). Adaptation - defined as the "adjustment in natural or human systems in response to actual or expected climatic stimuli or their effects, which moderates, harm or exploits beneficial opportunities" (Parry et al., 2007:869) - has been found to increase food security (Garrity et al., 2010), net farm revenue, and food production in SubSaharan Africa (Di Falco and Veronesi, 2011; Di Falco, 2014).

This study focuses on sustainable land management (SLM) practices, as a subset of adaptation strategies, land fragmentation (LF) and their combined effect on food security. SLM is defined as maintaining sufficient natural resources and ecosystem functions for an indefinite period, while meeting rising food and raw material demands (Fernandes and Burcroff, 2006). SLM increases resilience to climate change and variation (Liniger et al., 2011), reduces socio-ecological vulnerability (Kok et al., 2016) and, as a result, increases food security (Branca et al., 2013). Studies have also examined the effects of LF on food security where LF is the cultivation of multiple scattered plots (Kawasaki, 2010). For instance, the number of plots decreases farm income (Bizimana et al., 2004), decrease productivity and causes yield loss in border areas (Van Dijk, 2003), decreases efficiency (Rahman and Rahman, 2008) and increases production cost (Hung et al., 2007; Kawasaki, 2010) by increasing travelling time between plots (Niroula and Thapa, 2005). However, by 
considering costs and benefits of purchased inputs Niroula and Thapa (2007) found a positive effect of LF on farmers' income. Benefits mainly accrue as dispersed landholdings reduce production risks (Bentley, 1987; Blarel et al., 1992; and Di Falco, 2014) by allowing crop diversification across seasons and agro-ecological zones which in turn leads to food security improvements. Many papers have investigated the cost side of LF, while its benefits have been mostly ignored. The contribution of this study is to provide evidence that LF can be beneficial for food security. Moreover, although LF is expected to hold back farmers from effective use of SLM practices, the joint effects of SLM practices and LF on food security have not been studied yet. Thus, it was hypothesized that LF reduces the quality and quantity of SLM practises on remote plots, negatively affecting food security. However, at the same time by reducing production risks LF could enhance food security. Probit and Poisson models were used to analyse the food security consequences of the interactions between LF and SLM practices.

This article is structured into six sections. Section 3.2 describes the study area and explains how the data was collected. Section 3.3 sets out the analytical framework and Section 3.4 presents the empirical models used. Section 3.5 provides the empirical results, followed by some concluding remarks in Section 3.6.

\subsection{Study area and data collection}

The study area, the Gamo Highlands, is located in southwest Ethiopia. Although agriculture is sensitive to climate impacts (Zewdie, 2014), it is the dominant source of livelihood in Ethiopia (Croppenstedt and Muller, 2000), followed by weaving in the Gamo communities. The level of food security is generally low in Gamo: homes in Gamo communities are ringed by enset ${ }^{9}$ to increase access to food and farmers can take advantage of a range of agroclimatic conditions. To facilitate the latter, farmers own multiple homes to decrease the burden of manure application in multiple plots and the time of commuting during production seasons. However, food availability changes over the year, and the poor have nothing to eat at the height of the food shortage season in Gamo (Mesfin et al., 2014).

The topography of the Gamo Highlands is mountainous, creating three distinct agroecological zones based on altitude. This requires farmers to diversify crops and production periods to suit each agro-ecological zone. Samberg et al. (2010) found that traditional

\footnotetext{
${ }^{9}$ Enset is an herbaceous species in the banana family. It is perennial crop and its deep roots make it more resilient to drought than cereal crops so that it enhances food security. Moreover, it is used to feed cattle that provide manure which in turn is used to fertilize the soil.
} 
farming practices in heterogeneous landscapes have resulted in diverse agro-systems in the Gamo Highlands.

The household level primary data used for this study were collected in the year 2015 from three kebeles (lowest level of administrative unit) in Dita district, namely: Done, Haila and Ocholo-Badiga. These kebeles were selected because the local government's ongoing geographical data inventory is fully complete for these kebeles. A stratified random sampling technique was used to select farmers from these kebeles, based on multiple plot ownership and agro-ecological zones. Quantitative data were collected for 297 household heads. Food security data were inventoried for the month of May, which is usually the height of the food shortage season. A male and female were interviewed per household, but food security questions were specifically addressed to female respondents, because women are generally responsible for food in the Gamo communities. The geographic secondary data (i.e. plot location and size) was collected by experts employed by the local government using global positioning system devices to certificate land use rights. The district's average farm size of 1.7 hectares (ha) was fragmented into 21 plots, signalling a high level of fragmentation (exceeding the national average holding size of 1.0 ha fragmented into 2.4 plots) (Deininger and Jin, 2006).

\subsection{Analytical framework}

Climate change and variability are major challenges to household food security, requiring farmers to apply SLM practices to achieve food security. LF and SLM practices are assumed to have both synergetic and trade off effects on the food production of smallholders. For this purpose, we examined whether food security is determined by the extent of LF (expressed using several LF indices), the use of SLM practices and the interaction between LF and SLM. Given the lack of an available and appropriate theoretical model, we took an empirical approach, in which we first discuss both the dependent and explanatory variables.

\subsubsection{Food security indicators}

Maxwell (1996) identified two objective measures of food security, namely: gross household food production and purchase, and the caloric intake of the household in the last 24 hours. However, these measures fail to take into account the vulnerability and sustainability components of food security. Hence, there has been a shift towards multiple subjective perception measures of food security, which can capture more dimensions of 
food security. Furthermore, in practice, it is difficult to choose the best indicator, hence, combining indicators can improve the measurement of food security (Maxwell et al., 2014).

The values for three food security indicators for the food shortfall period (i.e., May) in the Gamo Highlands were calculated using a series of questions ${ }^{10}$ (see Table 3.1) developed by previous studies (Maxwell et al., 2014). These indicators (dependent variables) are: i) coping strategies index (CSI), ii) household food insecurity access scale (HFIAS), and iii) household dietary diversity scale (HDDS).

The CSI counts the occurrence and severity of behaviours engaged in by individuals when they face a shortage of money or resources to buy food (Maxwell et al., 2014). The CSI can be context specific and mainly captures the quantity or sufficiency elements of food security (Maxwell et al., 2014). To calculate the CSI, the value of eight study area-specific individual coping behaviours (indicated by Q2, Q5, Q6 and Q9-Q13 in Table 3.1) were added ${ }^{11}$ together and the cutoff points of Maxwell et al. (2014) were used to determine the food security status of a household.

The HFIAS has been validated in both developed and developing regions (Gebreyesus et al., 2015). The HFIAS is determined from 9 questions (Q1-Q9 in Table 3.1). These questions were designed to take into account household behaviour with respect to insecure access to foodstuffs (Maxwell et al., 2014). The food security perception values of a household (columns i to iv in Table 3.1 for the first 9 questions) were summed and the method of Coates et al. (2007) used to assign a HFIAS ${ }^{12}$ category to each household.

To determine the HDDS of a household, the household perception values for Q14-Q20 under column $i$ to iv in Table 3.1 were added. The value of the HDDS ranges from 0-21 (Swindale and Bilinsky, 2006). The HDDS is the total number of food groups consumed by household members over the reference period. A more diversified diet implies a better caloric and protein intake and tends to capture the quality and diversity dimensions of food security (Maxwell et al., 2014).

\footnotetext{
${ }^{10}$ Each question has four alternative answers. Never means the incidence never happened, rarely refers the incidence happened 1 to 2 times, sometimes denotes the incidence happened 3 to 10 times and often denotes the incidence happened more than 10 times per month. The corresponding food security indicator values range from 0 to 3 .

${ }^{11}$ To compute CSI, add the values of each household's food security perception under columns i to iv in Table 3.1. If the sum of values added to a household $i$ is between $0-2,3-12,13-40$ or $>40$, then household $i$ is categorized as food secure, mildly food insecure, moderately food insecure or severely food insecure, respectively.

12 HFIAS categories: 1 . food secure, 2. mildly food insecure, 3. moderately food insecure and 4. severely food insecure. HFIAS category $=1$ if $[(Q 1 \leq 1) \& Q 2$ to $Q 9=0]$, HFIAS category $=2$ if $[(Q 1 \geq 2$ or $Q 2 \geq 1$ or $Q 3=1$ or $Q 4=1) \& Q 5$ to $Q 9=0$ ], HFIAS category $=3$ if $[(Q 3 \geq 2$ or $Q 4 \geq 2$ or $1 \leq Q 5 \leq 2$ or $1 \leq Q 6 \leq 2) \& Q 7$ to $Q 9=0$ ], and HFIAS category $=4$ if [Q5=3 or $\mathrm{Q} 6=3$ or $\mathrm{Q} 7 \geq 1$ or $\mathrm{Q} 8 \geq 1$ or $\mathrm{Q} 9 \geq 1$ ].
} 
The CSI measure showed the highest prevalence of food insecurity (95\%) in the survey areas, followed by HFIAS with $93 \%$.

Table 3.1 Frequency of occurrence of self-expressed answers to food security questions

\begin{tabular}{|c|c|c|c|c|c|}
\hline \multirow[t]{4}{*}{ Questions } & \multicolumn{4}{|c|}{ Percentage of occurrence $(n=297)$} & \multirow{4}{*}{$\begin{array}{l}\text { Food } \\
\text { security } \\
\text { dimension }\end{array}$} \\
\hline & \multirow{2}{*}{$\begin{array}{l}i \\
\text { Never }\end{array}$} & \multirow{2}{*}{$\begin{array}{l}\text { ii } \\
\text { Rarely }\end{array}$} & \multirow{2}{*}{$\begin{array}{l}\text { iii } \\
\text { Some- } \\
\text { times }\end{array}$} & \multirow{2}{*}{$\begin{array}{l}\text { iv } \\
\text { Often }\end{array}$} & \\
\hline & & & & & \\
\hline & value $=0$ & value $=1$ & value $=2$ & value $=3$ & \\
\hline Q1. Worry about food & 26 & 63 & 11 & 0 & Stability \\
\hline Q2. Unable to eat preferred food & 11 & 81 & 8 & 0 & Acceptability \\
\hline Q3. Eat a limited variety of food & 16 & 74 & 10 & 0 & Diversity \\
\hline Q4. Eat food that you didn't want to eat & 17 & 73 & 10 & 0 & Acceptability \\
\hline Q5. Eat a small meal & 45 & 50 & 5 & 0 & Quantity \\
\hline Q6. Skip a meal in a day & 67 & 31 & 2 & 0 & Quantity \\
\hline Q7. No food to eat in a household & 69 & 28 & 3 & 0 & Quantity \\
\hline Q8. Go to sleep at night hungry & 68 & 30 & 2 & 0 & Stability \\
\hline Q9. Go 24 hours without eating food & 79 & 20 & 1 & 0 & Quantity \\
\hline Q10. Adult skips meal to allow children to eat & 31 & 66 & 3 & 0 & Quantity \\
\hline Q11. Borrow food or money to buy food & 52 & 46 & 2 & 0 & Quantity \\
\hline Q12. Harvest immature crops & 36 & 60 & 4 & 0 & Quantity \\
\hline Q13. Eat seed stock held to sow & 16 & 81 & 3 & 0 & Quantity \\
\hline Q14. Household member ate grain & 8 & 89 & 3 & 0 & Diversity \\
\hline Q15. Household member ate tubers & 1 & 71 & 28 & 0 & Diversity \\
\hline Q16. Household member ate pulses & 21 & 77 & 2 & 0 & Diversity \\
\hline Q17. Household member ate vegetables & 24 & 72 & 4 & 0 & Diversity \\
\hline Q18. Household member ate fruit & 74 & 26 & - & 0 & Diversity \\
\hline Q19. Household member ate dairy & 33 & 66 & 1 & 0 & Diversity \\
\hline Q20. Household member ate sugar/honey & 91 & 7 & 1 & 0 & Diversity \\
\hline
\end{tabular}

Source: Survey data

\subsubsection{Land fragmentation indicators}

Seven indicators were employed to measure LF (see Table 3.2). LF supports food security when the micro-environmental contrasts between non-adjacent plots of an owner are significant, whereas formal risk-reduction methods (such as credit) are limited or costly (Bentley, 1987; Blarel et al., 1992). LF enhances crop diversification and hence farm profitability (Di Falco et al., 2010). However, LF can also be detrimental to food supply by increasing inefficiency and decreasing productivity (Hung et al., 2007; Rahman and Rahman, 2008). Based on this evidence it can be contended that LF provides an opportunity for food security which can be exploited while its detrimental effect should be minimized. 
Table 3.2 Summary statistics for variables

\begin{tabular}{|c|c|c|c|c|c|c|}
\hline & & $\%$ & mean & $S D$ & $\min$ & $\max$ \\
\hline \multicolumn{7}{|c|}{ Dependent variables, dummy } \\
\hline HFIAS & 1 if household is food secure & 6.7 & & & & \\
\hline CSI & 1 if household is food secure & 5.1 & & & & \\
\hline$H D D S$ & household dietary diversity score & & 4.8 & 1.5 & 0 & 8 \\
\hline \multicolumn{7}{|c|}{ Independent variables } \\
\hline \multicolumn{7}{|c|}{ A) $L F$ indicators } \\
\hline soil & number of soil types & & 3.9 & 1.4 & 1 & 5 \\
\hline plots & number of plots & & 20.6 & 13.8 & 1 & 80 \\
\hline distance & non-overlapping distance to plots, $\mathrm{km}$ & & 2.6 & 1.6 & 0.1 & 8.7 \\
\hline$s f i$ & Simpson index for $L F$ & & 0.9 & 0.1 & 0 & 0.97 \\
\hline$a e z$ & 1 if production in 2 agro-ecological zones & 36 & & & & \\
\hline farm & land size, ha & & 1.7 & 1.6 & 0.1 & 15.3 \\
\hline homes & number of homes & & 1.5 & 0.7 & 1 & 4 \\
\hline \multicolumn{7}{|c|}{ B) SLM practices (dummy $1=$ if SLM is applied) } \\
\hline seed & quality seed use & 76.1 & & & & \\
\hline manure & manure use & 94.0 & & & & \\
\hline indigenous & indigenous tree planting & 73.7 & & & & \\
\hline terrace & stone terrace or soil bund & 83.8 & & & & \\
\hline enset & planting more enset & 84.5 & & & & \\
\hline diversify & crop diversification & 58.9 & & & & \\
\hline legume & legume-barley rotation & 85.5 & & & & \\
\hline fertilizer & fertilizer applied per square metre & & 0.2 & 0.6 & 0 & 4.9 \\
\hline \multicolumn{7}{|c|}{ C) Socioeconomic characteristics } \\
\hline gender & 1 if household head is male & 90.6 & & & & \\
\hline literacy & 1 if household head can read and write & 21.6 & & & & \\
\hline dependence & dependency ratio & & 113.5 & 95.9 & 0 & 1,100 \\
\hline experience & years of farming experience & & 33.8 & 15.6 & 0 & 76 \\
\hline labour & family labour size & & 3.5 & 2.3 & 0 & 15 \\
\hline income & off-farm income (in '000 birr) & & 4.5 & 3.7 & 0 & 9.9 \\
\hline remittance & 1 if household receives remittances & 11.5 & & & & \\
\hline asset & number of assets & & 3.6 & 2.2 & 0 & 17 \\
\hline tlu & tropical livestock units & & 3.5 & 2.7 & 0 & 22.9 \\
\hline credit & 1 if have access to credit when required & 58.9 & & & & \\
\hline market & walking distance to nearest market (hour) & & 1.9 & 1.1 & 0.3 & 6 \\
\hline productivity & yield per hectare (in '000 kg) & & 51.1 & 151 & 0 & 248.5 \\
\hline shock & number of shocks observed & & 10.4 & 4.7 & 0 & 20 \\
\hline \multirow[t]{2}{*}{ landqual } & Index for land quality & & 0.41 & 0.21 & 0 & 1 \\
\hline & Number of observations & & & & & 297 \\
\hline
\end{tabular}

Source: Survey data

Hung et al. (2007) used Simpson index, [1-( $\left.\left.\sum_{i=1}^{n} a_{i}^{2} / A^{2}\right)\right]$, to compute LF where $a_{i}$ is the area of the $A^{\text {th }}$ plot in hectares, and $A$ is the farm size in hectares, which equals the sum of 
the area of all $\mathrm{n}$ plots of the farm, $A=\sum_{i=1}^{n} a_{i}$. A Simpson index value of 1 implies severe $\mathrm{LF}$, while a value of 0 represents a perfect land consolidation.

\subsubsection{SLM practices}

SLM practices affect food security by influencing crop yield. The selection procedure of SLM practices as an adaptation strategy in this study was as follows: First, a survey of 13 potential SLM measures based on their importance to soil quality improvement and productivity was held. Second, farmers were asked about whether or not they have altered these SLM measures to adapt to climate change and variability they perceived in the last 25 years (i.e. changes or variations in temperature, precipitation, barley yield or erosion change). If farmers respond to climate change they perceived, they are considered as adapters. Farmers are autonomous adapters if they are responding, although they did not perceive climate change and variability. Interestingly, almost $95 \%$ percent of farmers were purposely changing SLM practices to deal with climate change and variability. The remaining $5 \%$ were autonomous adapters and non-adapters. Finally, SLM measures which correlated with the farmers' perception of climate change and variability at the $10 \%$ significance level were considered for this study. Although the effects on food production of SLM practices vary according to the practice adopted, these practices generally have a positive effect (Branca et al., 2013). Thus, SLM practices are expected to increase food security.

\subsubsection{Socioeconomic characteristics of households}

A household's socioeconomic characteristics are expected to either positively or negatively affect food security. Food security is for instance negatively affected by the dependency ratio (Garrett and Ruel, 1999). The dependency ratio is defined as the ratio of household members aged less than 15 years plus age greater than 64 years to household members of working age (aged 15-64 years).

Off-farm income and family labour size can positively affect food security. Off-farm income is income earned by household members from agricultural employment on other people's farms, plus non-agricultural work and remittances. The presence of remittances is represented by a dummy, given lack of data on the size of remittances. Family labour size is the number of active population (age 15 to 64 years) in a household because age is an important determinant of earning capacity. Farmers use up assets and livestock during food shortage periods and restore these wealth components during food abundant periods 
(Maxwell and Wiebe, 1999; Demeke et al., 2011). Tropical livestock units (TLU) ${ }^{13}$ by Chilonda and Otte (2006) was used to standardize the measurement of livestock.

Market access is defined as the time needed to reach the relevant local market. Proximity to market increases access to off-farm income, information on inputs and transportation and, therefore, is expected to increase food security (Dorward et al., 2003). Unconstrained credit access is assumed to enhance food security, while access to credit from informal sources with high interest rate or formal sources with conditions for the use of credit (e.g., asset building) can decrease food security in the short term. Holden and Shiferaw (2004) note that credit for fertilizer improves food security.

Barley yield per hectare expressed in thousands of kilograms is expected to increase food security (Feleke et al., 2005). Land quality was measured as a ratio of the number of plots with vigorous barley growth to the sum of plots with vigorous and stunted crop development. Land quality is expected to increase food production (Ndiritu et al., 2015). The frequent observation of climatic and non-climatic shocks over the last five years is a sign that, in a good year, the stock of cereals retained from bumper harvests should be increased and assets should be built, as a coping strategy to compensate for bad seasons. Thus, past scores for shocks observed are alerts and assumed to reinforce food security.

\subsection{Empirical model}

Food security is measured by either binary variables or by a discrete non-negative integer variable; hence, correspondingly, probit and count data models are appropriate. For the probit model, let $y_{i}$ be the observed food security status of the $i^{\text {th }}$ household: $y_{i}$ equals 1 if household $i$ is food secure and zero otherwise, while the level of household $i^{\prime} s$ food security $y_{i}^{*}$ is the difference between the resources available for household $i, r_{i}$, to buy food and the consumption need of household $i, c_{i}$. From this, the latent (unobserved) variable $y_{i}^{*}$ that can take all values in the range $(-\infty, \infty)$ is given by:

$y_{i}=\left\{\begin{array}{l}1, \text { if } y^{*}=r_{i}-c_{i}>0 \\ 0, \text { if } y^{*}=r_{i}-c_{i} \leq 0\end{array}\right.$

The probit model assumes that each subject has a binary food security response which is given by:

${ }^{13} \mathrm{TLU}=(0.5 \times$ cattle $)+(0.5 \times$ horse $)+(0.3 \times$ donkey $)+(0.6 \times$ mule $)+(0.1 \times$ sheep $)+(0.1 \times$ goat $)+(0.01 \times$ chicken $)$ 


$$
\begin{aligned}
y_{i}^{*}=\alpha_{0}+ & \sum_{k=1}^{8} \alpha_{k} S L M_{i k}+\sum_{j=1}^{7} \beta_{j} L F_{i j} \\
& +\sum_{k=1}^{8} \sum_{j=1}^{7} \gamma_{k j} \times S L M_{i k} \times L F_{i j}+\sum_{r=1}^{14} \delta_{r} X_{i r}+\varepsilon_{i}
\end{aligned}
$$

Where $S L M_{i k}$, is a land management practice $k$, applied as an adaptation strategy by household $i, L F_{i j}$ is a land fragmentation indicator $j$ of household $i$, and $X_{i r}$ is a socioeconomic characteristic $r$ of household $i$. And $\alpha_{0}, \alpha_{k}, \beta_{j}, \gamma_{k j}$, and $\delta_{r}$ are coefficients to be estimated. The $S L M_{i k} \times L F_{i j}$ shows the interaction between the focus variables $S L M_{i k}$ and the moderator variables $L F_{i j}$. The Poisson model is used when the equidispersion property of the model holds (i.e., when there is equality between the mean and variance). The Poisson model can be expressed as:

$p\left(y_{i}\right)=\frac{\lambda^{y_{i}} \exp -\lambda_{i}}{y_{i} !}, \quad y_{i}=0,1,2,3, \ldots, I$

Where $p\left(y_{i}\right)$ is the probability of $y$ (i.e., the frequency of occurrence of food insecurity for household $i$ during food shortage period) and $\lambda_{i}$ is the expected food security/insecurity frequency. To estimate the Poisson model, the expected food insecurity frequency is assumed to be a function of the explanatory variables such that:

$$
\begin{aligned}
\lambda_{i}=\exp \left(\alpha_{0}\right. & +\sum_{k=1}^{8} \alpha_{k} S L M_{i k}+\sum_{j=1}^{7} \beta_{j} L F_{i j} \\
& +\sum_{k=1}^{8} \sum_{j=1}^{7} \gamma_{k j} \times S L M_{i k} \times L F_{i j}+\sum_{r=1}^{14} \delta_{r} X_{i r}+\varepsilon_{i)}
\end{aligned}
$$

The equi-dispersion property of the model can be tested by specifying:

$$
\operatorname{var}\left[y_{i}\right]=E\left[y_{i}\right]\left[1+\theta E\left(y_{i}\right)\right]
$$

If $\theta$ is not significantly different from zero, we can use the Poisson model. Otherwise the negative binomial model, which relaxes the equality assumption, can be used (Byrs et al., 2003). The negative binomial model regression is not the only way to model data that fail to hold the equi-dispersion property - the Poisson model with robust option can also be used (Cameron and Trivedi, 2009). In this empirical model, endogeneity problems can occur because farmers self-select into SLM practices. We cannot address this endogeneity as 
many farmers applied multiple SLM measures, which leads to too many dependent variables for stage one of a multinomial endogenous switching model (Kassie et al., 2015). In the second stage of a multinomial switching model, endogeneity cannot be dealt with as food security is measured as a categorical variable. Moreover, it is difficult to find a good control group because of a contamination problem as farmers are altering existing SLM or introducing new ones. For this, our estimation results should be interpreted as association rather than causal effects.

A likelihood ratio test is used by comparing the log likelihood of the unrestricted model to that of the reduced model to test three hypotheses. The first null hypothesis states that the food security effects of all the coefficients of SLM measures applied are assumed to be jointly equal to zero (i.e., $H_{0}: \alpha_{k}=0$ ). The second null hypothesis states that the $\mathrm{LF}$ indicators do not have a significant effect on household food security (i. e., $H_{0}: \beta_{j}=0$ ). The third null hypothesis states that the coefficients of the moderating effects of LF indicators on SLM practices are equal to zero (i.e., $H_{0}: \gamma_{k i}=0$ ).

\subsection{Model results and discussion}

The marginal effects of the estimated probit and Poisson models are presented in Table 3.4. For both models the Wald chi-squared test statistic rejected the hypothesis stating that all of the estimated coefficients are jointly equal to zero at the $1 \%$ significance level. The equidispersion property of the Poisson model was rejected at the $1 \%$ significance level; therefore, to address the equi-dispersion problem, we estimated a negative binomial model. However, for the negative binomial regression, the dispersion parameter was a missing value so we could not determine whether or not to use the negative binomial model to solve the problem. Therefore, the Poisson model with robust option was finally used (Cameron and Trivedi, 2009). Correlation coefficients between explanatory variables indicated in Table 3.2 were not more than 0.65; these correlations were considered low enough to avoid multicollinearity issues. However, some of the SLM practices (e.g., introduction of a new crop) were dropped because of multicollinearity with other practices. 
Table 3.3 Factors affecting food security

\begin{tabular}{|c|c|c|c|c|c|c|}
\hline Variables & \multicolumn{4}{|c|}{ Probit Models } & \multicolumn{2}{|l|}{$\begin{array}{l}\text { Poisson Model } \\
\text { HDDS }\end{array}$} \\
\hline \multicolumn{7}{|l|}{ LF indicators } \\
\hline soil & -0.087 & $(0.125)$ & $-0.815^{* * *}$ & $(0.194)$ & $0.045^{* *}$ & $(0.018)$ \\
\hline farm & -0.018 & (0.139) & 0.068 & $(0.164)$ & 0.006 & $(0.010)$ \\
\hline homes & 0.046 & $(0.214)$ & $2.809^{* * *}$ & $(0.620)$ & -0.022 & $(0.028)$ \\
\hline plots & -0.012 & $(0.021)$ & $0.110^{* * *}$ & $(0.028)$ & 0.001 & $(0.002)$ \\
\hline$a e z$ & $1.381^{* * *}$ & $(0.386)$ & $1.768^{* *}$ & $(0.688)$ & -0.007 & $(0.026)$ \\
\hline$s f i$ & $144.458^{* *}$ & (63.663) & $121.264^{* * *}$ & (39.054) & $0.290^{*}$ & $(0.163)$ \\
\hline distance & $1.142^{* * *}$ & $(0.402)$ & -0.053 & $(0.438)$ & -0.011 & $(0.010)$ \\
\hline \multicolumn{7}{|l|}{ SLM practices } \\
\hline seed & $-6.109^{*}$ & (3.311) & -0.226 & (5.073) & & \\
\hline Indigenous & $-9.010^{* *}$ & (3.694) & $104.227^{* * *}$ & $(37.587)$ & & \\
\hline terrace & -0.049 & (3.434) & $31.470^{*}$ & $(16.830)$ & $0.160^{* *}$ & $(0.065)$ \\
\hline enset & $18.134^{* * *}$ & $(6.817)$ & -19.054 & (18.734) & & \\
\hline diversify & -4.254 & $(3.776)$ & $-14.717^{* * *}$ & (3.762) & & \\
\hline legume & $131.987^{* *}$ & (58.801) & 6.038 & (4.245) & & \\
\hline fertilizer & -4.559 & (4.281) & $16.714^{* * *}$ & (3.513) & -0.343 & $(0.660)$ \\
\hline \multicolumn{7}{|l|}{ Interaction terms } \\
\hline seed $\times$ sfi & $7.354^{*}$ & (3.986) & 3.379 & $(6.115)$ & & \\
\hline indigenous $x_{s f i}$ & $10.869^{* *}$ & $(4.507)$ & $-114.683^{* * *}$ & $(40.978)$ & & \\
\hline terrace $\times$ sfi & -1.465 & (3.973) & $-38.272^{* *}$ & $(19.067)$ & & \\
\hline enset $X_{\text {sfi }}$ & $-15.085^{* *}$ & $(6.799)$ & 23.379 & (22.199) & & \\
\hline diversify $\times$ sfi & 5.022 & $(4.485)$ & $15.018^{* * *}$ & $(4.569)$ & & \\
\hline legume $\times$ sfi & $-142.481^{* *}$ & $(63.070)$ & $-8.787^{*}$ & $(5.166)$ & & \\
\hline diversify $\times$ distance & -0.126 & $(0.256)$ & $-1.010^{* *}$ & $(0.410)$ & & \\
\hline indigenous $\times$ distance & -0.049 & $(0.177)$ & $1.299 * * *$ & $(0.483)$ & & \\
\hline enset $\times$ distance & $-1.206^{* * *}$ & $(0.403)$ & -0.331 & $(0.389)$ & & \\
\hline \multicolumn{7}{|l|}{ Socioeconomic variables } \\
\hline gender & $1.211^{* * *}$ & $(0.403)$ & & & -0.019 & $(0.051)$ \\
\hline literacy & 0.632 & $(0.492)$ & 0.160 & $(0.652)$ & -0.002 & $(0.036)$ \\
\hline dependence & $-0.008^{* *}$ & $(0.003)$ & $-0.027^{* * *}$ & $(0.009)$ & 0.001 & $(0.001)$ \\
\hline experience & -0.004 & $(0.008)$ & & & $-0.002^{*}$ & $(0.001)$ \\
\hline labour & -0.069 & $(0.085)$ & $-0.264^{*}$ & $(0.151)$ & 0.007 & $(0.008)$ \\
\hline income & -0.017 & $(0.055)$ & 0.049 & $(0.072)$ & 0.006 & $(0.005)$ \\
\hline remittance & $-1.231^{* * *}$ & $(0.446)$ & $-1.581^{*}$ & (0.961) & -0.011 & $(0.059)$ \\
\hline asset & $0.206^{* * *}$ & $(0.080)$ & 0.049 & $(0.131)$ & $0.035^{* * *}$ & $(0.009)$ \\
\hline tlu & -0.024 & $(0.061)$ & $-0.209^{* *}$ & $(0.099)$ & 0.005 & $(0.007)$ \\
\hline credit & -0.367 & $(0.403)$ & $2.841^{* * *}$ & $(0.915)$ & $-0.096^{* * *}$ & (0.034) \\
\hline market & 0.030 & $(0.163)$ & $1.715^{* * *}$ & $(0.453)$ & -0.016 & (0.017) \\
\hline productivity & $0.019^{* * *}$ & $(0.004)$ & $0.065^{* * *}$ & $(0.015)$ & -0.001 & (0.001) \\
\hline landqual & $1.239^{*}$ & $(0.641)$ & $4.859^{* * *}$ & (1.169) & 0.012 & $(0.088)$ \\
\hline shock & -0.002 & $(0.028)$ & 0.045 & $(0.053)$ & 0.005 & $(0.004)$ \\
\hline constant & $-140.643^{* *}$ & $(60.299)$ & $-123.966^{* * *}$ & (37.639) & $0.964^{* * *}$ & (0.153) \\
\hline LR chi2 & 2514.76 & & 5865.32 & & 102.95 & \\
\hline Prob $>$ chi2 & 0.000 & & 0.000 & & 0.000 & \\
\hline Observations & 297 & & 297 & & 297 & \\
\hline
\end{tabular}

Robust standard errors in parentheses

*** $\mathrm{p}<0.01, * * \mathrm{p}<0.05, * \mathrm{p}<0.1$

A likelihood ratio test supported the importance of the LF indicators, adaptation measures and their interaction in terms of influencing food security. For example, the first null 
hypothesis, that the effect of the adaptation measures used is simultaneously equal to zero, was rejected at the $1 \%$ significance level for probit models. The second null hypothesis, that the coefficients of the LF indicators are jointly equal to zero, was rejected at the $1 \%$ significance level for probit models. Moreover, the third null hypothesis, that the interaction effects of the LF indicators and SLM practices on food security are equal to zero, was rejected at the $1 \%$ significance level for probit models. However, these hypotheses were not rejected for the Poisson model and hence we have not controlled for interaction terms and SLM practices except for terracing for the Poisson model in Table 3.3. Terracing was included as it had a significant effect on food security.

\subsubsection{Role of LF}

Consistent with the expectation, LF improved different food security dimensions by reinforcing farmers' efforts to achieve food security. For instance, farmers who produced crops in two distinct agro-ecological zones (meaning farmers that had plots both in the midlands and highlands) were more likely to be food secure than farmers who produced crops in a single agro-ecological zone. For example, for HFIAS and CSI respectively, farmers who were producing in two agro-ecological zones were found to be $11 \%$ and $7 \%$ more likely to be food secure than farmers who were producing in one agro-ecological zone. A marginal increase in the Simpson index increased the probability of food security, as measured by the HFIAS, by $83 \%$. Moreover, a unit increase in either the number of homes owned or the number of plots increased the probability of food security, as measured by the CSI, by $11 \%$ or $0.4 \%$, respectively. In addition, a unit increase in the number of soil types across separate plots cultivated led to a 0.2 additional dietary diversity score (see Table 3.4).

These results imply that LF allows farmers to diversify crops and crop planting periods to benefit from micro-environmental contrasts. This is a form of insurance in situations where a loss in production in one season is compensated by a gain in another season or the yield of one crop compensates for the loss of another. Moreover, growing a wide range of crops in separate agro-ecological zones allows farmers to produce crops that ripen in different seasons over a year, enhancing access to fresh food and a healthy diet year round. Multiple homes ownership enhances food access, because it has a positive effect on the magnitude and quality of investment in land by decreasing commuting costs. Although, cultivating multiple soils decreases food security (CSI), the overall result provides evidence for benefits of LF (Bentley, 1987; Di Falco et al., 2010). 
Table 3.4 Marginal effects

\begin{tabular}{|c|c|c|c|c|c|c|}
\hline Variables & HFIAS & & CSI & & $H D D S$ & \\
\hline \multicolumn{7}{|l|}{ LF indicators } \\
\hline soil & -0.007 & $(0.010)$ & $-0.032^{* * *}$ & $(0.008)$ & $0.216^{* *}$ & $(0.085)$ \\
\hline farm & -0.001 & $(0.011)$ & 0.003 & $(0.006)$ & 0.030 & $(0.046)$ \\
\hline homes & 0.004 & $(0.017)$ & $0.110^{* * *}$ & $(0.024)$ & -0.103 & $(0.136)$ \\
\hline plots & -0.001 & $(0.002)$ & $0.004^{* * *}$ & $(0.001)$ & 0.001 & $(0.009)$ \\
\hline$A E Z$ & $0.108^{* * *}$ & $(0.031)$ & $0.069 * *$ & $(0.027)$ & -0.035 & (0.123) \\
\hline SFI & $0.828^{* *}$ & $(0.372)$ & $0.684^{*}$ & $(0.408)$ & $1.389^{*}$ & $(0.785)$ \\
\hline distance & -0.008 & $(0.008)$ & 0.012 & $(0.009)$ & -0.051 & $(0.046)$ \\
\hline \multicolumn{7}{|l|}{ SLM practices } \\
\hline seed & 0.016 & $(0.023)$ & $0.067^{* * *}$ & $(0.013)$ & & \\
\hline Indigenous & 0.002 & $(0.029)$ & $0.061^{* *}$ & $(0.026)$ & & \\
\hline terrace & $-0.161^{* * *}$ & $(0.061)$ & $-0.131^{* * *}$ & $(0.037)$ & $0.768^{* *}$ & $(0.312)$ \\
\hline enset & -0.001 & $(0.021)$ & -0.008 & $(0.029)$ & & \\
\hline diversify & -0.020 & $(0.025)$ & $-0.168^{* * *}$ & $(0.018)$ & & \\
\hline legume & -0.033 & $(0.042)$ & $-0.086^{* *}$ & $(0.034)$ & & \\
\hline Fertilizer & -0.355 & $(0.360)$ & $0.652^{* * *}$ & $(0.153)$ & -1.647 & (3.165) \\
\hline \multicolumn{7}{|c|}{ Socioeconomic characteristics } \\
\hline gender & $0.094^{* * *}$ & $(0.035)$ & & & -0.091 & $(0.245)$ \\
\hline literacy & 0.049 & $(0.038)$ & 0.006 & $(0.026)$ & -0.009 & $(0.172)$ \\
\hline dependence & $-0.001^{* *}$ & $(0.001)$ & $-0.001^{* * *}$ & $(0.001)$ & 0.001 & $(0.001)$ \\
\hline experience & -0.001 & $(0.001)$ & & & $-0.008^{*}$ & $(0.004)$ \\
\hline labour & -0.005 & $(0.007)$ & -0.010 & $(0.006)$ & 0.034 & $(0.040)$ \\
\hline income & -0.001 & $(0.004)$ & 0.002 & $(0.003)$ & 0.027 & $(0.025)$ \\
\hline remittance & $-0.096^{* *}$ & $(0.039)$ & -0.062 & $(0.038)$ & -0.051 & $(0.285)$ \\
\hline asset & $0.016^{* *}$ & $(0.006)$ & 0.002 & $(0.005)$ & $0.169^{* * *}$ & $(0.044)$ \\
\hline tlu & -0.002 & $(0.005)$ & $-0.008^{* *}$ & $(0.004)$ & 0.023 & $(0.033)$ \\
\hline credit & -0.029 & $(0.031)$ & $0.111^{* * *}$ & $(0.035)$ & $-0.462^{* * *}$ & $(0.160)$ \\
\hline market & 0.002 & $(0.013)$ & $0.067^{* * *}$ & (0.019) & -0.074 & (0.079) \\
\hline productivity & $0.002^{* * *}$ & $(0.001)$ & $0.003^{* * *}$ & $(0.001)$ & -0.002 & (0.002) \\
\hline landqual & $0.096^{*}$ & $(0.054)$ & $0.189^{* * *}$ & $(0.047)$ & 0.057 & $(0.423)$ \\
\hline shock & -0.000 & $(0.002)$ & 0.002 & $(0.002)$ & 0.022 & $(0.017)$ \\
\hline
\end{tabular}

Robust standard errors in parentheses

*** $\mathrm{p}<0.01, * * \mathrm{p}<0.05, * \mathrm{p}<0.1$

Source: survey data

\subsubsection{Role of SLM practices}

Although farmers had limited access to costly quality seed and fertilizers, the use of these inputs increased the probability of being food secure, as measured by CSI ( $7 \%$ and $65 \%$, respectively). The use of quality seed has the potential to increase productivity and income (Teklewold et al., 2013). The probability of being food secure, as represented by CSI, was $6 \%$ higher for families that planted native trees than for families that did not plant native trees. Indigenous trees are commonly planted in the Gamo Highlands, to control erosion and enhance soil fertility. Sanchez et al. (1979) observed that a shift towards agro-forestry practices is a sustainable way to improve food production in the densely populated areas of East Africa where farm sizes are small. 
Practicing either crop diversification or legume-barley rotation decreased the possibility of a family being food secure, as represented by the CSI by, $17 \%$ or $9 \%$ respectively. However, multiple crop production is promoted for dietary diversity and to reduce overall production risks in subsistence-based farming (Pellegrini and Tasciotti, 2014). We contend that diversification possibly becomes more effective when farmers diversify effectively to take advantage of micro-environmental contrasts by selecting crop species and varieties best suited to the plots owned.

Terracing was found to decrease the probability of being food secure in the Gamo Highlands, as reflected by the HFIAS and CSI (16\% and 13\%, respectively). However, Shively (1999) found that terracing increases food production. This unexpected result can probably be attributed to the fact that farmers who practice terracing more frequently cultivate sloped plots that are less fertile and more eroded than farmers who do not terrace. Hence, in the short term, terracing decreases the probability of being food secure. Moreover, terraces that are constructed from soil and are renewed in each production season cannot sustainably improve soil fertility. However, terracing led to 0.8 additional dietary diversity score. The food security effect of SLM practices is partly inconsistent with studies by Di Falco et al. (2011); and Teklewold et al. (2013) that were conducted in the region. These differential food security effects of SLM practices may stem from differences in SLM practices used, the period in which food security was measured and indicators used to measure food security. Notwithstanding, a review of studies supports the overall effects of SLM practices on food security found (Dutilly-Diane et al., 2003; Branca et al., 2013). These studies found that SLM results in higher output, although the magnitude and variability of results vary with the specific practices employed and rainfall distribution.

\subsubsection{Moderating role of the LF indicators}

The food security effects of the SLM practices employed were a function of the level of LF indicators. Our discussion in this section focuses on reduced models (i.e. models without interaction terms for equation 2 and 4 ). It is impossible to estimate a separate effect of SLM measures on food security for a model with interaction terms because the value of interaction terms can change with the value of component terms (Williams, 2012). For ease of exposition, we presented in table 3.5 marginal effect of SLM practices at the representative values of Simpson index 0.1, 0.3, 0.5, 0.7 and 0.9, although we estimated marginal effects for index values ranging from 0 to 0.97 . Moreover, we reported in table 3.5 the marginal effects for SLM practices that have a significant effect. 
Table 3.5 Marginal effect of SLM practices at the representative values of Simpson index

\begin{tabular}{|c|c|c|c|c|c|}
\hline \multirow[t]{2}{*}{ Value of Simpson index } & \multicolumn{4}{|l|}{ CSI } & \multirow{2}{*}{$\begin{array}{l}\text { HDDS } \\
\text { terrace }\end{array}$} \\
\hline & seed & indigenous & diversify & legume & \\
\hline 0.1 & $0.125^{* *}$ & $0.267^{* * *}$ & $-0.305^{* * *}$ & $-0.107^{* * *}$ & $0.618^{* *}$ \\
\hline 0.3 & $0.116^{* *}$ & $0.249^{* * *}$ & $-0.284^{* * *}$ & $-0.099 * * *$ & $0.654^{* *}$ \\
\hline 0.5 & $0.105^{* *}$ & $0.225^{* * *}$ & $-0.256^{* * *}$ & $-0.098^{* * *}$ & $0.693^{* *}$ \\
\hline 0.7 & $0.083^{*}$ & $0.179^{* * *}$ & $-0.204^{* * *}$ & $-0.071^{* * *}$ & $0.735^{* *}$ \\
\hline 0.9 & $0.054^{* *}$ & $0.117^{* *}$ & $-0.133^{* * *}$ & $0.047^{* * *}$ & $0.778^{* *}$ \\
\hline
\end{tabular}

For food security measured as HDDS, terracing on average increased dietary diversity by a factor of 0.77 for the reduced model while other practices left dietary diversity unaffected. While the marginal effect of terracing on dietary diversity increased from 0.62 to 0.78 as the Simpson index increased from 0.1 to 0.9 for reduced model. For food security measured as CSI, on average, quality seed use increased the probability of being food secure by $6 \%$. While quality seed use increased the probability of being food secure by $13 \%$ and $5 \%$ when the Simpson index was 0.1 and 0.9 respectively. The results in table 3.4 imply that the marginal food security effects of SLM practices that increased the probability of being food secure were decreasing as the Simpson index increased except terracing. However, the marginal food security effects of SLM practices that decreased the probability to be food secure were decreasing as the Simpson index increased. The overall result implies that the negative food security effects of SLM practices are dominant when LF becomes higher.

\subsubsection{Role of household socioeconomic factors}

Socioeconomic variables, for instance; asset ownership and being male increased probability to be food secure while dependence ratio decreased probability to be food secure and the results are consistent with Guo (2011) and Feleke et al. (2005) respectively.

Moreover, increasing land productivity by one hundred kg increased the likelihood of being food secure by 0.2 and $0.3 \%$ respectively for HFIAS and CSI. These findings are consistent with (Ndiritu et al., 2015). A unit increase in land quality, enhanced the probability of being food secure by $19 \%$ and $10 \%$ for the food security indices CSI and HFIAS, respectively. The positive effect of productivity and land quality implies that investment in land quality improves food security in the long term. 


\subsection{Conclusion}

Climate change and variability are worsening the food security status of households that rely on subsistence agriculture that is characterised by LF. The adoption of SLM practices is one way to deal with adverse climate effects. This study shows that although farmers were adopting SLM practices, the share of food insecure households in the Gamo Highlands of Ethiopia was high, ranging from 93-95\% depending on the indicator used.

The empirical results confirm that LF provides more potential opportunities for improving food security than challenges. LF indicators (such as cultivation in distinct agro-ecological zones, the Simpson index and multiple home ownership) increased the probability of a household being food secure. Furthermore, LF increases farm diversity (including soil types and the fertility of plots cultivated), leading to diversity in crops grown and production seasons, allowing farmers to reduce risks and harvest fresh produce throughout the year, thereby improving food security. Finally, production across different agro-ecological zones helps to cope with price fluctuations and balances food demand, thus increasing food security.

The food security effects of the SLM practices employed range from negative to positive. Use of quality seed and tree planting are SLM practices that enhanced food security. Chemical fertilizer use also enhanced food security, although it was not used sustainably because farmers paid a mark-up price for fertilizer and were forced to use it. In contrast, terracing, legume-barley rotation and crop diversification had a negative effect on food security, possibly because making terraces from soil and renewing these terraces every production period is not sustainable and successful crop-rotation for food production requires informed decisions.

The food security effects of the SLM practices employed to deal with climate change and variability were positively or negatively moderated by the level of LF. The marginal food security effects of these practices also changed at different values of the Simpson index. However, the adverse food security effects of SLM practices dominated the positive food security effects of these practices as the level of LF increased.

Overall, the findings imply that increasing the quality rather than the quantity of SLM practices is important to cope with the adverse impacts of climate change and variability on food security. Farmers' food security can also be enhanced by taking advantage of synergies between SLM and LF and resolving their contrasting effects. Given the benefits and challenges of the high level of LF in the study area, further research is needed to investigate what factors have led farmers to maintain this severe fragmentation. Now, LF is largely 
exogenous to farmers - which is why we do not consider endogeneity problems in our estimation - but it is clear that the assembling of plots into larger heterogeneous clusters of the plots could help farmers to become more food secure. Plot assembly may be possible through the voluntary bartering of plots, introduction of an inheritance scheme that avoids further plot disintegration and the creation of a land rental market by introducing land privatization. Each of these policy options requires additional research.

This study has some caveats. First, the analysis of longitudinal data would have been useful to capture the dynamics of food security and weather. For instance, crop loss is not uniform over periods; hence, the food security status of subsistence agricultural households varies across seasons and years. Second, although the subjective perception measures of food security reflect the farmers' reality, these measures fail to capture elements that would be better considered using objective yardsticks, such as calories. Finally, results should be interpreted with some care as we have not been able to solve for possible endogeneity problems in our estimations. Despite these caveats, this study contributes to the body of literature on food security under changing and variable climate and in an area where there is limited access to formal risk reduction measures (such as insurance) by studying how land fragmentation moderates the food security effects of SLM practices. 


\section{Land fragmentation, technical efficiency, and adaptation to climate change by farmers in Ethiopia}

Households in the Gamo Highlands of Ethiopia rely on barley for their diet and allocate most of their highly-fragmented land to barley production. Moreover, farmers alter land management practices as a strategy to adjust to climate change and variability. However, to what extent land fragmentation and land management jointly influence the technical efficiency of barley production is unknown. In addition, it is not known whether technical efficiency is uniform across multiple separated plots. In this study, we adapted two stochastic frontier panel models on plot-level cross-sectional data to investigate this. The model results indicate that fragmentation conditions the effect of land management practices on efficiency. The study found that efficiency was not uniform across different plots and for different farmers. A total average technical efficiency of $49 \%$ implies the existence of large yield gaps. To close these gaps, policies designed to address the specific components of inefficiency need to be implemented.

Based on:

Cholo, T., Peerlings, J., and Fleskens, L. Land fragmentation, technical efficiency, and adaptation to climate change by farmers in Ethiopia. Journal of Productivity Analysis, under review 


\subsection{Introduction}

Climate change has a negative impact on agricultural productivity in Africa (Deressa and Hassan, 2009; Schlenker and Lobell, 2010), significantly increasing the risk of hunger (Parry et al., 1999; Wijeratne et al., 2007). Sub Saharan Africa (SSA) is the most vulnerable region to climate change in the world (Kotir, 2011; Challinor et al., 2007) and faces relatively large challenges in adapting to the changing climate (Scholes and Biggs, 2004). A meta analysis of 52 articles projects that climate change will reduce the mean yield of eight crops in Africa and South Asia by $8 \%$ by 2050 (Knox et al., 2012).

Adaptation to climate change is a possible way out for farmers to live with a changing climate (IPCC, 2001; Adger et al., 2003; Kurukulasuriya and Mendelsohn, 2008). Adaptation is defined as an "adjustment in natural or human systems in response to actual or expected climatic stimuli or their effects, which moderates harm or exploits beneficial opportunities" (Parry et al., 2007). Adaptation supports farmers to improve their access to food and livelihood security targets (Kandlinkar and Risbey, 2000; Vermeulen et al., 2012). Adaptation also increases farm net revenue and food production in SSA, including Ethiopia (Di Falco et al., 2011; Di Falco, 2014).

Given changes in land use (FAO, 2012), rising demand for agricultural products (Tolessa et al., 2017), and the adverse impacts of the changing climate on yield, a rising yield per hectare is important to Ethiopia, because opportunities to bring additional virgin soil under cultivation are scant, especially in the densely-occupied Gamo Highlands. Thus, sustainable intensification - defined as producing more yield from the same area of land while reducing adverse environmental impacts, but also increasing natural capital and ecosystem services - is needed (Pretty et al., 2011). There are different models of sustainable intensification, but in this study, we focus on sustainable land management (SLM), which is deployed as a strategy to adapt to climate change and variability. For this, we collected information on the application of SLM practices at the level of individual plots; for example, we inventoried the quantity of manure applied and the number and age of indigenous trees planted per plot -indicators that are usually measured only at the farm level. By practicing SLM, farmers can invest in a yield rise while reducing the adverse impacts of agriculture on natural resources and ecosystem services (Fernandes and Burcroff, 2006; Motavalli et al., 2013; Schirpke et al., 2017).

Agricultural fields in the Gamo Highlands of Ethiopia are notably fragmented (Deininger and Jin, 2006; Teshome et al., 2014), and fragmentation is expected to increase due to the population boom, customary land inheritance rules, and the usufruct rights of farmers (Gashaw, 2017). Land fragmentation (LF) refers to the production of crops on disjoint 
multiple plots (Nguyen et al., 1996; Kawasaki, 2010). Previous studies have focused mainly on the effects of LF on productivity, inefficiency and profit (Rahman and Rahman, 2008; Di Falco et al., 2010; Reidsma et al., 2010; Manjunatha et al., 2013), overlooking how LF impacts on the technical inefficiency of SLM practices and how technical inefficiency can be plot-varying.

To our knowledge, no study has examined the interaction between the effects of LF and SLM practices on technical inefficiency. Moreover, most previous studies analysed yield and inefficiency on the level of the agricultural holding, but not on a plot level (Niroula and Thapa, 2007). The assumption in earlier farm-level studies that inefficiency is plot-invariant is quite a strong one; in contrast, we assume that inefficiency can be both plot-invariant and plot-varying for a given farmer owning multiple disjointed plots. Although barley is a staple crop for millions of people in the Gamo Highlands, and the yield is affected by the changing climate and variability, so far, studies like Tan et al. (2010) have focused on the yield of cereals other than barley (such as rice, maize and wheat). So, the purpose of this study is to examine how LF and SLM practices jointly influence technical inefficiency in barley production in the Gamo Highlands of Ethiopia. For this, we estimated i) plot-invariant and plot-varying inefficiency and ii) the interacted effects of LF and SLM practices on technical inefficiency. To explain these effects, we adapted stochastic frontier (SF) models for panel data (which are designed to work on farms observed over multiple periods) for use with cross-sectional data for farms with multiple plots. The paper is structured as follows: Section 4.2 provides the theoretical and empirical explanation for adapting the SF models for panel data for use with cross-sectional data. Sections 4.3 and 4.4 present the data and empirical model. Section 4.5 discusses the results and, finally, Section 4.6 presents the conclusion.

\subsection{Theoretical framework}

Applications of SF models to examine productivity and efficiency dates back to Aigner et al. (1977) and Meeusen and van Den Broeck (1977). More recently, Rahman and Rahman (2008); Tan et al. (2010) have applied SF models to examine the effect of LF on output and technical efficiency. According to Koopmans (1951), for a technically-efficient producer it is impossible to increase output without increasing input use or without decreasing the production of at least one output. A technically-inefficient farmer has room to produce the same level of output with less of at least one input or could produce more output with the same inputs.

We assume that LF can either increase or reduce technical inefficiency. Moreover, we suppose that the effects of SLM practices on inefficiency are conditioned by the magnitude 
of the LF. First, fragmentation increases commuting costs and results in wastage of time and inputs (e.g., of fertiliser due to fertiliser leaking from containers when farmers work away from home). Furthermore, fragmentation holds farmers back from the maximisation of investments in land improvement in remote and small plots, and restricts available land use options and land management practices, which may lead to negative externality effects (De Lisle, 1982; Bentley, 1987). For instance, although indigenous tree planting potentially reduces soil erosion and composted leaves can improve soil fertility, tree planting can compete with crops for water and cause border disputes on fragmented plots. Moreover, farmers in the Gamo Highlands can be reluctant to grow heavy staple crops (such as potatoes and enset) in remote fields due to the burden of transporting final products, although remote plots are as suitable as homestead plots for the production of these crops. However, fragmentation can reduce output loss by spreading production risks (Blarel et al., 1992).

In this study, we estimated two SF models for panel data: i) an SF panel model with a multistage procedure developed by Kumbhakar et al. (2014), hereafter called the 'random effects stochastic frontier (RESF) model'; and ii) a 'true' fixed effects SF model proposed by Greene (2005), hereafter called the 'true fixed effects stochastic frontier (TFESF) model'. The RESF and TFESF models are different; the former has two sources of inefficiency and the latter has one. We adapted these two panel models for a dataset containing crosssectional plot-level data. As a consequence, in our model, the panel data has two dimensions: i) the different farms and ii) the two plots observed per farm. Collecting data on two plots for the same farmer allowed us to estimate both plot-invariant (persistent) efficiency and plot-varying (residual) efficiency.

First, the RESF model was adapted to decompose technical inefficiency into persistent (plotinvariant) and residual (plot-varying) components. Moreover, the RESF model separates farmer effects from both persistent inefficiency and residual inefficiency. In so doing, the model avoids the upward bias in persistent inefficiency. Downward bias in overall efficiency is also avoided because persistent inefficiency is no longer confounded within farmer effects (Kumbhakar et al., 2014). Persistent inefficiency is farmer-specific (i.e., it reflects the effect of inputs like management and other unobserved inputs, which vary across farms). Persistent inefficiency can change only when there is a change in something that affects the management style of the farmer (Kumbhakar et al., 2015), for example; a change in land ownership or the provision of training to farmers on innovative SLM practices.

However, residual efficiency is both farm- and plot-specific. Efficiency can vary from plot to plot for the same farmer. A farmer can diversify the quality, quantity and type of investment in soil fertility improvement between plots because of land fragmentation. For instance, a 
farmer could be reluctant to undertake tree planting on small fragmented plots. In addition, a farmer can vary the quality and quantity of land improvement in different plots, due to the variation in the distance to the plots, the size of the plots, the soil type and fertility level of the plots, the susceptibility of the plots to erosion, and the slope of plots. Additionally, LF could lower the farmer's propensity to innovate in land management. For instance, a farmer could avoid innovative and labour intensive land management practices in remote plots. It is also important to note that some land management practices can be uniform across plots for a given farmer (i.e., use of manure). For this, identifying persistent and residual components of inefficiency is vital, because they have different policy implications.

The RESF model, which separates farmer effects, persistent inefficiency and plot-varying inefficiency, is specified as follows:

$y_{i j}=\beta_{0}+x_{i j}^{\prime} \beta+\mu_{i}-\eta_{i}+v_{i j}-u_{i j} \quad i=1,2, \ldots, n \quad \mathrm{j}=1,2$

Where, $y_{i j}$ is the In of barley output per hectare (ha) for farm $j$ observed in plot $j$, and $x_{i j}$ (in $\mathrm{In}$ ) is the vector of inputs allocated to plot $j$ by the producer in farm $i$ to realize $y_{i j}$. A parameter vector $\beta$ characterises the structure of the production technology. The error term is decomposed into four constituents: $\mu_{i}$ and $v_{i j}$ are the noise while $\eta_{i}$ and $u_{i j}$ are non-negative inefficiency components. The random disturbance term $v_{i j}$ is included to capture the effect of statistical noise on observed yield per hectare as a result of measurement errors, omitted variables and favourable and unfavourable exogenous production shocks that are out of the producer's control. Moreover, $\mu_{i}$ captures unobserved, producer-specific heterogeneities, which are plot-invariant. These random shocks can increase or decrease yield, ceteris paribus. However, $\eta_{i}$ and $u_{i j}$ account for plotinvariant and plot-varying technical managerial constraints, respectively, resulting in the actual yield of plot $j$ being different from its potential yield per hectare $y_{i j}$ (i.e., technical inefficiency).

We used a multistep procedure to estimate the model: the parameters of the production function, $\beta$ (other than intercept and variance components) were estimated first without setting distributional assumptions on the error components (Kumbhakar and Heshmati, 1995; Kumbhakar et al., 2014). We used maximum likelihood in the next stage to estimate the efficiency components. To apply the procedure, we first had to rewrite equation (4.1) as:

$y_{i j}=\beta_{0}^{*}+x_{i j}^{\prime} \beta+\alpha_{i}+\varepsilon_{i j}$ 
Where $\beta_{0}^{*}=\beta_{0}-E\left(\eta_{i}\right)-E\left(u_{i j}\right) ; \alpha_{i}=\mu_{i}-\eta_{i}+E\left(\eta_{i}\right)$ and $\varepsilon_{i j}=v_{i j}-u_{i j}+E\left(u_{i j}\right)$. This specification allows a zero mean to be obtained, as well as constant variance for $\alpha_{i}$ and $\varepsilon_{i j}$ (Kumbhakar et al., 2014; Kumbhakar et al., 2015). Following Kumbhakar et al. (2014), equation (4.2) can be estimated in three steps.

Step 1: Equation (4.2) is the commonly known specification for a random effects panel data model, thus the standard random effect panel regression yields estimated values for $\beta$ represented as $\hat{\beta}$. This step also allowed the estimated values of $\alpha_{i}$ and $\epsilon_{i j}$ (represented as $\hat{\alpha}_{i}$ and $\hat{\epsilon}_{i j}$ ) to be obtained.

Step 2: Plot-varying technical inefficiency, $u_{i j}$ was obtained using estimated values of $\epsilon_{i j}$ from step 1, as:

$\varepsilon_{i j}=v_{i j}-u_{i j}+E\left(u_{i j}\right)$

and by assuming $v_{i j}$ is independent and identically distributed (iid) $N\left(0, \sigma_{v}^{2}\right)$ and $u_{i j}$ is $N^{+}\left(0, \sigma_{u}^{2}\right)$. This step gave a prediction of the plot-varying residual technical efficiency (RTE) component, $\hat{u}_{i j}, R T E=\exp \left(-\hat{u}_{i j}\right)$, for details see Kumbhakar et al. (2014) and Jondrow et al. (1982).

Step 3: To estimate plot-invariant or persistent technical efficiency, $\eta_{i}$, we followed a procedure similar to step 2. To do this, we used the best linear predictor of $\alpha_{i}$ from step 1 , as:

$$
\alpha_{i}=\mu_{i}-\eta_{i}+E\left(\eta_{i}\right)
$$

and considering $\mu_{i}$ is iid $N\left(0, \sigma_{\mu}^{2}\right)$ and $\eta_{i}$ is $N^{+}\left(0, \sigma_{\eta}^{2}\right)$, equation (4.4) was estimated using the standard normal-half-normal SF model cross-sectionally (Jondrow et al., 1982; Kumbhakar et al., 2014). Estimates of the plot-invariant (i.e., persistent) technical inefficiency component, $\eta_{i}$ were obtained using the Jondrow et al. (1982) procedure. Persistent technical efficiency (PTE) was obtained from $P T E=\exp \left(-\hat{\eta}_{i}\right)$. The overall technical efficiency (OTE) was then obtained from the product of PTE and RTE (Kumbhakar et al., 2015). That is, OTE $=P T E \times R T E$

Second, the true fixed effect stochastic frontier (TFESF) model proposed by Greene (2005) was adapted to estimate the effect of plot-varying exogenous variables. The TFESF model was used, because in the RESF model with multistage procedure by Kumbhakar et al. (2014) the means to accommodate heteroscedasticity has not yet been developed (Kumbhakar et 
al., 2014). Moreover, the TFESF model allows the inefficiency to be heteroskedastic. For these reasons, we adapted the TFESF model to estimate the effect of exogenous covariates on technical inefficiency. For this, we analysed the TFESF model at two levels: i) TFESF Model I (i.e., restricted model, a model without interaction terms) and ii) TFESF Model II (i.e., unrestricted model, a model with interaction terms), comprising the effect of land fragmentation, SLM practices and the interaction between LF and SLM practices on technical inefficiency. The TFESF Model II was considered to examine whether or not the efficiency effects of SLM practices are conditioned by LF.

The specification of a TFESF model accounting for heteroscedasticity is:

$$
\begin{aligned}
& y_{i j}=\alpha_{i}+x_{i j}{ }^{\prime} \beta+\varepsilon_{i j} \\
& \varepsilon_{i j}=v_{i j}-u_{i j} \\
& v_{i j} \sim N\left(0, \sigma_{v}^{2}\right) \\
& u_{i j} \sim N^{+}\left(u_{i j}, \sigma_{i j}^{2}\right) \\
& \mu_{i j}=z_{i j} \delta \\
& \sigma_{i j}^{2}=\exp \left(z_{i j} \gamma\right)
\end{aligned}
$$

$$
i=1,2, \ldots, n \text { and } j=1,2
$$

Where $y_{i j}$ represents output per hectare for farm $i$ on plot $j, x_{i j}$ are vectors of inputs, $\beta$ is a technology parameter, $\alpha_{i}$ is farm-specific heterogeneity, $v_{i j}$ is the noise and $u_{i j}$ is the inefficiency. The mean of inefficiency and heteroskedastic inefficiency are represented by $\mu_{i j}$ and $\sigma_{i j}^{2}$ respectively. The constant 1 and exogenous variables affecting inefficiency are represented by $z_{i j}$ while $\delta$ and $\gamma$ are the corresponding coefficient vectors, respectively.

\subsection{The study area and data}

The study area, the Gamo Highlands, is located high above the Great East African Rift Valley. The mountain chains of the Gamo Highlands are characterised by a predominance of enset and cereal-based cropping systems and livestock production. Barley is the predominant crop and is produced mainly for consumption rather than market. Weaving is the second most dominant livelihood strategy.

Lack of working capital, limited endowments of agricultural land, and land fragmentation influence land use, investment in land improvement and agricultural production in Ethiopia (Belay and Manig, 2004). Moreover, farmers in Ethiopia have only land use rights, and land cannot be used as collateral. These limited land use rights decrease the propensity of farmers to invest in land improvement. 
The data for this study was obtained from a household survey. Farmers' socioeconomic features and plot-level data were collected from Done kebele (a 'kebele' is a lower level administrative unit in Ethiopia). Done kebele is part of Dita woreda (a 'woreda' is a higher level administrative units comparable to a province), which is located in the Gamo Highlands. Plot-level data collection was limited to a single kebele, because gathering information on land management practices (e.g., the amount of manure applied and number of native trees planted) for multiple plots per owner is demanding. Moreover, the two plots selected per farm were far from each other. A stratified random sampling technique was followed to select plots. A hundred households were surveyed in the 2016 meher season (the main barley production season). Using a simple random sampling approach, two barley plots per farm were selected; a homestead plot close to home and a remote (the furthest) plot from home. Farmers who had only either a homestead or a remote plot were dropped. Plot-level data was fully collected for 184 plots belonging to 92 farmers. Geolocation data collected by experts employed by the local government using global positioning system (GPS) devices was used as secondary data. Table 4.1 presents a summary of the data used for this study.

\subsubsection{Output}

The average barley yield of a plot was 2,057 kg per hectare (ha) for the meher season 2015. Although investment in soil improvement in nearby plots is high, the average yield of a plot close to home was $2,062 \mathrm{~kg}$, which is not significantly different from the yield in a remote plot, which was $2,052 \mathrm{~kg}$ per ha. Plots close to home were a mean distance of $0.36 \mathrm{~km}$ from home, while remote plots were $1.1 \mathrm{~km}$ away from home on average.

\subsubsection{Inputs}

The main inputs for barley production in the study area are land, labour, manure and chemical fertiliser. Plot size is an important factor of production; on average, households farm 1.6 hectares of land on 26 plots. Scale inefficiencies in production and poor investment in land quality improvement are inevitable for small plots, leading to high production inefficiency. Family labour is the main source of labour. The availability of family labour is expected to increase yield by increasing the application of land management practices and post-harvest crop management. As labour use per plot is not known, we calculated it by 
multiplying the adult equivalent family labour size ${ }^{14}$ by the share of hours ${ }^{15}$ members of the family worked on a specific barley plot.

\subsubsection{Land fragmentation indicators}

Although we used various indicators to measure LF to capture different dimensions of LF, we employed two plot-varying LF indicators. LF indicators measured were the Simpson index for LF, the sum of non-overlapping distance from the homestead to all plots per farm, the distance from the homestead to the barley plot, and the size of the plot used for barley production. The former two LF indicators are plot-invariant, while the latter two are plotvarying. We followed the approach of Hung et al. (2007) to measure the Simpson index. The Simpson index value ranges from 0 (when a household has a single plot) to 1 (when a household has many plots). GPS devices were used to measure the distance to, and size of, the barley plot.

We considered two prominent debates on the relationship between LF and efficiency. First, that LF reduces efficiency (Sherlund et al., 2002; Bizimana et al., 2004; Rahman and Rahman, 2008; Manjunatha et al., 2013) and, second, that multiple plot ownership increases technical efficiency, which was found to be the case in China (Tan et al., 2010), implying the existence of variation effects. LF decreases expected output, but reduces output variation from year to year and increases the minimum output in the worst year in India (Heston and Kumar, 1983). Wan and Cheng (2001) showed that the adverse effects of LF on returns to scale and output are too small in China to recommend radical land policy reform. Based on the finding of these previous studies, we expected that the notable LF in our study area would reduce technical efficiency.

\subsubsection{SLM practices}

The SLM practices considered in this study are the practices that farmers apply to adapt to a changing climate and the climate variability that they have observed in the last 25 years. The selection of practices was as follows: First we surveyed 13 SLM practices that potentially increase soil fertility and control soil erosion. Second, we asked farmers whether or not they had perceived climate change and variability (i.e., a change in temperature, precipitation, or barley productivity) in the last 25 years. Third, farmers were asked whether or not they

\footnotetext{
${ }^{14}$ Adult equivalent labour $=0.25 \times$ household size age $10-14+1 \times$ household size age $15-65+0.75 \times$ age $>65$

${ }^{15}$ Share of hours a labourer worked $=52$ weeks $\times 6$ days $\times 8$ hours $\times$ land $1 \div$ land 2 (see table 4.1 for land 1 and 2 )
} 
were altering practices with the intention to adapt to climate change and variability. Farmers who said that they had responded to perceived climate change were considered 'adapters'. If a farmer did not perceive climate change, but changed their SLM practices, (s)he was considered to be an autonomous adapter. We collected plot-level data on 4 SLM practices that are significantly correlated with farmers' perceptions of climate change. These were manure application, indigenous tree planting, legume-barley rotation and the use of quality seed (see Table 4.1).

Table 4.1 Summary statistics of variables

\begin{tabular}{|c|c|c|c|c|c|c|}
\hline Variables & Description of variables & $\%$ & mean & $S D$ & $\min$ & $\max$ \\
\hline Output & $\begin{array}{l}\text { Barley yield per ha observed in plot } j, \mathrm{~kg} \\
\text { Inputs }\end{array}$ & & 2,056 & $1,401.8$ & 87 & 5,000 \\
\hline Manure & manure applied on plot $j, \mathrm{~kg}$ & & 398.3 & 454.2 & 0 & 3,000 \\
\hline Labour & $\begin{array}{l}\text { Share of family labour available to be used on plot } j \\
\text { in } 2015, \text { hour }\end{array}$ & & 731.8 & 989 & 9.7 & $7,690.8$ \\
\hline Fertiliser & $\begin{array}{l}\text { Chemical fertiliser applied on plot j, } \mathrm{kg} \\
\text { Plot-invariant causes of inefficiency } \\
\text { Education and experience }\end{array}$ & & 22.5 & 22.5 & 0 & 100 \\
\hline Literacy & 1 if household head can read and write & 25 & 0.25 & 0.43 & 0 & 1 \\
\hline Experience & $\begin{array}{l}\text { Farming experience, years } \\
\text { land fragmentation indicators }\end{array}$ & & 35.6 & 16.9 & 1 & 76 \\
\hline Plot & Number of plots & & 25.5 & 16.3 & 2 & 80 \\
\hline sfi & Simpson index for land fragmentation & & 0.87 & 0.1 & 0.5 & 0.97 \\
\hline Distance2 & $\begin{array}{l}\text { Sum of non-overlapping distance from home to all } \\
\text { plots, } \mathrm{km}\end{array}$ & & 2.8 & 1.6 & 0.2 & 7.2 \\
\hline Land2 & $\begin{array}{l}\text { Total land holding size, ha } \\
\text { Plot-varying causes of inefficiency } \\
\text { Plot characteristics }\end{array}$ & & 1.6 & 1.5 & 0.13 & 8.32 \\
\hline Slope & 1 if slope of barley plot j is steep & 26 & 0.26 & 0.44 & 0 & 1 \\
\hline Fertility & 1 if barley plot $j$ is fertile & 31 & 0.32 & 0.47 & 0 & 1 \\
\hline Distance1 & Distance to a barley plot j from home, $\mathrm{km}$ & & 0.71 & 0.66 & 0.001 & 2.7 \\
\hline Land 1 & $\begin{array}{l}\text { Plot j allocated for barley production, ha } \\
\text { SLM practices }\end{array}$ & & 0.08 & 0.09 & 0.002 & 0.61 \\
\hline Legume & 1if legume applied on plot $j$ last year & 65 & 0.65 & 0.48 & 0 & 1 \\
\hline Indigenous & 1 if indigenous tree planted on plot $j$ & 46 & 0.46 & 0.50 & 0 & 1 \\
\hline $\begin{array}{l}\text { Seed } \\
\text { Obs. }\end{array}$ & $\begin{array}{l}1 \text { if quality barley seed used on plot } j \\
\text { Number of observations }\end{array}$ & 42 & 0.42 & 0.50 & 0 & $\begin{array}{l}1 \\
184\end{array}$ \\
\hline
\end{tabular}

Source: survey data

The deployment of these practices is important to maintain agriculture profitable and to sufficiently feed the growing population, while preserving the natural capital and ecosystem services (Tappan and McGahuey, 2007). Effective investment in land increases resilience and soil quality, which in turn leads to efficiency improvement. Land management practices, such as the amount of manure applied and local trees planted, are assumed to increase productivity and efficiency by compensating for, or decreasing, soil loss.

The technical efficiency effects of the interaction between SLM and LF indicators can either be positive or negative. LF could increase inefficiency as it increases commuting costs; LF 
also discourages innovation in the use of SLM practices and the quality of investment in soil upgrading could be higher in homestead plots than in remote plots. For instance, the amount of manure applied or age and number of local trees planted per hectare are expected to decrease as the plot gets faraway from the homestead.

\subsubsection{Plot characteristics}

Plot characteristics are expressed using dummies for soil fertility and the slope of a plot. We assumed that the adverse effects of low soil fertility and slope on productivity and efficiency can be offset by effective land management practices.

\subsubsection{Education and experience}

Household education and farming experience influence technical efficiency by influencing the capacity and know-how of farmers to combine factors of production and utilise available technology (Battese et al., 1996; Wang, 2002). However, these variables are plot-invariant and not used as explanatory variables for the main analysis.

\subsection{Empirical model}

For the stochastic production frontier, the translog specification for the yield of the $j^{\text {th }}$ plot of farm $i$ was selected:

$\ln \left(y_{i j}\right)=\beta_{0}+\sum_{m=1}^{3} \beta_{m} \ln x_{m i j}+1 / 2 \sum_{m=1}^{3} \sum_{r=1}^{3} \beta_{m r} \ln x_{m i j} \cdot \ln x_{r i j}$

$+\mu_{i}-\eta_{i}+v_{i j}-u_{i j}$

Where $\ln \left(y_{i j}\right)$ is the natural logarithm of output per ha for farm $i$ observed in plot $j$ in 2015 in the meher season; and $x_{m i j}$ and $x_{r i j}$ are the amounts of input $m$ or $r$ used for barley production on plot $j$ by farmer $j$, and $\beta^{\prime} s$ are the coefficients for the inputs of the frontier model.

The technical inefficiency $\left(u_{i j}\right)$ of farm $i$ is expressed as follows: 


$$
\begin{array}{r}
u_{i j}=\delta_{0}+\sum_{s=1}^{2} \delta_{s} L F_{s i j}+\sum_{w=1}^{4} \tau_{w} S L M_{w i j}+\sum_{s=1}^{2} \sum_{w=1}^{4} \pi_{s w} L F_{s i j} \times S L M_{w i j}+ \\
\sum_{j=1}^{2} \rho_{k} P_{k i j}+\omega_{i j}
\end{array}
$$

Where $u_{i j}$ is the non-negative, unobservable random variable that captures the technical inefficiency of farm $i$ for plot $j$. In $S L M_{w i j}, \mathrm{w}$ is the land management practice that is deployed as an adaptation strategy on plot $j$ of farm $i$, and $L F_{s i j}$ is the plot-varying $\mathrm{LF}$ indicator $s$ for plot $j$ of farm $i$. The joint effect of LF indicators and SLM practices on barley output is given by $L F_{s i j} \times S L M_{w i j} . P_{k i j}$ is fertility or slope level $k$ for plot $j$ of farm $i$. The letters of the Greek alphabet in equation 4.12 stand for the coefficients of the covariates explaining inefficiency, while $\omega_{i j}$ is the error term for technical inefficiency.

The maximum likelihood estimation for the RESF model, as discussed in equation 4.1-4.4, was carried out to estimate equation 4.11. The STATA ado file in STATA version 13.1 developed by Kumbhakar et al. (2015) was used to execute the estimation of $\beta s$ and the efficiency components (OTE, RTE and PTE) in the multistep procedure. However, the maximum likelihood estimation for the TFESF model, as discussed in equations 4.5-4.10, was carried out to estimate equations 4.11 and 4.12 in one step. In this way, the $\beta^{\prime} s$ and the coefficients of the inefficiency variables were estimated jointly. To estimate the parameters of the TFESF model, the 'sfpanel' syntax in the STATA version 13.1 was used.

The general likelihood ratio ${ }^{16}(\lambda)$ test was applied: i) to examine the existence of technical inefficiency; ii) to determine functional form (i.e., translog versus Cobb-Douglas function); and iii) to test the importance of SLM practices and LF or interaction between SLM and LF in explaining technical inefficiency.

\subsection{Results and discussion}

The results are presented in the following four sub-sections. The first sub-section discusses the results of hypotheses tests; the second discusses the output elasticities of the production frontier estimation; the third describes the components of inefficiency, and the fourth discusses the causes of inefficiency for restricted (i.e., Model I, for which the interaction terms are not controlled) and unrestricted (i.e., Model II, for which the

\footnotetext{
${ }^{16} \lambda=-2\left[\ln L\left(H_{0}\right)-\ln L\left(H_{1}\right)\right]$ where $L\left(H_{0}\right)-L\left(H_{1}\right)$ is the log likelihood value of the restricted and unrestricted model.
} 
interaction terms are considered as factors affecting efficiency) TFESF models (see Table 4.5).

\subsubsection{Hypotheses tests}

A summary of the hypotheses tests for equations 4.11 and 4.12 is given in Table 4.2. The first hypothesis states that there is no inefficiency (i.e., ordinary least squares [OLS] is an ideal estimator). The second hypothesis is that the translog (TL) specification of equation 4.11 is reduced to the Cobb-Douglas (CD) specification. To conduct the test statistics for hypotheses 1 and 2, the log likelihood values of the OLS, RESF and TFESF models for equation 4.11 were used. The test results indicate the presence of technical inefficiency, because the null hypothesis of no inefficiency was rejected at the $1 \%$ significance level for the RESF and TFESF models (see column A.1 of Table 4.2). Moreover, the TL was not reduced to the $C D$ specification, because the null hypothesis that the cross-products of input variables jointly equal zero was rejected for both models (see column A.2 of Table 4.2).

Table 4.2 Summary of hypotheses tests

\begin{tabular}{|c|c|c|c|c|c|c|c|}
\hline \multirow[t]{2}{*}{ Model } & & $\begin{array}{l}\text { Test } \\
\text { statistics }\end{array}$ & $\begin{array}{l}\text { A.1 } \\
\text { No } \\
\text { technical } \\
\text { inefficiency }\end{array}$ & $\begin{array}{l}A .2 \\
\text { TL model } \\
\text { versus } C D \\
\text { model }\end{array}$ & $\begin{array}{l}A .3 \\
\text { Joint effect } \\
\text { of } L F \\
\text { indicators } \\
\text { is zero } \\
\end{array}$ & $\begin{array}{l}\text { A.4 } \\
\text { Joint effect } \\
\text { of SLM } \\
\text { practices } \\
\text { is zero } \\
\end{array}$ & $\begin{array}{l}\text { A.5 } \\
\text { No } \\
\text { interaction } \\
\text { effect }\end{array}$ \\
\hline & & & & $\beta_{m r}=0$ & $\delta_{s}=0$ & $\tau_{w}=0$ & $\pi_{z w}=0$ \\
\hline \multirow[t]{4}{*}{$R E S F$} & Eq. 11 & $\lambda$ & 10.66 & 27.74 & & & \\
\hline & & $d f$ & 1 & 6 & & & \\
\hline & & $p$-value & 0.000 & 0.000 & & & \\
\hline & & decision & rejected & rejected & & & \\
\hline \multirow[t]{4}{*}{ TFESF II } & Eq. 11 and & $\lambda$ & 182.86 & 586.55 & 29.46 & 900.31 & 17.40 \\
\hline & 12 & $d f$ & 1 & 6 & 2 & 4 & 8 \\
\hline & & $p$-value & 0.000 & 0.000 & 0.000 & 0.000 & 0.005 \\
\hline & & decision & rejected & rejected & rejected & rejected & rejected \\
\hline
\end{tabular}

Hypotheses 3 to 5 were tested using the log likelihood value of the TFESF model for equations 4.11 and 4.12. The third hypothesis is that LF indicators, for example, plot size used for barley production and distance to a barley plot, jointly do not affect technical efficiency. This null hypothesis was rejected at the $1 \%$ significance level (see column A.3 of Table 4.2). The fourth hypothesis is that the four SLM practices that are jointly deployed on the barley plots do not affect technical inefficiency. The fifth hypothesis states that the interaction terms (i.e., SLM and LF indicators) jointly do not affect efficiency. The likelihood ratio test rejected the fourth and fifth null hypotheses at the $1 \%$ significance level (see columns A.4 and A.5 of Table 4.2, respectively). The hypotheses test results suggest that 
SLM practices, LF indicators, and their interactions with SLM practices are important determinants of technical efficiency.

\subsubsection{Elasticities and returns to scale}

Table 4.3 presents the yield elasticities and standard errors (SE) of the TFESF model. As the specification is TL for equation 4.11, the elasticities are the first derivative of In of output per ha, with respect to In of an input. The results show that the sum of yield elasticities of the inputs was 1.1 and 1.15 for models I and II, respectively (see Table 4.3). However, for the TFESF Model II only, the null hypothesis that the production technology produces constant returns to scale was rejected at the $1 \%$ significance level in favour of increasing returns to scale. This implies that a $1 \%$ increase in the use of inputs would result in a more than proportionate increase in yield.

Table 4.3 Yield elasticities

\begin{tabular}{lllll}
\hline Variables & TFESF Model I & & TFESF Model II \\
& Elasticities & $S E$ & Elasticities & $S E$ \\
\hline In(labour) & $0.452^{* * *}$ & 0.061 & $0.425^{* * *}$ & 0.009 \\
$\ln ($ manure) & $0.307^{* * *}$ & 0.058 & $0.228^{* * *}$ & 0.007 \\
$\ln ($ fertiliser) & $0.333^{* * *}$ & 0.029 & $0.344^{* * *}$ & 0.006 \\
Indigenous & & & $0.030^{* * *}$ & 0.003 \\
Legume & & & $0.073^{* * *}$ & 0.002 \\
Seed ${ }^{17}$ & & $0.055^{* * *}$ & 0.003 \\
Returns to scale & 1.092 & $1.145^{* * *}$ & \\
\hline$* * * \mathrm{p}<0.01,{ }^{* *} \mathrm{p}<0.05, * \mathrm{p}<0.1$ & & &
\end{tabular}

The yield elasticities of the inputs were almost equal. Although the high yield elasticity of fertiliser is important to ensure food security, fertiliser is less environmentally friendly than manure. A kilogram increase in fertiliser use led to a $0.3 \%$ change in yield for TFESF Model II. Moreover, the yield elasticity of manure and other SLM practices was positive and significant, which is promising for the environment, because the use of SLM practices is sustainable, as SLM practices are eco-friendly and economical for farmers. The yield elasticity of labour is comparable to Seyoum et al. (1998) for maize production in Ethiopia.

\footnotetext{
17 If dummy variable (seed) changes from 0 to 1 , the \% impact of seed on yield is $100[\exp (0.055)-1]$.
} 


\subsubsection{Technical efficiency components}

The RESF model by Kumbhakar et al. (2014) is able to distinctly report the magnitude of persistent plot-invariant efficiency (PTE) and plot-varying efficiency (RTE) components. Results show that efficiency varies greatly between plots, as well as between farmers. The RTE was between $44 \%$ and $92 \%$, whereas the PTE was between $22 \%$ and $92 \%$, implying that efficiency variation is significant for both RTE and PTE. The mean value of RTE was $75 \%$, i.e., higher than the mean value of PTE of $65 \%$. This implies that although the mean inefficiency of $35 \%$ between farmers was higher than the mean inefficiency of $25 \%$ between plots, it is important to reduce inefficiency between farms and between plots to ensure sustainable production in a changing climate, as both inefficiency levels are significant. Moreover, this result confirms the findings of Kumbhakar et al. (2014).

Table 4.4 Technical efficiency sores

\begin{tabular}{llll}
\hline & Residual efficiency & Persistent efficiency & Overall efficiency \\
\hline Mean & 0.75 & 0.65 & 0.49 \\
SD & 0.09 & 0.18 & 0.16 \\
Min & 0.44 & 0.22 & 0.10 \\
Max & 0.92 & 0.92 & 0.84 \\
\hline
\end{tabular}

Moreover, the mean OTE of $49 \%$ (and its range from $10 \%$ to $84 \%$ ) implies a large gap between actual and potential output; hence, farmers have room to increase output by more than $51 \%$ without increasing the use of inputs (such as labour) by adopting the technologies and techniques used on the best-managed fields.

\subsubsection{Factors affecting inefficiency}

This section focuses on the estimation results of the two TFESF models: TFESF models I and II presented in Table 4.5. LF indicators affect inefficiency. In particular, the size of the plot used for barley production reduced inefficiency after some threshold level (a plot size below 0.18 hectare increased inefficiency, while above this size decreased inefficiency). This indicates that larger plots could increase investment in land quality improvement. Farmers construct homes closer to larger plots to ease manure application and other forms of investments that enhance soil quality in these plots. This result implies that increasing the size of a plot, for example, by reducing LF through the voluntary exchange of plots, is critical to reduce inefficiency. This result is also supported by the findings of Niroula and Thapa (2007). 
Distance to the barley field from home either increase efficiency (TFESF Model II) or has no effect on efficiency (TFESF Model I). However, distance was found to decrease efficiency in studies by Tan et al. (2010), and Rahman and Rahman (2008) found that the larger the number of plots (i.e., LF) the lower the efficiency. The variation in results can be attributed to the fact that, as opposed to the expectation, investment in nearby plots was not higher than in remote plots. For example, the mean of manure and fertiliser applied per hectare in nearby plots was not significantly higher than for remote plots. However, the mean of labour hours used per hectare for nearby plots was significantly (i.e., at the $5 \%$ level) lower than for remote plots. Moreover, higher altitude plots faraway from home, which are more suitable for barley production, are more likely to be fallow.

Table 4.5 Estimation of parameters for TFESF model for barley production

\begin{tabular}{|c|c|c|c|c|}
\hline Variable & Model I & $S E$ & Model II & $S E$ \\
\hline \multicolumn{5}{|l|}{ Production function } \\
\hline $\ln$ (manure) & $0.204^{* * *}$ & $(0.043)$ & $0.156^{* * *}$ & $(0.014)$ \\
\hline $\ln ($ labour) & $0.384^{* *}$ & $(0.154)$ & $0.340^{* * *}$ & $(0.030)$ \\
\hline $\ln ($ fertiliser $)$ & 0.475 & $(0.364)$ & $0.437^{* * *}$ & $(0.048)$ \\
\hline $\ln$ (manure) $\times \ln$ (manure) & 0.019 & $0.013)$ & $0.015^{* * *}$ & $(0.001)$ \\
\hline $\ln ($ manure $) \times \ln ($ labour $)$ & -0.010 & $(0.009)$ & $-0.006^{* *}$ & $(0.003)$ \\
\hline $\ln$ (manure) $\times \ln ($ fertiliser $)$ & -0.017 & $(0.030)$ & $-0.010^{* * *}$ & $(0.003)$ \\
\hline $\ln$ (labour) $\times \operatorname{In}$ (labour) & 0.004 & $(0.008)$ & $0.006^{* *}$ & $(0.003)$ \\
\hline $\ln$ (labour) $\times \ln$ (fertiliser) & -0.009 & $(0.022)$ & 0.002 & $(0.004)$ \\
\hline $\ln ($ fertiliser $) \times \ln ($ fertiliser $)$ & 0.050 & $(0.095)$ & $0.056^{* * *}$ & $(0.007)$ \\
\hline Seed & & & $0.777^{* * *}$ & $(0.029)$ \\
\hline Indigenous & & & $0.245^{* * *}$ & $(0.024)$ \\
\hline Legume & & & $0.642^{* * *}$ & $(0.028)$ \\
\hline \multicolumn{5}{|l|}{ Factors affecting inefficiency } \\
\hline Land1 & $7.814^{* * *}$ & (1.732) & $11.745^{* * *}$ & (3.642) \\
\hline Land1 $\times$ land1 & & & $-32.404^{* * *}$ & $(8.502)$ \\
\hline Distance 1 & -0.078 & $(0.152)$ & $-1.324^{* * *}$ & $(0.279)$ \\
\hline Manure & $0.001^{* *}$ & $(0.0002)$ & 0.001 & $(0.001)$ \\
\hline Seed & -0.241 & $(0.204)$ & 0.133 & $(0.369)$ \\
\hline Indigenous & 0.078 & $(0.186)$ & $-0.714^{* *}$ & $(0.364)$ \\
\hline Legume & $0.644^{* * *}$ & $(0.182)$ & $0.670^{*}$ & $(0.370)$ \\
\hline Fertility & $-0.546^{* *}$ & $(0.235)$ & $-0.595^{* * *}$ & $(0.193)$ \\
\hline Slope & -0.243 & $(0.226)$ & & \\
\hline Labour & $0.0004^{* * *}$ & $(0.0002)$ & $0.001^{* * *}$ & $(0.0002)$ \\
\hline Land1 $\times$ manure & & & 0.003 & $(0.007)$ \\
\hline Land $\times$ indigenous & & & 3.639 & (2.971) \\
\hline Land1 $\times$ seed & & & -4.723 & $(3.568)$ \\
\hline Land $\times$ legume & & & 3.088 & (3.482) \\
\hline Distance $1 \times$ manure & & & -0.0004 & $(0.001)$ \\
\hline Distance $1 \times$ indigenous & & & $1.104^{* * *}$ & $(0.314)$ \\
\hline Distance $1 \times$ seed & & & 0.070 & $(0.314)$ \\
\hline Distance $1 \times$ legume & & & $0.647^{* *}$ & $(0.323)$ \\
\hline Observations & & & & 184 \\
\hline
\end{tabular}


SLM practices did have a significant effect on efficiency. For instance, increasing tree planting was found to improve efficiency, while legume barley rotation and manure application decreased efficiency, as manure application is demanding, particularly on fragmented plots. The use of quality seed did not affect efficiency.

The technical efficiency effects of SLM practices were jointly conditioned by LF indicators. However, the effect of some specific SLM practices on efficiency was not conditioned by the level of LF. For instance, manure application on larger plots used for barley production neither improved nor lowered efficiency. Some possible explanations for this result are: First, although farmers commonly construct separate homes to increase manure application on larger plots located away from their main home, the amount of manure and fertiliser applied per hectare decreases significantly as plot size increases. Second, increasing indigenous tree planting on larger plots did not change inefficiency, even though we hypothesised that planting trees on fragmented plots would lead to more border conflicts, creating an negative interaction effect. This result may be explained by the fact that the age of trees planted and size of the plot used for barley production were not strongly correlated; in addition, the number of indigenous trees planted and the size of the plot used were also not significantly correlated. The average age of trees planted was 8 years and the average number of trees planted per ha was 34 , which was not sufficient to significantly alter erosion and soil fertility levels. Finally, manure application on distant plots did not affect efficiency; the reason for this is perhaps that an inadequate amount of manure is used, as applying this practice on remote plots is demanding.

The absence of a significant effect of most of the specific SLM practices and the interaction between most of the specific SLM and LF indicators on efficiency implies that SLM practices, or the way they are applied, are unable to improve efficiency. In particular, the lack of manure and resources to buy inputs (such as quality seed or tree seedlings) may be a cause for this. Moreover, the SLM practices employed by farmers may not be sufficiently effective in addressing the current impact of climate change. Support of experts and training of farmers to stimulate innovation in land management and increasing access to credit to buy inputs are needed to make existing SLM practices more effective. Soil fertility enhancement was found to be efficiency improving - implying the positive long-term effect of SLM practices.

\subsection{Conclusion}

Increasing barley yield is imperative to feed the increasing population in the Gamo Highlands. However, a changing climate is expected to increase the gap between grain 
supply and demand, largely by decreasing yield per hectare. Smallholder farmers have limited options to meet the rising food demand, but face ample constraints. For instance, virgin land to increase production is unavailable or scarce. Farm fields are fragmented, which impedes the effective implementation of sustainable land management practices to deal with climate change impacts, leading to production inefficiency. However, on the other hand, land fragmentation allows farmers to access various plots with heterogeneous soil types and distinct agro-ecological zones that are important to spread production risks. For these reasons, we hypothesised that LF and SLM practices jointly affect efficiency. Furthermore, we postulated that technical efficiency might not be constant across multiple separate plots for a given farmer.

We found that LF indicators did jointly affect technical efficiency and that larger plot size and distance to barley plot were efficiency improving. Furthermore, we also found that SLM practices jointly affected technical efficiency; specifically indigenous tree planting was efficiency improving, but legume and manure application were efficiency impeding as manure use is a demanding activity. Moreover, LF indicators and SLM practices jointly influenced technical efficiency. The overall result implies that SLM practices are not innovative enough to enhance efficiency or that there are constraints (e.g., lack of resources) that hinder their full potential.

The assumption that technical efficiency across multiple separate plots owned by the same farmer is equal needs to be reconsidered in efficiency studies. We found that technical efficiency varies across plots for farmers. The mean technical efficiency across plots was $75 \%$ and across farmers was $65 \%$. The overall mean technical efficiency was $49 \%$. This indicates that farmers have significant room to increase yield without using additional inputs, offering perspectives for increasing food supply in situations where virgin soil for food production is unavailable and limited.

This study introduced the joint effect of SLM practices and LF on technical efficiency as a contribution to existing studies. Moreover, the study proved that the assumption that efficiency is constant across multiple separate plots leads to an inaccurate estimation of inefficiency levels. Efficiency is plot-invariant and plot-varying for farmers with multiple plots. Therefore, farmers can increase technical efficiency and yield if awareness is created about the drawbacks of fragmentation. Moreover, constraints that limit the full potential of existing SLM practices should be lifted (e.g., resources provided to buy inputs) and new, more innovative SLM practices introduced. Policy measures that reduce residual and persistent inefficiency are desirable as the magnitude of both inefficiency estimates is considerable. Future studies in the area can focus on the scale and allocative efficiency effects of land fragmentation. In this study we considered 2 plots per farm out of 26 plots 
per farm on average, due to resource reasons, but future studies could increase the number of plots studied to better explain the economic, social and environmental effects of land fragmentation. 


\section{Gendered climate change adaptation practices in fragmented farm fields of Gamo Highlands, Ethiopia}

The objective of this study is to assess the existence of gendered climate change adaptation practices of smallholder farmers in the Gamo Highlands of Ethiopia. We hypothesized that smallholders' adaptation practices are gendered because of land fragmentation and gendered division of labour. To explore this, we considered sustainable land management practices as a tool for sustainable adaptation and assessed the effect of land management practices deployed and land fragmentation on intra-household time allocation. The results indicate that although land fragmentation increased hours worked by men and women significantly, fragmentation increased the working hours of men more than women. Application of a larger number of sustainable land management practices increases the mean working hours of women, but leaves unaffected the working hours of men, implying that adaptation practices are gender-biased. Therefore, this study can guide land management decisions by pointing out that fragmentation results in long working hours and adaptation practices may disproportionately affect women.

Based on:

Cholo, T., Peerlings, J. and Fleskens, L. Gendered climate change adaptation practices in fragmented farm fields of Gamo Highlands, Ethiopia. Regional Environmental Change, submitted

\subsection{Introduction}


Agriculture is the sector most affected by climate change in developing countries (Kurukulasuriya and Mendelsohn, 2008; Kotir, 2011), and the majority of the poor depend on agriculture for their livelihood in sub-Saharan Africa (Jayne et al., 2003). The poor (Parry et al., 1999; Thomas and Twyman, 2005; Mendelsohn et al., 2006; IPCC, 2014) and women are the most affected group within agricultural households (Cannon, 2002; Parry et al., 2007) because of the social division of responsibilities and differences in access to and control over resources (Doss, 2001; Marlene and Henry, 2002; Murray et al., 2016). Moreover, women and the poor are underrepresented in studies, negotiations and policies related to addressing climate change impacts (Minu and Ulrike, 2009; Jerneck, 2018). Climate change tends therefore to exacerbate existing gender inequality, causing women to face larger negative impacts of climate change than men (Cannon, 2002; Alston, 2013). Gender inequality is defined as prejudicial treatment of individuals or groups because of their gender (Shastri, 2014). For instance, a changing climate led to flooding and crop loss in the Philippines, increasing women's vulnerability and domestic burdens, since women are accountable for family food security and cleaning the house after flooding (Peralta, 2009).

Adaptation to climate change enhances food security (Burke and Lobell, 2010; Di Falco et al., 2011; Jerneck, 2018), reduces vulnerability to climate change impacts and reinforces resilience (Field, 2012). However, benefits and costs of adaptation practices can be unfairly distributed between men and women (Edvardsson and Hansson, 2013). For instance, alteration of gender roles was used in the Philippines as a strategy to adapt to climate change. However, although the alteration of gender roles increased women's access to resources, it burdened women more as they became both farm managers and caretakers of family welfare (Tatlonghari and Paris, 2013). That is to say that adaptation practices are not gender-neutral (Alston, 2011; Jerneck, 2018), as they are practiced differently by men and women (Jin et al., 2015), and their effects also differ between men and women (Jerneck, 2018) because of differences in their respective social roles and responsibilities and control over resources (Mersha and Van Laerhoven, 2016; Jerneck, 2018). Most studies have concentrated on gender differences in climate change impacts (Terry, 2009; Alston, 2013; Jin et al., 2015). However, a few earlier studies assess gendered adaptation practices. For instance, Smucker and Wangui (2016) observe gendered knowledge about adaptation practices in Tanzania; Jin et al. (2015) point out gender differences in the choice of climate change adaptation measures in China; and Mersha and Van Laerhoven (2016) look at gendered barriers to adaptation practices in Ethiopia. Moreover, Demetriades and Esplen (2008) indicate the inadequacy of scientific investigations explaining unequal sharing of benefits and burdens of climate change adaptation endeavours. This study contributes to climate change adaptation literature by explaining gendered drawbacks of adopting 
sustainable land management practices in fragmented farmlands to deal with climate change.

Hung et al. (2007) and Kawasaki (2010) describe land fragmentation (LF) as cultivation of multiple separated parcels. Multiple separated plots per owner can result in plots being far apart from each other and from home. In Ethiopia LF is exogenous to farmers, as there is no land market and farmers have inherited already fragmented plots. LF is affecting working hours of both men and women and how time is allocated between different tasks (McCall, 1985). Moreover, LF influences the use of sustainable land management practices (Nigussie et al., 2017). Sustainable land management can be defined as an adaptive strategy that jointly enhances environmental quality and farmers' livelihood (Fernandes and Burcroff, 2006). Plus, it is expected that fragmentation is worsening the inequity of sharing the loads of adaptation endeavours between men and women. For instance, manure use and tree planting on multiple plots are adaptation practices in Gamo communities in the Ethiopian highlands that potentially result in extra commuting time, higher workloads and longer working hours for women compared to men. Adding manure to remote plots and collecting firewood from fragmented and faraway plots are tasks mostly undertaken by women in these communities. As a result, women work longer hours and lose time that otherwise would be allocated to rest and leisure, which leads to more time poverty for women than for men (Bardasi and Wodon, 2006; Kes and Swaminathan, 2006). Time poverty occurs when workers do not have enough time for rest and leisure after considering time used for production and domestic work (Bardasi and Wodon, 2006).

Additionally, land fragmentation decreases efficiency of crop production (Manjunatha et al., 2013) and lowers food production per hectare (Rahman and Rahman, 2008). This affects women more than men due to their reproductive roles (Doss, 2001); as an illustration, women are more responsible for household welfare (i.e., nourishing children and labour force) in Gamo communities.

This study was conducted in the Gamo Highlands of Ethiopia, where the land is fragmented and farmers are responding to climate change and variability they have observed (Bryan et al., 2009). The purpose of the study is to explore the existence of gendered climate change adaptation practices amongst Gamo communities. The research questions addressed in this paper are: i) Does land fragmentation increase hours allocated to work? ii) Does land fragmentation lead to more hours allocated to work by women than by men? iii) Do sustainable land management practices result in more hours allocated to work by women than by men? 
The outline of the paper is as follows: Section 5.2 and 5.3 present the study area and description of data and the theoretical framework, respectively. Section 5.4 explains the empirical model. Section 5.5 discusses the results, and the final section presents the conclusions.

\subsection{The study area and data collection}

The study region is the Gamo Highlands, a heterogeneous mountainous landscape located in southwest Ethiopia, high above and east of two lakes, Abaya and Chamo. Seasonal variation of farm tasks causes farmers to work longer hours per day during peak labour seasons (i.e. seasons with high work pressure). Both women and men work long hours, more to meet their basic needs than for profit motives because of their low human capital status and lack of sufficient access to agricultural technologies (such as fertilizer and quality seed). The gender division of labour enforced by custom in the Gamo communities causes women to allocate more hours per week to unpaid work than men, as discussed by Rutherford (2010), and leads to power asymmetries in access to and control over the factors of production (Doss, 2001). Moreover, women and men have separate roles and duties and decision-making power, leading to further gender inequality in the Gamo communities. Women undertake both farm work and domestic work, but men are hardly involved in domestic tasks such as fetching water, collecting fodder and cooking for the family. In addition, women work longer hours than men not only because of the domestic division of labour, but also because some family farm activities are solely performed by women. For instance, composting and applying manure are productive activities solely performed by women. Moreover, land management practices to cope with climate change, such as planting indigenous trees and applying more manure, further exacerbate the already high time burden of women. The time demand for these tasks may be especially significant in the case of multiple plots at a distance from home and from each other, and this is expected to increase women's hours allocated to work considerably.

The household level primary data used for this study was collected in the year 2015 from three kebeles (the lowest-level administrative unit) namely: Done, Haila and Ocholo-Badiga in Dita woreda (the next highest-level administrative unit). These kebeles were selected because the local government's ongoing geographic data inventory is fully complete for these kebeles. A stratified random sampling technique was used to select farmers from these kebeles, based on multiple plot ownership and agri-environmental zones. Quantitative data were collected from 297 households. For each household, both the husband and wife were interviewed; in cases of a female-headed household this was the woman leading the farm and a son. There were no households headed by unmarried men. 
In addition to household data collected, hours allocated to work by the husband and wife (i.e. hereafter men and women) and their demographic characteristics such as age and education were inventoried as well as the perceived work burdens of men and women for the peak labour seasons (i.e., harvesting and planting) and the off-peak season at one moment in time by specifying the seasons for respondents. The LF indices were calculated from spatially-explicit secondary data on household plots that was collected by experts employed by the local government using global positioning system (GPS) devices to certify land use rights.

\subsection{Theoretical framework}

Time is a scarce resource that can be allocated to work and leisure. More time spent on work reduces leisure and hence leads to higher time poverty and work burden (Bardasi and Wodon, 2006). Work-related stressful experiences contribute to depression and psychological disorders (Tennant, 2001), and working long hours may cause various health problems (Burke and McAteer, 2007). Time scarcity also affects food choices, which can lead to serious health problems (Jabs and Devine, 2006). Moreover, the burden of competing tasks on an individual's time constrains that individual's choice of how to allocate their time, increases the intensity of work and creates tradeoffs among different tasks (Kes and Swaminathan, 2006). Time poverty contributes to income poverty in several ways (see Burchardt (2008) for empirical evidence). First, participation in non-market works that are labour intensive and unproductive reduces time that could be allocated for productive activities and therefore income. Second, because of the gender division of labour, particularly women are less likely to participate in income generating activities. Third, time poverty impedes human capital development by limiting the individual's access to education and skill development that could result in better paid jobs (Kes and Swaminathan, 2006; Burchardt, 2008).

Time poverty is positively related to the hours worked. In this research the number of hours worked per week by men and women in three different seasons is used to capture the work burden and time poverty associated with adaptation endeavours and LF. Worked hours are the sum of paid and unpaid work following the classification of both used by the United Nations (2005). Paid work is divided into off-farm and on-farm work, the latter including subsistence production on family farms. Unpaid work consists of mainly domestic work. The harvesting and planting seasons are considered to be the two peak seasons because work pressure is high, while the off-peak season is the season following the harvesting season when work pressure is relatively low in the Gamo Highlands.

5.3.1 Time allocated to work 
Men and women in Gamo communities typically work six days a week and work longer hours per day than international labour organization (ILO) standard, (i.e., 48 hours per week for industry workers) (ILO, 1921). However, the number of hours allocated to work is likely to be gender specific. Time allocation is especially relevant in peak labour seasons (i.e., planting and harvesting seasons) when time is most scarce. On average, our data show that women and men allocate 89 and 70 hours per week to work during the harvesting season, respectively, and during the planting season the mean working hours of men and women, respectively, are 87 and 71 hours per week. Also during the off-peak season women allocate more hours to work than men, on average, 77 hours versus 62 hours per week, respectively. Women devote more hours to work than men in all seasons. The hypothesis that women and men on average allocate equal time to work was rejected the $1 \%$ significance level for all seasons. Moreover, $89 \%$ of men and $90 \%$ of women involved in the survey opined that women work more hours than men. These findings are consistent with Wright (2007) and Craig (2005). The reason for the gender gap in hours worked is that women are responsible for most domestic work in Gamo communities.

Although the vast majority (91\%) of household heads interviewed were men, close to twothirds of the male-headed households reported that harvesting crops from and transporting heavy manure to remote plots results in more working hours for women than for men. Men were accountable for farm production (i.e. for harvesting and planting), while women were responsible for both domestic work and farm production. Meanwhile, $95 \%$ of the household heads said that women were responsible for adding manure to soils, $30 \%$ reported that women were accountable for carrying the harvest from the multiple plots to the homestead, and $90 \%$ reported that women were responsible for collecting and carrying fodder and hay from various plots to the homestead. Survey responses further showed that men sow and harvest crops on scattered plots, but were rarely involved in weeding, the task left for women, while women are equally responsible for activities done by men as well as for activities solely done by women, including gathering and carrying fodder and hay and cooking and supplying food to farm workers. Women and young girls are more responsible for carrying the grain harvested from the field to the threshing floor close to the homestead, and for fetching firewood and vegetables. Next we discuss the variables that can explain the number of hours worked by men and women. 


\subsubsection{Land fragmentation indicators}

Land fragmentation is measured such that it captures three important dimensions of fragmentation. The measures used are the non-overlapping distance from home to all plots, the number of plots, having plots in different agro-ecological zones and the Simpson index for land fragmentation. Hung et al. (2007) defined the Simpson index as [ $\left.1-\left(\sum_{i=1}^{n} a_{i}^{2} / A^{2}\right)\right]$ where $a_{i}$ is the area of the $i^{\text {th }}$ plot in hectares, and $A$ is the farm size in hectares, which equals the sum of the area of all $n$ plots of the farm, $\sum_{i=1}^{n} a_{i}$. The value of the index ranges from 0 for ownership of a single plot to 1 for ownership of several plots.

The mean farm size in the study area was 1.7 hectares. On average, a household owned 21 plots and the number of plots ranged from 1 to 80 plots. The non-overlapping distance from home to all plots owned by a farm was measured using GPS devices. Having plots in different agro-ecological zones refers to the ownership of plots in two distinct agro-ecological zones, namely midland and highland (see Table 5.1). These LF indices are expected to increase hours allocated to work per week for men and women by increasing commuting time from home to plots and between plots. Moreover, LF is expected to increase working hours of women more than of men because of gender roles and division of labour.

\subsubsection{SLM practices}

SLM practices considered in the study were selected in a number of steps. First, a survey was made of 13 potential SLM practices based on their importance to soil and water conservation and suitability for local conditions. Second, farmers were asked about whether or not they have altered/used these SLM practices to adapt to the climate change and variability they have perceived in the last 25 years. Climate change and variability indicators are changes in temperature, precipitation and crop productivity. Farmers' observed climate change and variability over the last 25 years were used to measure climate change and variability since we were unable to find long-term meteorological data for the study area. However, farmers' perceptions of climate change and variability were consistent with trends of meteorological data and studies in Ethiopia and sub-Saharan Africa (Maddison, 2007; Bryan et al., 2009; Bryan et al., 2013). If farmers respond to climate change, they are perceived as adapters. Interestingly, almost $95 \%$ percent of the farmers in this study are changing SLM practices to deal with climate change and variability.

Finally, SLM practices correlated with the farmers' perception of climate change and variability at the $10 \%$ significance level were considered for this study. The eight SLM measures used as climate change adaptation strategies are indicated in Table 5.2. 
Interestingly, of these 8 SLM measures, more than $82 \%$ of the farmers applied at least 4 SLM practices to adapt to the changing climate. The number of SLM practices (SLMn) applied per farm is obtained by adding all SLM practices used on a farm. For instance, if a given farm applied five SLM practices out of the eight practices indicated in Table 5.1, the SLMn value of the farm is 5 and so on. We assume that SLMn will increase women's working hours more than men's working hours for each of the seasons.

Table 5.1 Summary statistics of variables

\begin{tabular}{|c|c|c|c|c|c|c|}
\hline Variable & Description of variables & $\%$ & mean & $S D$ & $\min$ & $\max$ \\
\hline \multicolumn{7}{|c|}{ Hours allocated to work by spouses ${ }^{18}$} \\
\hline planting & Hours allocated to work per week in planting season & & 78.7 & 16.1 & 0 & 108 \\
\hline harvesting & Hours allocated to work per week in harvesting season & & 79.5 & 16.8 & 0 & 114 \\
\hline work-off & Hours allocated to work per week in off-peak season & & 69.9 & 18.8 & 0 & 114 \\
\hline \multicolumn{7}{|c|}{ SLM practices (dummy, $1=$ yes $)$} \\
\hline seed & Quality seed use & 76 & & & & \\
\hline manure & Manure use & 94 & & & & \\
\hline indigenous & Indigenous tree planting & 74 & & & & \\
\hline terrace & Stone terrace or soil bund application & 84 & & & & \\
\hline legume & Legume barley rotation & 86 & & & & \\
\hline enset & Expansion of enset planting & 59 & & & & \\
\hline new-crop & New crop introduction & 59 & & & & \\
\hline diversify & Crop diversification & 59 & & & & \\
\hline SLMn & Number of SLM practices applied & & 6.15 & 1.87 & 0 & 8 \\
\hline \multicolumn{7}{|c|}{ Land fragmentation indicators } \\
\hline sfi & Simpson index for land fragmentation & & 0.85 & 0.1 & 0 & 0.97 \\
\hline distance 2 & $\begin{array}{l}\text { Sum of non-overlapping distance from home to plots } \\
(\mathrm{km})\end{array}$ & & 2.6 & 1.6 & 0.1 & 8.7 \\
\hline plots & Number of plots & & 21 & 13.8 & 1 & 80 \\
\hline aez & 1 if a farmer farms in two distinct agro-ecological zones & 36 & & & & \\
\hline \multicolumn{7}{|c|}{ Socioeconomic characteristics } \\
\hline genderh & 1 if gender of household head is male & 91 & & & & \\
\hline literacy & 1 if household head can read and write & 21 & & & & \\
\hline age & Age of a husband or wife & & 49.6 & 16 & 15 & 98 \\
\hline family & Family members under age 10 & & 2.4 & 1.6 & 0 & 9 \\
\hline labour & Active family labour size (age 15-64) & & 4.1 & 2.4 & 0.25 & 16.5 \\
\hline tlu & Number of tropical livestock units & & 2.5 & 2.7 & 0 & 22.9 \\
\hline income & Amount of off-farm income (thousands of birr) & & 1.6 & 2.7 & 0 & 20 \\
\hline
\end{tabular}

Source: Survey data

\subsubsection{Socioeconomic characteristics}

Socioeconomic factors affecting hours worked comprise gender, age, education, family labour size, off-farm income and number of children (Birch, 2005; Burke and McAteer, 2007; Wright, 2007; Birch et al., 2009). Being a male-headed household potentially decreases the working hours of women as women and men share available domestic and family farm

\footnotetext{
18 Or woman and son in case of female-headed households.
} 
works. Thus female-headed households are expected to work more hours than men. Women are commonly caretakers of children in Gamo communities - hence the number of family members under age 10 is expected to increase hours allocated to domestic work for women more than for men. When the available work can be distributed to more people the workload goes down, thus family labour availability is expected to decrease the hours worked per week by both men and women and is expected to decrease their time poverty. Off-farm incomes are mostly generated by men who migrate to urban areas, and this may increase the working hours of women (Mu and Van de Walle, 2011) since domestic work and farm tasks are left to the women.

\subsection{Empirical model}

To determine how LF and SLM practices affect the working hours of men and women in each season, we specify the following time allocation model:

$$
\begin{gathered}
\ln y_{i g s}=\alpha_{g s}+\sum_{j=1}^{3} \beta_{j g s} \ln L F_{i j}+\gamma_{g s} S L M n_{i}+\sum_{r=1}^{4} \delta_{r g s} \ln x_{i r}+ \\
\sum_{u=1}^{2} \rho_{u g s} d_{i u}+\varepsilon_{i g s} \\
g=1,2: \quad s=1,2,3
\end{gathered}
$$

where $y_{i g s}$ is the number of hours worked by individual $i$ of gender $g$ in season $s, L F_{i j}$ is the LF indicator $j$ for individual $i, S L M n_{i}$ is the number of SLM practices applied by individual $i, x_{i r}$ is socio-economic characteristic $r$ of individual $i$ and $d_{i u}$ is a dummy variable for demographic characteristic $u$ of individual $i . \alpha_{g s}, \beta_{j g s}, \gamma_{g s}, \delta_{r g s}$ and $\rho_{u g s}$ are coefficients to be estimated. $\varepsilon_{i g s}$ is the error term; $g=1$ is woman and $g=2$ is man; and $s=1$ is planting season, $s=2$ is harvesting season and $s=3$ is off-peak season. For LF indicators: $j=1$ is Simpson index, $j=2$ is distance and $j=3$ is agro-ecological zone.

So we have a system of 6 equations, i.e., 2 gender types (g) times 3 seasons (s). We assume the errors to have zero mean and to be independent across individuals, but for a given individual errors are assumed to be correlated across equations. The justification for this is that we expect the same unobservable factors to play a role in each of the equations. In such a case, although OLS is a consistent estimator, it is not efficient (Zellner, 1962; Cameron and Trivedi, 2009). To increase the efficiency of the estimation, we use Seemingly Unrelated Regression (SUR) to estimate the model, as suggested by Cameron and Trivedi (2005) and Zellner (1962). To get heteroskedasticity-robust standard errors for the SUR estimator, we employ bootstrap regression as suggested by Cameron and Trivedi (2009). Moreover, the Breusch-Pagan Lagrange test is applied to test the null hypothesis that states that the error terms across the six equations are independent. 
To show whether LF affects hours worked by women and men differently, we tested four hypotheses using a likelihood ratio test by imposing restrictions on parameters across equations (Cameron and Trivedi, 2009). The first null hypothesis, $A_{1}$ states that each of the LF indicators does not affect hours allocated to work by women throughout the seasons. For instance, the Simpson index does not affect hours worked by women during the planting season (i.e., $A_{1}: \beta_{111}=0$ ) and so forth. The second null hypothesis, $A_{2}$ states that each of the LF indicators does not affect hours allocated to work by men for all seasons. For instance, distance to plots does not affect hours worked by men during the planting season is given by $A_{2}: \beta_{221}=0$. The third null hypothesis, $A_{3}$ states that each of the LF indicators has the same impact on the mean hours worked by men and women in the same season. For instance, the Simpson index has an equal impact on hours worked by women and men during the harvesting season ( $i . e_{.}, A_{3}: \beta_{112}=\beta_{122}$ ). The fourth null hypothesis, $A_{4}$ states that each of the LF indicators has an equal impact on hours worked by women throughout the seasons. For instance, the Simpson index has the same impact on working hours of women during the harvesting and planting season (i.e., $A_{4}: \beta_{111}=\beta_{112}$ ) and so forth.

To show whether SLM practices affect the working hours of women differently than those of men, we tested a further four hypotheses using a likelihood ratio test. The fifth null hypothesis, $A_{5}$, states that the number of SLM practices applied does not affect hours allocated to work by women for all seasons. For instance, the null hypothesis that the number of SLM practices used does not have a significant effect on the working hours of women during the harvesting season is given by $A_{5}: \gamma_{12}=0$. The sixth null hypothesis, $A_{6}$, states that the number of SLM practices applied does not affect hours allocated to work by men throughout the seasons. For instance, the number of SLM practices does not have a significant effect on hours worked by men during harvesting season (i.e., $A_{6}: \gamma_{22}=0$ ) and so on. The seventh null hypothesis, $A_{7}$, states that the number of SLM practices deployed has the same impact on the mean hours worked by men and women in the same season, such as during harvesting season (i.e., $A_{7}: \gamma_{12}=\gamma_{22}$ ) and so on. The eighth null hypothesis, $A_{8}$, states that the number of SLM practices applied has the same impact on working hours of women across seasons. For instance, the null hypothesis that the number of SLM practices applied has the same impact on working hours of women in the planting and harvesting season is given by $A_{8}: \gamma_{11}=\gamma_{12}$. 


\subsection{Results and discussion}

This section presents the estimation results of the SUR model in Table 5.2 and 5.3 and hypotheses tests in Table 5.4 and 5.5. There are 295 observations in the regression because of the exclusion of two individuals, a man and a woman, that worked zero hours per week in all three seasons. We have estimated six equations using SUR. Goodness-of-fit $\left(R^{2}\right)$ and chi-squared $\left(\chi^{2}\right)$ values of each equation are indicated at the bottom of Table 5.3. For instance, the $R^{2}$ and $\chi^{2}$ for the hours allocated to work by women during the harvesting season equation were 0.086 and 27.74 , respectively. The null hypothesis stating that the regressions with regressors do not improve the model more than a constant only model was rejected at the $1 \%$ significance level for the peak seasons for both men and women. Moreover, this hypothesis was rejected at the $5 \%$ and $10 \%$ significant levels, respectively, for the off-peak season for women and men.

Table 5.2 The correlation matrix of residuals

\begin{tabular}{|c|c|c|c|c|c|c|}
\hline & $\begin{array}{l}\text { Planting } \\
\text { (men) }\end{array}$ & $\begin{array}{l}\text { Planting } \\
\text { (women) }\end{array}$ & $\begin{array}{l}\text { Off-peak } \\
\text { (men) }\end{array}$ & $\begin{array}{l}\text { Off-peak } \\
\text { (women) }\end{array}$ & $\begin{array}{l}\text { Harvesting } \\
\text { (men) }\end{array}$ & $\begin{array}{l}\text { Harvesting } \\
\text { (women) }\end{array}$ \\
\hline Planting (men) & 1 & & & & & \\
\hline Planting (women) & 0.123 & 1 & & & & \\
\hline Off-peak (men) & 0.611 & 0.079 & 1 & & & \\
\hline Off-peak (women) & -0.003 & 0.523 & 0.189 & 1 & & \\
\hline Harvesting (men) & 0.761 & 0.061 & 0.612 & -0.001 & 1 & \\
\hline Harvesting (women) & 0.239 & 0.669 & 0.155 & 0.425 & 0.224 & 1 \\
\hline
\end{tabular}

Most of the errors in the six equations estimated were positively correlated, but the errors for the equations 'men peak seasons' and 'women off-peak season' were negatively correlated, as shown in Table 5.2. The null hypothesis stating that the error terms across the six equations are independent was rejected at the $1 \%$ significance level (i.e., the correlation between errors in the six equations was significant). The significant correlation of errors in the six equations was as expected because working hours allocated by men and women across seasons have similar underlying determinants. The correlation between errors in the equations for women and men was not strong (ranging from -0.001 to 0.239), while the correlation between errors in equations for similar gender across seasons was high, varying from 0.425 to 0.761 (see Table 5.2). Moreover, correlation coefficients between variables in Table 5.1 are less than 0.6 , so multicollinearity is not an issue. 


\subsubsection{LF indicators}

The agro-ecological zone and sum of non-overlapping distance to all plots from home did not have a significant effect on time allocated to work by both men and women. However, the Simpson index increased the working hours for both men and women during peak seasons, but it did not affect the working hours for both sexes during the off-peak season.

For the harvesting and planting seasons, a marginal change in the Simpson index increased working hours for women by about $0.3 \%$, while it increased working hours for men by almost $0.5 \%{ }^{19}$ (see Table 5.3).

Table 5.3 Factors affecting time allocation of men and women

\begin{tabular}{|c|c|c|c|c|c|c|}
\hline \multirow[b]{2}{*}{ Variables } & \multicolumn{3}{|c|}{ Men } & \multicolumn{3}{|l|}{ Women } \\
\hline & Planting & Harvesting & Off-peak & Planting & Harvesting & Off-peak \\
\hline \multirow[t]{2}{*}{$\ln ($ age $)$} & $-0.074^{*}$ & -0.036 & $-0.135^{* *}$ & -0.036 & -0.028 & $-0.112^{* *}$ \\
\hline & $(0.040)$ & $(0.045)$ & $(0.057)$ & $(0.037)$ & $(0.037)$ & $(0.050)$ \\
\hline \multirow[t]{2}{*}{ Literacy } & 0.045 & 0.045 & -0.003 & -0.018 & -0.012 & -0.033 \\
\hline & (0.031) & (0.033) & $(0.047)$ & $(0.048)$ & $(0.036)$ & $(0.064)$ \\
\hline \multirow[t]{2}{*}{ Genderh } & $-0.107^{* *}$ & $-0.136^{* * *}$ & -0.047 & $0.071^{*}$ & 0.032 & 0.026 \\
\hline & $(0.044)$ & $(0.044)$ & $(0.064)$ & $(0.042)$ & $(0.029)$ & $(0.046)$ \\
\hline \multirow[t]{2}{*}{$\ln$ (family) } & -0.029 & -0.024 & $-0.064^{*}$ & 0.008 & 0.010 & 0.006 \\
\hline & $(0.024)$ & $(0.025)$ & $(0.035)$ & (0.019) & $(0.017)$ & $(0.036)$ \\
\hline \multirow[t]{2}{*}{$\ln$ (labor) } & -0.014 & 0.006 & 0.002 & 0.018 & 0.008 & 0.032 \\
\hline & $(0.022)$ & $(0.025)$ & $(0.034)$ & $(0.023)$ & $(0.019)$ & $(0.031)$ \\
\hline \multirow[t]{2}{*}{$\ln (t l u)$} & $0.037^{*}$ & 0.001 & -0.012 & 0.019 & 0.032 & 0.023 \\
\hline & $(0.021)$ & $(0.029)$ & $(0.031)$ & $(0.023)$ & $(0.023)$ & $(0.033)$ \\
\hline \multirow[t]{2}{*}{$\ln ($ inct $)$} & -0.013 & -0.018 & 0.005 & 0.001 & 0.012 & $0.047^{* *}$ \\
\hline & $(0.018)$ & (0.019) & $(0.027)$ & $(0.016)$ & $(0.015)$ & $(0.021)$ \\
\hline \multirow{2}{*}{$S L M n$} & 0.007 & 0.005 & $0.019 *$ & $0.015^{* *}$ & $0.014^{* * *}$ & $0.018^{* *}$ \\
\hline & $(0.006)$ & $(0.006)$ & $(0.010)$ & $(0.006)$ & $(0.005)$ & $(0.009)$ \\
\hline \multirow[t]{2}{*}{$\ln (s f i)$} & $0.471^{* * *}$ & $0.521^{* * *}$ & 0.286 & $0.338^{* *}$ & $0.267^{* *}$ & 0.161 \\
\hline & $(0.147)$ & $(0.163)$ & (0.189) & (0.151) & $(0.135)$ & $(0.202)$ \\
\hline \multirow[t]{2}{*}{ In(distance) } & 0.005 & -0.018 & 0.015 & 0.013 & 0.009 & 0.016 \\
\hline & $(0.023)$ & $(0.024)$ & $(0.038)$ & $(0.022)$ & $(0.019)$ & $(0.036)$ \\
\hline \multirow[t]{2}{*}{$a e z$} & -0.020 & -0.018 & -0.039 & -0.004 & -0.024 & 0.004 \\
\hline & $(0.020)$ & $(0.026)$ & $(0.034)$ & $(0.022)$ & $(0.020)$ & $(0.032)$ \\
\hline \multirow[t]{2}{*}{ Constant } & $4.421^{* * *}$ & $4.340^{* * *}$ & $4.505^{* * *}$ & $4.088^{* * *}$ & $4.211^{* * *}$ & $4.372^{* * *}$ \\
\hline & (0.193) & $(0.207)$ & $(0.266)$ & (0.194) & $(0.183)$ & $(0.264)$ \\
\hline$R$-squared & 0.106 & 0.081 & 0.058 & 0.086 & 0.086 & 0.068 \\
\hline Chi-squared & 34.97 & 26.10 & 18.33 & 27.74 & 27.88 & 21.48 \\
\hline$p$-value & 0.000 & 0.006 & 0.074 & 0.003 & 0.003 & 0.030 \\
\hline Observation & 295 & 294 & 295 & 295 & 295 & 295 \\
\hline
\end{tabular}

** $\mathrm{p}<0.01, \quad{ }^{* *} \mathrm{p}<0.05, \quad * \mathrm{p}<0.1, \quad$ Standard errors in parentheses, Source: Estimated from survey data

LF indicators together affected hours worked by men during planting and harvesting seasons at the $1 \%$ and $5 \%$ significance levels, respectively, while LF indicators jointly did not

\footnotetext{
${ }^{19}$ If $\ln y_{i}=\beta_{0}+\beta_{1} x_{i}+\beta_{2} \ln \left(z_{i}\right)+\varepsilon_{i}$ then $d y_{i} / d x_{i}=e^{\beta_{1}}-1$ and $d y_{i} / d z_{i}=\beta_{2}$
} 
affect hours worked by women throughout the seasons. Moreover, we examined hypotheses $A_{1-} A_{4}$ to show whether LF indicators separately affect the working hours of women differently than that of men. Hypothesis $A_{1}$, which states that each of the LF indicators does not affect hours worked by women for all seasons, was not rejected for the non-overlapping distance to all plots and the agro-ecological zone. However, the hypothesis was rejected for the Simpson index at the $5 \%$ significance level for both peak seasons, as shown in Table 5.4. We did not report hypotheses test results for the agro-ecological zone. Hypothesis $A_{2}$, which states that each of the LF indicators does not affect hours worked by men, was also rejected for the Simpson index for peak seasons at the $1 \%$ significance level, but the hypothesis was not rejected for the LF indicators distance and agro-ecological zone for all the seasons (see Table 5.4). For both men and women, the Simpson index increased hours worked during the peak seasons, implying that activities and round trips to various plots are time-consuming during the peak seasons compared to the off-peak season. The findings are consistent with earlier theoretical arguments; for instance, McCall (1985) discussed that distance to plots leads to a lengthy commuting time to work. Commuting time increases more when people travel to plots at a distance to collect domestic necessities like firewood and fodder. This commonly results in multiple trips to plots and back home every day, particularly for women (McCall, 1985). Similarly, earlier studies found that LF increases family labour use (Hung et al., 2007) and time of commuting (Blarel et al., 1992; Nguyen et al., 1996). 
Table 5.4 Likelihood ratio test for hypotheses 20

\begin{tabular}{lllll}
\hline Hypothesis & Lambda & $d f$ & $p$-value & Decision \\
\hline Woman & & & & \\
$A_{1}: \beta_{111}=0$ & 4.99 & 1 & 0.023 & Rejected \\
$A_{1}: \beta_{112}=0$ & 3.91 & 1 & 0.048 & Rejected \\
$A_{1}: \beta_{113}=0$ & 0.63 & 1 & 0.427 & Not rejected \\
$A_{1}: \beta_{211}=0$ & 0.35 & 1 & 0.540 & Not rejected \\
$A_{1}: \beta_{212}=0$ & 0.21 & 1 & 0.650 & Not rejected \\
$A_{1}: \beta_{213}=0$ & 0.19 & 1 & 0.670 & Not rejected \\
$A_{4}: \beta_{111}=\beta_{112}$ & 0.28 & 1 & 0.590 & Not rejected \\
$A_{5}: \gamma_{11}=0$ & 6.27 & 1 & 0.012 & Rejected \\
$A_{5}: \gamma_{12}=0$ & 6.93 & 1 & 0.009 & Rejected \\
$A_{5}: \gamma_{13}=0$ & 4.06 & 1 & 0.044 & Rejected \\
$A_{8}: \gamma_{11}=\gamma_{12}$ & 0.04 & 1 & 0.830 & Not rejected \\
$A_{8}: \gamma_{11}=\gamma_{13}$ & 0.13 & 1 & 0.720 & Not rejected \\
$A_{8}: \gamma_{12}=\gamma_{13}$ & 0.13 & 1 & 0.720 & Not rejected \\
Men & & & & \\
$A_{2}: \beta_{121}=0$ & 10.32 & 1 & 0.001 & Rejected \\
$A_{2}: \beta_{122}=0$ & 10.19 & 1 & 0.001 & Rejected \\
$A_{2}: \beta_{123}=0$ & 2.31 & 1 & 0.129 & Rejected \\
$A_{2}: \beta_{221}=0$ & 0.06 & 1 & 0.810 & Not rejected \\
$A_{2}: \beta_{222}=0$ & 0.52 & 1 & 0.470 & Not rejected \\
$A_{2}: \beta_{223}=0$ & 0.15 & 1 & 0.700 & Not rejected \\
$A_{4}: \beta_{121}=\beta_{122}$ & 0.19 & 1 & 0.660 & Not rejected \\
$A_{5}: \gamma_{21}=0$ & 1.23 & 1 & 0.267 & Not rejected \\
$A_{5}: \gamma_{22}=0$ & 0.59 & 1 & 0.443 & Not rejected \\
$A_{5}: \gamma_{23}=0$ & 3.77 & 1 & 0.052 & Not rejected \\
\hline & & & &
\end{tabular}

Source: Estimated from survey data

We extended the analysis for each LF indicator that had a significant effect on the working hours of women and men in a given season. For instance, we assessed hypotheses $A_{3}$ for the Simpson index that had a significant effect on time allocated to work by men and women during peak seasons. We evaluated whether the Simpson index has the same impact on the mean hours worked by men and women per week for a given season. The hypothesis was rejected for the harvesting season, implying that the Simpson index affected the working hours of men more than women. However, the hypothesis was not rejected at the $5 \%$ significance level for the planting season, implying that the Simpson index has an equal impact on working hours of men and women for the planting season (see Table 5.5). In other words, although the Simpson index affects the hours worked by men and women for both peak seasons, the mean impact of the Simpson index on working hours differed by gender during only the harvesting season.

\footnotetext{
${ }^{20}$ The subscripts of $\beta$ are as follows: If the first subscript is 1,2 or 3 it stands for Simpson index, distance or agroecological zone, respectively; if the second subscript is 1or 2 it stands for women or men, respectively; and if the third subscript is 1, 2 or 3 it stands for planting, harvesting or off-peak season, respectively. For $\gamma$ if the first subscript is 1 or 2 it stands for women or men, respectively; and if the second subscript is 1,2 or 3 it stands for planting, harvesting or off-peak season, respectively.
} 
Table 5.5 Impacts of LF on the working hours of men and women ${ }^{21}$

\begin{tabular}{lllll}
\hline Hypothesis & Lambda & $d f$ & $P$-value & Decision \\
\hline$A_{3}: \beta_{111}=\beta_{121}$ & 0.56 & 1 & 0.45 & Not rejected \\
$A_{3}: \beta_{112}=\beta_{122}$ & 2.34 & 1 & 0.01 & Rejected \\
\hline
\end{tabular}

We also assessed hypothesis $A_{4}$, which states that each of the LF indicators has the same impact on hours allocated to work by women across the planting versus the harvesting season. This hypothesis test was conducted for the Simpson index for both peak seasons only as other indicators did not have a significant effect on the working hours of men and women for all seasons. The hypothesis was not rejected for the Simpson index, implying that the Simpson index equally impacts hours worked by women for both peak seasons. We also assessed the same hypothesis for men and found the same result (i.e., the null hypothesis was not rejected). From hypotheses $A_{1}-A_{4}$ we can infer that the Simpson index has a significant gendered impact during the harvesting season, but other LF indicators do not indicate gender-biased effects on the working hours of men and women.

\subsubsection{SLM practices}

The estimation results of the SUR model presented in Table 5.3 show that the number of SLM practices deployed affected working hours of women for all seasons. As an illustrative example, when the number of SLM practices applied per farm increased by $1 \%$, women's working hours during the planting and harvesting season increased by $0.015 \%$ and $0.014 \%$, respectively. However, the number of SLM practices did not affect hours worked by men for all the seasons at the $5 \%$ significance level.

We also evaluated hypotheses $A_{5}-A_{6}$ to see whether SLM practices affect the working hours of women differently than that of men. The test results are presented in Table 5.4. The results show that hypothesis $A_{5}$, which states that the number of SLM practices deployed per farm does not affect the working hours by women across the three seasons, was rejected at the $1 \%$ significance level for the harvesting season and at the $5 \%$ level for the planting and off-peak seasons. However, the corresponding null hypothesis $A_{6}$ was not rejected (i.e., the number of SLM practices deployed did not affect hours worked by men). We could not extend the analysis further to hypotheses $A_{7}$ and $A_{8}$ because the number of SLM practices applied did not have a significant effect on hours worked by men, but it had a significant effect on hours worked by women. The significant effect on hours worked by women and the insignificant effect on hours worked by men are incomparable. Therefore, the hypothesis $A_{7}$ was rejected in favour of the hypothesis that states that the number of

\footnotetext{
${ }^{21}$ Subscripts of $\beta$ and $\gamma$ can be read as indicated in footnote 18 .
} 
SLM practices impacted the working hours of women differently than those of men during the planting and harvesting season. In other words, the mean effect of the number of SLM practices on working hours of women was higher than those of men. Regarding hypothesis $A_{8}$, the effect of the number of SLM practices applied on working hours of women did not vary from season to season. From the preceding results, we can infer that SLM practices are gendered in the Gamo Highlands of Ethiopia. These results are consistent with the findings of Tatlonghari and Paris (2013) that climate adaptation increased the work burden of women in the Philippines, as well as with other studies showing the existence of gendered climate change adaptation practices (Jin et al., 2015; Mersha and Van Laerhoven, 2016).

\subsubsection{Socioeconomic characteristics}

Socioeconomic factors have a significant effect on hours worked by both women and men (see Table 5.3 ). As age increased by $1 \%$, hours worked decreased by $0.14 \%$ and $0.11 \%$ during the off-peak season by men and women, respectively. Being a male-headed household decreased the hours allocated to work by men. Increase of income earned from off-farm income sources increased working hours by women during the off-peak season. Most women in Gamo communities often engage in off-farm activities during off-peak seasons and give up off-farm work when they are busy during peak seasons, while men migrate to urban areas to take off-farm jobs during off-peak season. These findings are consistent with those of Bardasi and Wodon (2006) indicating that socioeconomic factors influence hours allocated to work. 


\subsection{Conclusions}

This study argued that because of socially constructed roles and responsibilities of women and men (i.e., gender division of labour) and local conditions (i.e., notable LF), adaptation to climate change imposes more burdens on women than men. To explain this, we estimated a time allocation model and evaluated the effect of LF and the number of SLM practices on time allocated to work by men and women during two peak seasons (i.e., harvesting and planting) and the off-peak season.

The results indicated that two of the LF indicators, non-overlapping distance and agroecological zone, did not affect the working hours of men and women, but the Simpson index increased hours allocated to work by both men and women during the peak seasons. The results may imply that the area and the number of plots (i.e., Simpson index) aspects of LF are more powerful in increasing the working hours of both sexes than the distance dimension of LF. The custom of constructing separate secondary homes in Gamo communities to ease the application of SLM practices on fragmented farm fields reduces time of commuting between home to plots (i.e., distance), but it does not decrease the number of plots.

The working hours of women were significantly higher than that of men for all seasons, probably due to the gendered division of domestic labour, fetching domestic necessities from plots at a distance and the fact that some farm activities like adding manure are solely carried out by women. Moreover, the majority of household heads opined that LF increased the working hours of women more than that of men. However, the hypothesis tests show that the Simpson index increased the working hours of men more than that of women in the harvesting season. The household responsibility hypothesis (HRH) by JohnstonAnumonwo (1992) could explain the contrasts and why men worked for longer hours during harvesting season than women. According to the $\mathrm{HRH}$, women commute shorter distances to work than men, as women shoulder more domestic work than men in Gamo communities. That is to say that a gender-skewed division of household labour leads to the commuting differential between men and women - women harvest on closer plots than men so as to shoulder most of the domestic work. The result also supports a study by Turner and Niemeier (1997) that found that women have less commuting time to work than men.

Deployment of SLM practices as a strategy to adapt to climate change and variability was significantly increasing the working hours for women, exacerbating their already disadvantaged position. The finding is consistent with earlier studies (e.g., Jin et al., 2015; Smucker and Wangui, 2016; Jerneck, 2018) that showed that knowledge of climate change 
adaptation, the use of adaptation practices, and climate change adaptation barriers and burdens differ for men and women.

The overall result indicates the existence of gendered adaptation practices in the Gamo Highlands. LF (measured by the Simpson index) increased working hours of men during the harvesting season significantly more than it did for women. This implies that LF is biased towards a particular gender (towards men in this case). However, application of land management practices to deal with climate change and variability results in more hours of work for women and leaves working hours for men unaffected. This implies that application of SLM practices on fragmented farm fields to deal with climate change is gender-skewed (towards women in this case).

This study has some caveats. First, we only used a single indicator of gender bias, hours worked per week in three seasons. There are of course many other indicators of the position of women in a society, such as gender gaps in non-farm earnings (Abdulai and Delgado, 1999). In future research, these should be taken into account. Second, we used crosssectional data ignoring the effect of time; i.e., time varying explanatory variables could not be taken into account. So, we cannot see whether the position of women has improved over time or not. Finally, we ignored the division of working hours over different activities. Further studies can contribute by explaining how farm field dispersion and application of SLM practices affects hours allocated to paid work and to domestic work like child care, and by testing the validity of the HRH when women and men commute to work on multiple dispersed plots in all seasons.

Despite these caveats, we think this paper contributes to the discussion of the gendered effects of fragmentation and climate change adaptation. Reducing farm fragmentation through cooperative farming or voluntary bartering of plots between neighbouring farmers could help to solve the work hour loss associated with fragmentation. It is important to involve men in activities that are considered as women's tasks in order to reduce the gendered division of labour, so that women and men can work for equal hours and so that SLM practices will affect them equally. 


\section{Synthesis}




\subsection{Research outcome}

The objective of the thesis is to explain how land fragmentation (LF) and sustainable land management (SLM) practices influence the outcomes of sustainable adaptation to climate change in the Gamo Highlands of Ethiopia. The research focuses on the environmental (i.e., conservation of soils), economic (i.e., food security, technical efficiency) and social (i.e., the existence of gendered adaptation practices) effects of SLM practices and LF. To achieve the objective of the thesis, four research questions were answered.

The first research question: Is land fragmentation facilitating or obstructing adoption of climate change adaptation measures in Ethiopia? The research found that most of the farmers in the Gamo Highlands perceive that climate change is happening and adapt their farming practices in response. Farmers' perceptions of climate change were found to be consistent with meteorological data reported in Ethiopia (Deressa, 2007; Bryan et al., 2009). LF is largely exogenous in the Gamo Highlands as successors inherit farm fields which have already been fragmented by their descendents. With an average farm size of 1.7 hectares fragmented into 21 plots and with a variation of 1 to 80 plots per farm, LF in the Gamo Highlands is severe. The econometric results show that there was no clear answer to the question whether LF was facilitating or obstructing the adoption of SLM practices. However, a qualitative analysis found that farmers feel that LF hinders the application of SLM practices. The analysis also shows that farmers invest more in soil improvements on plots closer to home than plots at a distance. Previous studies (Clay et al., 1998; Di Falco et al., 2010; Teshome et al., 2014; Asfaw et al., 2016; Nigussie et al., 2017) also had mixed results. The results differ between studies, and within our study probably because of variation in the SLM practices examined, the extent of LF and fragmentation indices considered, and the level of analysis (i.e., plot level or farm level). In addition, the results differ because of indigenous customs of farmers in Gamo communities developed to simplify laborious land management practices. For instance, farmers construct multiple homes and use horses and mules to transport yields from and manure to plots at a distance. Farmers often temporarily move to these secondary homes close to faraway plots when they are harvesting, tilling or adding manure to those plots. Moreover, the costs associated with the adoption of SLM practices are largely ignored (McCall, 1985; Bentley, 1987; Niroula and Thapa, 2005).

The second research question is: What are the effects of land fragmentation and sustainable land management practices on food security? We found that farmers' food insecurity level was high in the Gamo Highlands during the food shortfall season. LF, as measured by different fragmentation indices, had mostly a positive effect on food security: it increased food security as it leads to using plots that differ both within and between agro-ecological zones, allowing farmers to diversify crops in time and space (Bentley, 1987; Di Falco et al., 
2010). The results partly contradict earlier studies, which probably used food production (Rahmana and Rahman, 2008), while this study used subjective food security indices to measure food security. Moreover, this study measured food security in the food shortfall period, the farmers in this study operate in distinct agro-ecological zones and the LF indices considered are more comprehensive than the ones used in previous studies. We found that the application of SLM practices to deal with climate change has both beneficial and detrimental effects on food security. In line with Di Falco et al. (2011), Damte et al. (2017) and Pendera and Gebremedhin (2007), we found that SLM practices improve food security (e.g., tree planting and quality seed use). The negative effects of SLM (e.g. of legume-barley rotation and terracing) on food security are in line with results from Damte et al. (2017), Kassie et al. (2009), and Branca et al. (2013). No effects of SLM practices on food security were found by Faltermeier and Abdulai (2009). The differences can be explained by variation in crop type and the SLM practices employed (Araya et al., 2011), differences in agro-climatic conditions and SLM practices adopted (Branca et al., 2013), the time that has elapsed since implementation of the SLM practices (Fanaye, 2017), the period in which food security was measured and the indicators used to measure food security. Research also suggests that investments in SLM practices need to be tailor-made to suit specific microclimatic and agro-ecological differences (Kassie et al., 2009). Furthermore, the food security effects of SLM practices are also conditioned by LF. For example, when the level of LF was high the negative food security effects of SLM practices became dominant. So, although farmers are adapting to perceived climate change, they remain vulnerable to food insecurity. Moreover, farmers indicated in the interviews that incidences of food shortage became more frequent because of harvest destruction due to unseasonable rain in recent years. Incidences of high rainfall are likely to occur in Ethiopia during La Niña years while dry years are likely to occur during El Niño years (Abtew et al., 2009).

The third research question is: What are the effects of land fragmentation and sustainable land management practices on technical inefficiency? We found that barley yields per hectare were low both in plots close to home and plots at a distance. However, SLM practices had a significant positive effect on yields. This is consistent with preceding literature (Pendera and Gebremedhin, 2007; Kassie et al., 2010; Schmidt and Tadesse, 2014). This signals that farmers can adapt to a changing climate and improve food security by applying SLM practices. However, the effect of specific SLM practices on technical efficiency varies from negative to positive. As an illustration, local tree planting was efficiency improving as it reduce erosion and increase soil fertility while adding manure was efficiency impeding as it is an effort-intensive practice. Moreover, the effects of SLM practices on efficiency are conditioned by the distance of the plot from home, e.g., tree planting in remote plots was less efficient than in plots close to home, probably due to significant yield losses as a result of less monitoring and theft. Also, plot size improves 
technical efficiency after some threshold level of plot size. Results show further that different farmers had different technical efficiency levels and that technical efficiency levels of farmers differed from plot to plot. We find an overall average technical efficiency of $49 \%$, implying that farmers have room to increase output by $51 \%$ without increasing the use of inputs (such as labor) by adopting the technologies and techniques used in the bestmanaged fields.

Finally, question four is: Do land fragmentation and sustainable land management practices have differential effects on the working hours of men and women? We found that women worked significantly more hours per week than men as a result of the skewed gender division of labor in the Gamo communities. LF significantly increased the working hours of both men and women, but increased the working hours of men more than those of women during the harvesting season. This indicates that women commute shorter distances than men and harvest crops on plots closer to home, so that they can also shoulder domestic tasks, which is consistent with the household responsibility hypothesis of JohnstonAnumonwo (1992). The application of a large number of SLM practices led to more working hours for women, but did not affect the time worked by men, implying that adopting SLM practices in agriculture is gendered in the Gamo Highlands.

The answers to the research questions contribute to the knowledge about how LF and SLM practices influence the outcomes of sustainable adaptation to climate change in the Gamo Highlands of Ethiopia. It has become clear that the adoption of SLM practices depends on LF and that both SLM practices and LF affect food security, technical efficiency, and the working hours of men and women. However, the effects are not always as hypothesized, e.g., food security can benefit from LF and distance to plot increases technical efficiency. Despite this, the overall results show that LF and SLM practices affect the outcomes of sustainable adaptation (i.e., food security, technical efficiency and workload) in desirable and undesirable ways in the Gamo Highlands. These results hold true for subsistence agriculture in most of the SSA countries with similar backgrounds. Therefore, it is important to deploy LF in climate change adaptation planning in SSA countries to optimize its benefits and costs and hence to better cope with increasing climate change impacts. 


\subsection{Discussion}

\subsubsection{Caveats}

The thesis mostly applied econometric techniques on cross-sectional farm household data and secondary data to answer the research questions. In addition, qualitative information obtained through focus group discussions was used to substantiate the econometric results. However, there are some caveats concerning the methodology used in this thesis.

First, the thesis employs cross-sectional household and plot level data to answer the research questions. However, panel data studies, including time dimensions are more powerful when the explanatory variables change over time. For example, in our sample there is no variation in weather conditions and institutional factors (such as policy), because all data are collected in the same period (Cameron and Trivedi, 2005). This implies that these variables cannot contribute to answering the research questions. Therefore, panel data are important to develop and test more complicated behavioral models (Hsiao, 1985). The analysis of longitudinal data would also have been especially useful to capture the investment costs and long-term effects of adopting SLM practices, the dynamics of technical efficiency and household food security, and the workload of women and men over time. For instance, crop loss due to bad weather is not uniform over the two production seasons and over the years in the Gamo Highlands. Therefore, the food security status of agricultural households varies across seasons and years.

Second, the thesis applies empirical models of which the specification is determined by literature research. Using economic theory and theoretical models could have contributed to a better model specification and a more explicit formulation of hypotheses. However, given the wide variety of explanatory variables, LF indicators and SLM practices; farmers' climate change and variability perceptions; and the gendered division of work no economic theory or model seemed to be appropriate for our analyses. Agricultural household models (e.g., Singh et al., 1986) lack technical detail while mathematical programming models (e.g., Norton and Hazell, 1986) are not easily econometrically estimated. So, we decided to use literature reviews to develop testable hypotheses and specify our empirical models in order to answer the research questions.

Third, although this study already uses plot data the information available for these plots is limited. In rugged mountainous landscapes like the Gamo Highlands, temperature, rainfall, sunlight exposure and erosion levels are expected to vary within a narrow distance and with elevation, and, therefore, between plots. Therefore, more detailed plot- level data can contribute to more accurate outcomes. 
Fourth, data have been collected for the food shortfall season. However, the food security effects of SLM and LF may be different during the food abundant season (such as the crop harvesting seasons).

Fifth, the thesis employed subjective/indirect perception measures of food security. These measures capture food security dimensions that objective measures do not cover (Maxwell, 1996). Moreover, subjective indicators are relatively easier to calculate than objective measures and better reflect the farmers' reality. However, subjective measures fail to capture elements that would be better considered using objective/direct yardsticks, such as calories per day (Garrett and Ruel, 1999). Important reasons to use subjective measures are that family members eat together and respondents do not recall the amount of foodstuff consumed by individual household members over a specified time period. Moreover, it is difficult to get information on household food expenditures for a specified period as households consume purchased food and food from own production. For the same reasons, most of the preceding studies used indirect objective measures of food security, including household asset indicators, productivity and income (Hossain and Singh, 2000; Di Falco et al., 2011).

Sixth, in Chapter 4 we lack detailed information on the time spend on specific labor tasks. To better understand the gendered effects of SLM and LF it is important to obtain that information. For example, does increased time spent on SLM practices lead to less time spend on child care, paid job participation, and health or other household welfare indicators? These kinds of questions need to be answered to fully understand the social effects of LF and SLM practises.

Finally, the results of the thesis in Chapter 3 (i.e., the food security effects of SLM practices) should be interpreted with some care as we have not been able to solve for possible endogeneity problems in our estimations. The thesis did not apply endogenous switching regression to address the endogeneity problem. Instead, MVP was applied as we have different SLM practices and farmers apply a different number of SLM practices. For example, 33\% of farmers applied all SLM practices in the survey period (i.e., 2015), while only 4 farmers out of 297 farmers did not apply any of the 8 SLM practices. Moreover, in Chapter 2, we found that the decision to adopt the 8 SLM practices was interdependent. To take account of this interdependence of adoption decisions, the study has to use an MVP model. The application of a binary probit or multinomial probit to model the adoption of SLM practices would ignore the correlation of error terms in the adoption equations, and would therefore lead to biased or inefficient estimates (Kassie et al., 2015; Asfaw et al., 2016; Nigussie et al., 2017). Therefore, to address the endogeneity and the correlation in 
error terms of adoption equations at the same time, endogenous switching regression that uses MVP to model adoption decisions (i.e. SLM practices) is required. An endogenous switching regression approach in which the adoption decisions are modeled by MVP has not yet been developed.

\subsubsection{Future research}

The caveats discussed suggest topics for future research. With respect to data it would be worthwhile to invest in a panel dataset that includes seasonal and annual data. This would enable us to study the effects of time varying factors such as weather and policy. The time span between investment and outcomes for some of the SLM practices could also be investigated in more detail in case of panel data. Moreover, more detailed information on plots (e.g., temperature, rainfall, sunlight exposure and erosion levels) increases the explanatory power of the estimated models. With respect to the gendered effects of LF and SLM practices, it is important to collect data on how women and men divide their time over different tasks. This would enable to investigate the substitution of time between different tasks which is e.g., relevant to determine whether or not less time is spent on raising children, off-farm work or education, for example, while adapting fragmented landscape agriculture to climate change.

To improve the theoretical consistency of our empirical models, development of a theoretical economic model that include, LF and different SLM practices, and that can be econometrically estimated would be worthwhile. With respect to the econometric models used it would be important to develop a multivariate endogenous switching regression model, or another estimation method to deal with possible endogeneity, as for example food security is affected by using several SLM practices.

The study suggested that although LF is exogenous to farmers, it could be deployed in climate change adaptation planning. For example, reducing fragmentation increases the intensity and quality of investment in remote fields and hence the outcomes of adaptation. However, the thesis did not investigate how land assembling can be done. Thus, studies that identify possible sets of effective land assembling methods can benefit policy makers and farmers. 


\subsection{Policy implications and concluding remarks}

Most farmers in the study area are aware of climate change and variability and are adapting their agricultural practices accordingly. Farmers' knowledge of climate change and their experiences with adapting their agricultural practices mean that there is scope for incentivizing farmers to apply improved or new adaptation strategies and to improve and expand the application of familiar SLM practices. Agricultural experts can use these opportunities to persuade and inspire farmers to improve existing adaptation practices, copy best adaptation practices from elsewhere and innovate SLM practices to deal with a changing climate. Extension workers and the local government could consider training farmers on climate change and SLM practices as a part of the training package provided to farmers at the Farmer Training Centers (FTC ${ }^{22}$ ) located in each kebele. Moreover, increasing access to short and medium weather forecasts is also important in dealing with the harvest destruction challenges of climate change and to adjust sowing periods. Furthermore, best SLM practices might not be implemented because of lack of resources to buy modern inputs, seedlings of local trees, or instruments for composting, etc. For this reason, it is important to establish access to credit e.g. via micro credit. Thus, constraints that limit the full potential of existing SLM practices should be lifted.

In addition to, the abovementioned measures, there are other ways of doing that. First, improved SLM practices should be developed and introduced. For instance, growing fodder grasses and trees on terraces instead of keeping them bare. Second, the availability, variety, and quality of modern inputs should be improved to enhance adaptation. For example, the availability, quality and variety of seeds used by farmers is generally poor, supply is not reliable and farmers have limited choices and alternatives. This strengthens the risk aversion of farmers making them continue with poor adaptation practices. Moreover, the government forces farmers to use a costly chemical fertilizer instead of increasing the supply of fertilizer so that farmers use fertilizers for plots on which they cannot apply enough manure. Third, the short and long-term maintenance of SLM practices is important to enhance the effectiveness of adaptation practices, but maintenance is often overlooked in Ethiopia. Extension workers, experts and farmers could collaborate to plan and implement short and long term maintenance services. Fourth, to be more effective, SLM practices need to be "tailor-made", plot specific or required to vary across agro-ecological zones instead of one-size-fits-all. Fifth, to improve SLM practices and their implementation the skills and knowledge of farmers and researchers should be improved. Sixth, although not studied for the Gamo Highlands, land tenure insecurity could limit the effectiveness of

\footnotetext{
${ }^{22}$ There are schools established in each kebele to provide practical and theoretical trainings to farmers
} 
SLM practices, thus the government needs to introduce policies to improve tenure security e.g., by means of land certification (which is in progress in the study area).

This thesis shows that LF creates opportunities and challenges for both the deployment of SLM practices as well as the corresponding outcomes of SLM practices (i.e., food security, technical efficiency and working hours). Severe LF could be reduced by means of land consolidation programs. However, farmers with limited access to formal risk reduction strategies should not miss out on the benefits of LF by introducing perfect land consolidation. Therefore, land consolidation programs should warrant heterogeneity in plots, e.g. with respect to their location in different agro-ecological zones. Gradual plot assembling could reduce opposition (e.g., by picking low-hanging fruits first) and have a demonstration effect. For instance, farmers initially not willing to barter plots may show interest after observing the benefits to neighboring farmers who have engaged in plot assembling.

For policy makers, it is important to increase the awareness of farmers that technical efficiency varies substantially between farms and plots. Therefore, farmers can increase technical efficiency and yields if awareness is created about the pros and cons of LF and SLM practices.

Adopting SLM practices in the Gamo Highlands is an extra burden for women. As indicated in the discussion not all the effects for women are understood yet, but it can be expected that the SLM practices used to adapt to climate change have negative consequences for the well-being of women and their families. Therefore, research on the gendered effects of climate change adaptation is highly recommended. Increasing the awareness of men and women might lead to a fairer sharing of responsibilities between men and women. Moreover, labour reducing SLM practices can be promoted.

The study also leads to some specific recommendations for individual farmers in the Gamo Highlands. First, the SLM practices that have been applied lack quality and intensity: for example, the number of local trees planted and quantity of manure applied per hectare are inadequate to deal with climate change impacts, while terrace risers are left bare instead of growing forage and grasses for cattle. Thus, farmers should increase the quality and intensity of SLM practices deployed to better adapt to a changing climate. Second, farmers should increase the use of available high yielding varieties to cope with climate change impacts better. Third, in the Gamo Highlands, weaving is the second dominant livelihood strategy, but the magnitude of off-farm income generated by farmers is low. Farmers need to become involved in off-farm activities to finance expenditures for modern agricultural inputs and increase food security. Fourth, although farmers' access to credit may be 
constrained, the average loan size of farmers taking out microcredit is also insignificant. Thus, farmers should increase their loan size from microcredit to buy modern inputs. Fifth, farmers are shifting to cereal crops and decreasing the use of enset for food, despite the fact that enset is a perennial crop that is more drought tolerant and more productive than cereals per area unit. Farmers should increase the use of enset for different livelihood activities (such as food, income generation and forage). Finally, although it is not studied for the Gamo Highlands, farmers are substituting cattle production with crop production and farmers produce only a few vegetable varieties. However, cattle and vegetable production tolerate rainy weather better than cereal production and can be used for consumption when heavy rain results in harvest destruction. Increased cattle and vegetable production would help build resilience to climate change impacts.

Despite its caveats, this study has improved our understandings of the interconnection between LF and SLM practices and the environmental, economic and social outcomes of adapting agriculture in the Gamo Highlands to climate change. It shows that farmers are aware of climate change and that they already taking action. This is promising. However, many challenges still lie ahead. 


\section{Literature cited}

Abdulai, A. and Delgado, C. 1999. Determinants of nonfarm earnings of farm-based husbands and wives in Northern Ghana. American Journal of Agricultural Economics, 81(1), pp.117-130.

Abtew, W., Melesse, A. M. and Dessalegne, T. 2009. El Niño southern oscillation link to the Blue Nile River basin hydrology. Hydrological Processes, 23, 3653-3660.

Adger, W. N., Huq, S., Brown, K., Conway, D. and Hulme, M. 2003. Adaptation to climate change in the developing world. Progress in Development Studies, 3, 179-195.

Adimassu, Z., Kessler, A. and Hengsdijk, H. 2012. Exploring determinants of farmers' investments in land management in the Central Rift Valley of Ethiopia. Applied Geography, 35, 191-198.

Aigner, D., Lovell, C. A. K. and Schmidt, P. 1977. Formulation and estimation of stochastic frontier production function models. Journal of Econometrics, 6, 21-37.

Alston, M. 2011. Gender and climate change in Australia. Journal of Sociology, 47, 53-70.

Alston, M. 2013. Women and adaptation. Wiley Interdisciplinary Reviews: Climate Change, 4, 351-358.

Anley, y., Bogale, A. and Hailegabriel, A. 2007. Adoption decision and use intensity of soil and water conservation measures by smallholder subsistence: Farmers in Dedo district, western Ethiopia. Land Degradation \& Development, 18, 289-302

Araya, T., Cornelis, W., Nyssen, J., Govaerts, B., Bauer, H., Gebreegziabher, T., Oicha, T., Raes, D., Sayre, K. D. and Haile, M. 2011. Effects of conservation agriculture on runoff, soil loss and crop yield under rainfed conditions in Tigray, Northern Ethiopia. Soil Use and Management, 27, 404-414.

Araya, T., Cornelis, W. M., Nyssen, J., Govaerts, B., Getnet, F., Bauer, H., Amare, K., Raes, D., Haile, M. and Deckers, J. 2012. Medium-term effects of conservation agriculture based cropping systems for sustainable soil and water management and crop productivity in the Ethiopian highlands. Field Crops Research, 132, 53-62.

Asfaw, S., Di Battista, F. and Lipper, L. 2016. Agricultural technology adoption under climate change in the Sahel: Micro-evidence from Niger. Journal of African Economies, 25, 637669.

Bardasi, E. and Wodon, Q. 2006. Measuring time poverty and analyzing its determinants: concepts and application to Guinea. In: Blackden, M. \& Wodon, Q. (eds.) Gender, time use, and poverty in sub-Saharan Africa. Washingon D.C.: World Bank.

Battese, G. E., Malik, S. J. and Gill, M. A. 1996. An investigation of technical inefficiencies of production of wheat farmers in four districts of Pakistan. Journal of Agricultural Economics, 47, 37-49. 
Belay, K. and Manig, W. 2004. Access to rural land in eastern Ethiopia: Mismatch between policy and reality. Agriculture and Rural Development in the Tropics and Subtropics, 105, 123-138.

Bentley, J. 1987. Economic and ecological approaches to land fragmentation: In defense of a much-aligned phenomenon. Annual Review of Anthropology, 16, 31-67.

Berhanu, W. and Beyene, F. 2015. Climate variability and household adaptation strategies in Southern Ethiopia. Sustainability, 7, 6353-6375.

Birch, E.-R. 2005. Studies of the labour supply of Australian women: What have we learned? Economic Record, 81, 65-84.

Birch, R. E., Le, T. A. and Miller, W. P. 2009. Household divisions of labour: Teamwork, gender and time. New York, Palgrave and Macmillan.

Bizimana, C., Nieuwoudt, W. L. and Ferrer, S. R. 2004. Farm size, land fragmentation and economic efficiency in southern Rwanda. Agrekon, 43, 244-262.

Björnberg, K. E. and Hansson, O. S. 2013. Gendering local climate adaptation. Local Environment, 18, 217-232.

Blaikie, P. M. and Sadeque, S. Z. 2000. Policy in high places: environment and development in the Himalayan region. ICIMOD.

Blarel, B., Hazell, P., Place, F. and Quiggin, J. 1992. The economics of farm fragmentation: evidence from Ghana and Rwanda. The World Bank Economic Review, 6, 233-254.

Bonner, J. P. 1987. Land consolidation and economic development in India: A study of two Harayana villages. New Delhi: Allied Publishers.

Branca, G., Lipper, L., McCarthy, N. and Jolejole, M. C. 2013. Food security, climate change, and sustainable land management. A review. Agronomy for sustainable development, 33, 635-650.

Brown, K. 2011. Sustainable adaptation: An oxymoron? Climate and Development, 3, 21-31.

Bryan, E., Deressa, T. T., Gbetibouo, A. G. and Ringler, C. 2009. Adaptation to climate change in Ethiopia and South Africa: Options and constraints. Environmental Science and Policy, 12, 413-426.

Bryan, E., Ringler, C., Okoba, B., Roncoli, C., Silvestri, S. and Herrero, M. 2013. Adapting agriculture to climate change in Kenya: Household strategies and determinants. Journal of Environmental Management, 114, 26-35.

Burchardt, T. 2008. Time and income poverty.

Burke, M. and Lobell, D. 2010. Food security and adaptation to climate change: What do we know? In: Burke, M. \& Lobell, D. (eds.) Climate change and food security. Dordrecht: Springer.

Burke, R. and McAteer, T. 2007. Work hours and work addiction: The price of all work and no play. In: Pamela, L. P. \& Daniel, C. G. (eds.) Exploring the Work and Non-Work Interface (Research in Occupational Stress and Well-being. Emerald Group Publishing Limited. 
Byrs, A. L., Alloreb, H., Gillb, T. M. and Peduzzia, P. N. 2003. Application of negative binomial modeling for discrete outcomes $A$ case study in aging research. Journal of Clinical Epidemiology 56, 559-564.

Cameron, A. C. and Trivedi, P. K. 2005. Microeconometrics: methods and applications. UK, Cambridge University Press.

Cameron, A. C. and Trivedi, P. K. 2009. Microeconometrics using stata. College Station, TX, Stata Press.

Cannon, T. 2002. Gender and climate hazards in Bangladesh. Gender and Development, 10, 45-50.

Cappellari, L. and Jenkins, S. P. 2003. Multivariate probit regression using simulated maximum likelihood. The Stata Journal, 3, 278-294.

Challinor, A., Wheeler, T., Garforth, C., Craufurd, P. and Kassam, A. 2007. Assessing the vulnerability of food crop systems in Africa to climate change. Climatic Change, 83, 381399.

Charlesworth, N. 1983. The origins of fragmentation of landholdings in British India: a comparative examination. Carson Press Ltd., London.

Chilonda, P. and Otte, J. 2006. Indicators to monitor trends in livestock production at national, regional and international levels. Livestock Research for Rural Development, $18,117$.

Clay, D., Reardon, T. and Kangasniemi, J. 1998. Sustainable intensification in the highland tropics: Rwandan farmers' investments in land conservation and soil fertility. Economic Development and Cultural Change, 46, 351-377.

Coates, J., Swindale, A. and Bilinsky, P. 2007. Household Food Insecurity Access Scale (HFIAS) for measurement of food access: indicator guide. Washington, DC: Food and Nutrition Technical Assistance Project, Academy for Educational Development.

Conway, D. and Schipper, E. L. F. 2011. Adaptation to climate change in Africa: Challenges and opportunities identified from Ethiopia. Global Environmental Change, 21, 227-237.

Craig, L. 2005. The money or the care: A comparison of couple and sole parent households' time allocation to work and children. Australian Journal of Social Issues, 40, 521-540.

Cramb, R. A., Garcia, J. N. M., Gerrits, R. V. and Saguiguit, G. C. 1999. Smallholder adoption of soil conservation technologies: evidence from upland projects in the Philippines. Land Degradation \& Development, 10, 405-423.

Croppenstedt, A. and Muller, C. 2000. The Impact of farmers' health and nutritional status on their productivity and efficiency: evidence from Ethiopia. Economic Development and Cultural Change, 48, 475-502.

Damte, B., Mekonnen, A., Kassie, M., Di Falco, S. and Bezabih, M. 2017. Determinants of adoption and impacts of sustainable land management and climate smart agricultural practices (SLM-CSA). Environment for Development Discussion Paper Series. 
De Lisle, D. 1982. Effects of distance on cropping patterns internal to the farm. Annals of the Association of American Geographers, 72, 88-98.

Deininger, K. and Jin, S. 2006a. Tenure security and land-related investment: Evidence from Ethiopia. European Economic Review, 50, 1245-1277.

Deininger, K. and Jin, S. 2006b. Tenure security and land-related investment: Evidence from Ethiopia. European Economic Review, 50, 1245-1277.

Demeke, A. B., Keil, A. and Zeller, M. 2011. Using panel data to estimate the effect of rainfall shocks on smallholders food security and vulnerability in rural Ethiopia. Climatic Change, 108, 185-206.

Demetriades, J. and Esplen, E. 2008. The gender dimensions of poverty and climate change adaptation. IDS Bulletin 39, 24-31.

Demetriou, D., Stillwell, J. and See, L. 2013. A new methodology for measuring land fragmentation. Computers, Environment and Urban Systems, 39, 71-80.

Deressa, T. T. 2007. Measuring The Economic Impact of Climate Change on Ethiopian Agriculture: Ricardian Approach.

Deressa, T. T. and Hassan, R. M. 2009. Economic impact of climate change on crop production in Ethiopia: evidence from cross-section measures. Journal of African economies, 18, 529-554.

Deressa, T. T., Hassan, R. M., Ringler, C., Alemu, T. and Yesuf, M. 2009. Determinants of farmers' choice of adaptation methods to climate change in the Nile Basin of Ethiopia. Global Environmental Change, 19, 248-255.

Devereux, S. and Sussex, I. Food insecurity in Ethiopia. a DFID Ethiopia Seminar, London, 2000.

Di Falco, S. 2014. Adaptation to climate change in Sub-Saharan agriculture: assessing the evidence and rethinking the drivers. European Review of Agricultural Economics, 41, 405-430.

Di Falco, S., Penov, I., Aleksiev, A. and Van Rensburg, T. M. 2010. Agrobiodiversity, farm profits and land fragmentation: Evidence from Bulgaria. Land Use Policy, 27, 763-771.

Di Falco, S. and Veronesi, M. On adaptation to climate change and risk exposure in the Nile basin of Ethiopia. In 2011 International Congress, August 30-September 2, 2011a Zurich, Switzerland (No.115549). European Association of Agricultural Economists.

Di Falco, S. and Veronesi, M. 2011b. On adaptation to climate change and risk exposure in the Nile basin of Ethiopia. European Association of Agricultural Economists

Di Falco, S., Veronesi, M. and Yesuf, M. 2011. Does adaptation to climate change provide food security? A micro-perspective from Ethiopia. American Journal of Agricultural Economics 93, 825-842.

Dorward, A., Poole, N., Morrison, J., Kydd, J. and Ure, I. 2003. Markets, Institutions and Technology: Missing Links in Livelihoods Analysis. Development Policy Review, 21, 319332. 
Doss, C. R. 2001. Designing agricultural technology for African women farmers: Lessons from 25 years of experience. World Development, 29, 2075-2092.

Drechsel, P., Gyiele, L., Kunze, D. and Cofie, O. 2001. Population density, soil nutrient depletion, and economic growth in sub-Saharan Africa. Ecological Economics, 38, 251258.

Dutilly-Diane, C., Sadoulet, E. and Janvery, A. 2003. Household behaviour under market failures: how natural resource management in agriculture promotes livestock production in the Sahel. Journal of African Economies, 12, 343-370.

DWSB 2015. Dita Woreda Statistics Office (DWSB) annual report 2015. Dita: Dita District Statistics Office.

Edwards, F., Dixon, J., Friel, S., Hall, G., Larsen, K., Lockie, S., Wood, B., Lawrence, M., Hanigan, I., Hogan, A. and Hattersley, L. 2011. Climate Change Adaptation at the Intersection of Food and Health. Asia-Pacific Journal of Public Health, 23, 91S-104S.

Ehui, S. and Pender, J. 2005. Resource degradation, low agricultural productivity, and poverty in sub-Saharan Africa: pathways out of the spiral. Agricultural Economics, 32, 225-242.

Eriksen, S., Aldunce, P., Bahinipati, C. S., Martins, R. D., Molefe, J. I., Charles, N., O'Brien, K., Olorunfemi, F., Park, J., Sygna, L. and Ulsrud, K. 2011. When not every response to climate change is a good one: Identifying principles for sustainable adaptation. Journal of Climate change and Development, 3, 7-11.

Eriksen, S. and Brown, K. 2011. Sustainable adaptation to climate change. Climate and Development, 3, 3-6.

Eriksen, S. H. and O'Brien, K. 2007. Vulnerability, poverty and the need for sustainable adaptation measures. Climate Policy, 7, 337-352.

Falco, S. D. 2014. Adaptation to Climate Change in Sub-Saharan Agriculture: Assessing the Evidence and Rethinking the Drivers. European Review of Agricultural Economics 41 405-430.

Faltermeier, L. and Abdulai, A. 2009. The impact of water conservation and intensification technologies: empirical evidence for rice farmers in Ghana. Agricultural Economics, 40, 365-379.

FAO 2012. FAO Statistical Yearbook 2012 Rome, Food and Agricultural Organization of the United Nations.

FAO, IFAD and WFP 2015. The State of Food Insecurity in the World 2015. Meeting the 2015 international hunger targets: taking stock of uneven progress. Rome: FAO.

Feleke, S. T., Kilmer, R. L. and Gladwin, C. H. 2005. Determinants of food security in Southern Ethiopia at the household level. Agricultural Economics 33, 351-363.

Fenoaltea, S. 1976. Risk and Transaction Costs and the Organization of Medieval Agriculture Exploration in Economic History, 13, 129-151. 
Fernandes, E. C. and Burcroff, R. 2006. Sustainable land management: Challenges, opportunities, and trade-offs. Washington, D.C., World Bank.

Field, C. B. 2012. Managing the risks of extreme events and disasters to advance climate change adaptation: special report of the intergovernmental panel on climate change. UK, Cambridge University Press.

Gachathi, F. and Eriksen, S. 2011. Gums and resins: The potential for supporting sustainable adaptation in Kenya's drylands. Climate and Development, 3, 59-70.

Garrett, J. L. and Ruel, M. T. 1999. Are determinants of rural and urban food security and nutritional status different? some insights from Mozambique. World Development 27, 1955-1975.

Garrity, D. P., Akinnifesi, F. K., Ajayi, O. C., Weldesemayat, S. G., Mowo, J. G., Kalinganire, A., Larwanou, M. and Bayala, J. 2010. Evergreen Agriculture: a robust approach to sustainable food security in Africa. Food Security, 2, 197-214.

Gashaw, T. A. 2017. Agricultural land fragmentation and productivity in Ethiopia: Review. International Journal of Advanced Scientific Research, 2, 18-22.

Gebreyesus, S. H., Lunde, T., H.Mariam, D., Woldehanna, T. and Lindtjørn, B. 2015. Is the adapted Household Food Insecurity Access Scale (HFIAS) developed internationally to measure food insecurity valid in urban and rural households of Ethiopia? BMC Nutrition, 1, 2-10.

Greene, W. 2005. Fixed and random effects in stochastic frontier models. Journal of Productivity Analysis, 23, 7-32.

Guo, B. 2011. Household Assets and Food Security: Evidence from the Survey of Program Dynamics. Journal of family and economic issues, 32, 98-110.

Harvey, C. A., Rakotobe, Z. L., Rao, N. S., Dave, R., Razafimahatratra, H., Rabarijohn, R. H., Rajaofara, H. and MacKinnon, J. L. 2014. Extreme vulnerability of smallholder farmers to agricultural risks and climate change in Madagascar. Phil. Trans. R. Soc. B, 369(1639).

Hassan, R. and Nhemachena, C. 2008. Determinants of African farmers' strategies for adapting to climate change: multinomial choice analysis. African Journal of Agricultural and Resource Economics, 2, 83-104.

Heston, A. and Kumar, D. 1983. The persistence of land fragmentation in peasant agriculture: an analysis of South Asian cases. Explorations in Economic History, 20, 199230.

Holden, S. and Shiferaw, B. 2004. Land degradation, drought and food security in a lessfavoured area in the Ethiopian highlands: a bio-economic model with market imperfections. Agricultural Economics 30, 31-49.

Hossain, M. and Singh, V. P. 2000. Fertilizer use in Asian agriculture: implications for sustaining food security and the environment. Nutrient Cycling in Agroecosystems, 57, 155-169. 
Houghton, J. T. 1996. Climate change 1995: The science of climate change: contribution of working group I to the second assessment report of the Intergovernmental Panel on Climate Change (Vol. 2). Cambridge University Press.

Hsiao, C. 1985. Benefits and limitations of panel data. Econometric Reviews, 4, 121-174.

Hung, V. P., MacAulay, T. G. and Marsh, P. S. 2007. The economics of land fragmentation in the north of Vietnam. The Australian Journal of Agricultural and Resource Economics, 51, 195-211.

Hurni, H. 1998. Agroecological belts of Ethiopia: explanatory notes on three maps at a scale of $1: 1,000,000$. Soil conservation research program of Ethiopia. Explanatory notes on three maps at a scale of. Addis Ababa, Ethiopia.

Ilbery, B. W. 1984. Farm fragmentation in the Vale of Evesham. Area, 16, 159-165.

ILO 1921. Hours of Work (Industry) Convention, 1919 (No. 1). C001. Washington DC: International Labour Organization.

IPCC 2001. Climate Change: The Scientific Basis. In: Jenkinson, D. S., Hart, P.B.S., Rayner, J.H., Parry, L.C. (ed.) Modelling the turnover of organic matter in long-term experiments at Rothamstedt. Cambridge, UK.: Cambridge Univ. Press

IPCC 2014. Climate Change 2014 Synthesis Report Summary for Policymakers. 2014.

Jabarin, A. S. and Epplin, F. M. 1994. Impacts of land fragmentation on the cost of producing wheat in the rain-fed region of northern Jordan. Agricultural Economics, 11 191-196.

Jabs, J. and Devine, C. M. 2006. Time scarcity and food choices: an overview. Appetite, 47, 196-204.

Jayne, T. S., Yamano, T., Weber, M. T., Tschirley, D., Benfica, R., Chapoto, A. and Zulu, B. 2003. Smallholder income and land distribution in Africa: implications for poverty reduction strategies. Food Policy, 28, 253-275.

Jeffery, S., Verheijen, F. G. A., Van der Velde, M. and Bastos, A. C. 2011. A quantitative review of the effects of biochar application to soils on crop productivity using metaanalysis. Agriculture, Ecosystems and Environment, 114, 175-187.

Jerneck, A. 2018. Taking gender seriously in climate change adaptation and sustainability science research: views from feminist debates and sub-Saharan small-scale agriculture. Sustainability Science, 13, 403-416.

Jin, J., Wang, X. and Gao, Y. 2015. Gender differences in farmers' responses to climate change adaptation in Yongqiao district, China. Science of the Total Environment, 538, 942-948.

Johnston-Anumonwo, I. 1992. The influence of household type on gender differences in work trip distance. The Professional Geographer, 44, 161-169.

Jondrow, J., Lovell, C. K., Materov, I. S. and Schmidt, P. 1982. On the estimation of technical inefficiency in the stochastic frontier production function model. Journal of econometrics, 19, 233-238. 
Jones, P. G. and Philip, K. T. 2003. The potential impacts of climate change on maize production in Africa and Latin America in 2055. Global Environmental Change, 13, 51 59.

Kabubo, M. J. and Karanja, F. K. 2007. The economic impact of climate change on Kenyan crop agriculture: A Ricardian approach. Global and Planetary Change, 57, 319-330.

Kandlinkar, M. and Risbey, J. 2000. Agricultural impacts of climate change: If adaptation is the answer, what is the question? Climatic Change, 45, 529-539.

Kassie, M., Holden, S., Köhlin, G. and Bluffstone, R. 2009a. Economics of soil conservation adoption in high-rainfall areas of the Ethiopian Highlands.

Kassie, M., Köhlin, G., Bluffstone, R. and Holden, S. Are soil conservation technologies "winwin?" A case study of Anjeni in the north-western Ethiopian highlands. Natural Resources Forum, 2011. Wiley Online Library, 89-99.

Kassie, M., Pender, J., Yesuf, M., Kohlin, G., Bluffstone, R. and Mulugeta, E. 2007. Impact of soil conservation on crop production in the Northern Ethiopian Highlands. Intl Food Policy Res Inst.

Kassie, M., Teklewold, H., Jaleta, M., Mareny, P. and Erenstein, O. 2015a. Understanding the adoption of a portfolio of sustainable intensification practices in eastern and southern Africa Menale. Land Use Policy, 42 400-411.

Kassie, M., Teklewold, H., Marenya, P., Jaleta, M. and Erenstein, O. 2015b. Production risks and food security under alternative technology choices in Malawi: application of a multinomial endogenous switching regression. Journal of Agricultural Economics, 66, 640-659.

Kassie, M., Zikhali, P., Pender, J. and Köhlin, G. 2009b. Sustainable agricultural practices and agricultural productivity in Ethiopia: does agroecology matter? Working Papers in Economics 406.

Kassie, M., Zikhali, P., Pender, J. and Köhlin, G. 2010. The economics of sustainable land management practices in the Ethiopian highlands. Journal of Agricultural Economics, 61, 605-627.

Kawasaki, K. 2010. The costs and benefits of land fragmentation of rice farms in Japan. The Australian Journal of Agricultural and Resource Economics, 54, 509-526.

Kes, A. and Swaminathan, H. 2006. Gender and time poverty in sub-Saharan Africa. In: Blackden, C. M. \& Wodon, Q. (eds.) Gender, time use, and poverty in sub-Saharan Africa. Washington, D.C.: World Bank.

Kibue, G. W., Pan, G., Zheng, J., Zhengdong, L. and Mao, L. 2015. Assessment of climate change awareness and agronomic practices in an agricultural region of Henan Province China. Environment, Development and Sustainability, 17, 379-391.

King, R. 1977. Land Reform: a World Survey Boulder: Westview Press.

Kjellstrom, T. and Weaver, H. J. 2009. Climate change and health: Impacts, vulnerability, adaptation and mitigation. New South Wales Public Health Bulletin, 20, 5-9. 
Knox, J., Hess, T., Daccache, A. and Wheeler, T. 2012. Climate change impacts on crop productivity in Africa and South Asia. Environmental Research Letters, 7, 034032.

Kok, M., Lüdeke, M., Lucas, P., Sterzel, T., Walther, C., Janssen, P., Sietz, D. and De Soysa, I. 2016. A new method for analysing socio-ecological patterns of vulnerability. Regional Environmental Change 16, 229-243.

Koopmans, T. C. 1951. An analysis of production as pfficient combination of activities. New York.

Kotir, H. J. 2011. Climate change and variability in Sub-Saharan Africa: a review of current and future trends and impacts on agriculture and food security. Environment, Development and Sustainability, 13, 587-605.

Kumbhakar, S. C. and Heshmati, A. 1995. Efficiency measurement in Swedish dairy farms: An application of rotating panel data,1976-88. American Journal of Agricultural Economics, 77, 660-674.

Kumbhakar, S. C., Lien, G. and Hardaker, J. B. 2014. Technical efficiency in competing panel data models: a study of Norwegian grain farming. Journal of Productivity Analysis, 41, 321-337.

Kumbhakar, S. C., Wang, H. and Horncastle, A. P. 2015. A practitioner's guide to stochastic frontier analysis using Stata. . New York: Cambridge University Press.

Kurukulasuriya, P. and Mendelsohn, R. 2008. A Ricardian analysis of the impact of climate change on African cropland.

Lal, R. 1998. Soil erosion impact on agronomic productivity and environment quality. Critical reviews in plant sciences, 17, 319-464.

Lei, Y., Zhang, H., Chen, F. and Zhang, L. 2016. How rural land use management facilitates drought risk adaptation in a changing climate-A case study in arid northern China. Science of the Total Environment, 550, 192-199.

Liniger, H., Mekdaschi-Studer, R., Hauert, C. and Gurtner, M. 2011. Guidelines and best practices for Sub-Saharan Africa, field application. FAO.

Maddison, D. 2007. The perception of and adaptation to climate change in Africa (Vol. 4308). World Bank Publications.

Manjunatha, A., Anik, R. A., Speelman, S. and Nuppenau, E. 2013 A.V. Manjunathaa,b,*, Asif Reza Anikc, S. Speelmand, E.A. Nuppenaua. Impact of land fragmentation, farm size, land ownership and crop diversity on profit and efficiency of irrigated farms in India. Land Use Policy 31, 397- 405.

MARD 2013. Sustainable land management project II revised final draft document on environmental and social management framework (ESMF). Addis Ababa: Ministry of Agriculture and Rural Development (MARD).

Marlene, R. and Henry, D. 2002. Reducing risk and vulnerability to climate change in India: The capabilities approach. Gender and Development, 10, 78-83. 
Matouš, P., Todo, Y. and Mojo, D. 2013. Roles of extension and ethno-religious networks in acceptance of resource-conserving agriculture among Ethiopian farmers. International Journal of Agricultural Sustainability, 11, 301-316.

Maxwell, D., Vaitla, B. and Coates, J. 2014. How do indicators of household food insecurity measure up? An empirical comparison from Ethiopia. Food Policy, 47, 107-116.

Maxwell, D. and Wiebe, K. 1999. Land tenure and food security: Exploring dynamic linkage Dvelopment and change 30, 825-849.

Maxwell, D. G. 1996. Measuring food insecurity: the frequency and severity of "coping strategies". Food Policy, 21, 291-303.

McCall, B. 1985. The significance of distance constraints in peasant farming systems with special reference to sub-Saharan Africa. Applied Geography 5, 325-345.

McPherson, M. F. 1982. Land fragmentation: A selected literature review. Development Discussion Papers. Harvard institute for international development: Harvard University.

Meeusen, W. and van Den Broeck, J. 1977. Efficiency estimation from Cobb-Douglas production functions with composed error. International Economic Review, 18, 435-444.

Mendelsohn, R. and Dinar, A. 1999. Climate change, agriculture and developing countries: Does adaptation matter? The World Btnk Research Observer, 14, 277-93.

Mendelsohn, R., Dinar, A. and Williams, L. 2006. The distributional impact of climate change on rich and poor countries. Environment and Development Economics, 11, 159-178.

Mersha, A. A. and Van Laerhoven, F. 2016. A gender approach to understanding the differentiated impact of barriers to adaptation: responses to climate change in rural Ethiopia. Regional Environmental Change, 16, 1701-1713.

Mesfin, M., Gebrerufael, G. and Feleke, W. 2014. Enhancing household food security through Irish potato production in Gamo Highlands of southern Ethiopia. Scholarly Journal of Agricultural Science, 4, 410-419.

Minu, H. and Ulrike, R. 2009. Engendering the climate-change negotiations: experiences, challenges, and steps forward. Gender and Development, 17, 19-32.

Mizina, S. V., Smith, J. B., Gossen, E., Spiecker, K. F. and Witkowski, S. L. 1999. An evaluation of adaptation options for climate change impacts on agriculture in Kazakhstan. Mitigation and Adaptation Strategies for Global Change, 4, 25-41.

Motavalli, P., Nelson, K., Udawatta, R., Jose, S. and Bardhan, S. 2013. Global achievements in sustainable land management. International Soil and water conservation research, 1, 1-10.

$\mathrm{Mu}, \mathrm{R}$. and Van de Walle, D. 2011. Left behind to farm? Women's labourre-allocation in rural China. Labour Economics, 18, S83-S97.

Murray, U., Gebremedhin, Z., Brychkova, G. and Spillane, C. 2016. Smallholder farmers and climate smart agriculture: technology and labor-productivity constraints amongst women smallholders in Malawi. Gender, Technology and Development, 20, 117-148. 
Ndiritu, S., Kassie, M. and Shiferaw, B. 2015. Determinants of food security in Kenya, a gender perspective.

Nguyen, T., Cheng, E. and Findlay, C. 1996. Land fragmentation and productivity in China in the 1990s. China Economic Review, 7, 169- 180.

Nigussie, Z., Tsunekawa, A., Haregeweyn, N., Adgo, E., Nohmi, M., Tsubo, M., Aklog, D., Meshesha, T. D. and Abele, S. 2017. Factors influencing small-scale farmers' adoption of sustainable land management technologies in north-western Ethiopia. Land Use Policy, 67, 57-64.

Niroula, G. S. and Thapa, G. B. 2005. Impacts and causes of land fragmentation, and lessons learned from land consolidation in South Asia. Land Use Policy, 22, 358-372.

Niroula, G. S. and Thapa, G. B. 2007. Impacts of land fragmentation on input use, crop yield and production efficiency in the mountains of Nepal. Land Degradation and Development, 18, 237-248.

Norton, R. D. and Hazell, P. B. 1986. Mathematical programming for economic analysis in agriculture. Macmillan.

O'Brien, K. and Leichenko, R. 2007. Human security, vulnerability and sustainable adaptation. New York: Human Development Report Office.

Olesen, J. E. and Bindi, M. 2002. Consequences of climate change for European agricultural productivity, land use and policy. European Journal of Agronomy 16, 239-262.

Orindi, V., A. , Ochieng, B., Otiende, S., Bhadwal, K., Anantram, S., Nair, V. K. and Kelkar, U. 2006. Mapping climate vulnerability and poverty in Africa. In: Thornton, P. K., Jones, P. G., Owiyo, T., Kruska, R. L., Herrero, M., Kristjanson, P., Notenbaert, A., Bekele, N. \& Omolo, A. (eds.) In Mapping ClimateVulnerability and Poverty inAfrica. Nairobi: International Livestock Research Institute (ILRI).

Pachauri, K. R. and Meyer, L. 2014. Synthesis Report: Contribution of working groups I, II and III to the fifth assessment report of the intergovernmental panel on climate change. Geneva, Switzerland, IPCC.

Parry, M., Canziani, O., Palutikof, J., van der Linden, P. and Hanson, C. 2007. Climate change 2007: impacts, adaptation and vulnerability (Vol. 4). Cambridge, Cambridge University Press

Parry, M., Rosenzweig, C., Iglesias, A., Fischer, G. and Livermore, M. 1999. Climate change and world food security: a new assessment. Global Environmental Change 9, S51-S67.

Parrya, M. L., Rosenzweigb, C., Iglesiasc, A., Livermored, M. and Fischere, G. 2004. Effects of climate change on global food production under SRES emissions and socio-economic scenarios. Global Environmental Change, 14, 53-67.

Pellegrini, L. and Tasciotti, L. 2014. Crop diversification, dietary diversity and agricultural income: empirical evidence from eight developing countries. Canadian Journal of Development Studies, 35, 211-227. 
Pendera, J. and Gebremedhin, B. 2007. Determinants of agricultural and land management practices and impacts on crop production and household income in the highlands of Tigray, Ethiopia. Journal of African Economies 17, 395-450.

Peralta, A. 2009. Financing for Climate Change Mitigation and Adaptation in the Philippines.

Pretty, J., Toulmin, C. and Williams, S. 2011. Sustainable intensification in African agriculture. International Journal of Agricultural Sustainability, 9, 5-24.

Rahmana, S. and Rahman, M. 2008. Impact of land fragmentation and resource ownership on productivity and efficiency: The case of rice producers in Bangladesh. Land Use Policy, 26, 95-103.

Reidsma, P., Ewert, F., Lansink, A. O. and Leemans, R. 2010. Adaptation to climate change and climate variability in European agriculture: The importance of farm level responses. European journal of agronomy, 32, 91-102.

Reilly, J. and Schimmelpfennig, D. 1999. Agricultural impact assessment, vulnerability, and the scope for adaptation. Climate Change, 43, 745-788.

Richardson, B. C. 1974. Distance regularities in Guyanese rice cultivation. The Journal of Developing Areas, 8, 235-256.

Roco, L., Bravo-Ureta, B., Engler, A. and Jara-Rojas, R. 2017. The Impact of Climatic Change Adaptation on Agricultural Productivity in Central Chile: A Stochastic Production Frontier Approach. Sustainability, 9, 1648.

Rutherford, S. 2010. Are you going home already? The long hours culture, women managers and patriarchal closure. Time and Society, 10, 259-276.

Samberg, L. H., Shennan, C. and Zavaleta, E. S. 2010. Human and Environmental Factors Affect Patterns of Crop Diversity in an Ethiopian Highland Agroecosystem. The Professional Geographer, 62, 395-408.

Sanchez, P. A., Buresh, R. J. and Leakey, R. R. 1979. Trees, soils, and food security. Philosophical Transactions of the Royal Society of London B: Biological Sciences, 352, 949-961.

Schirpke, U., Kohler, M., Leitinger, G., Fontana, V., Tasser, E. and Tappeiner, U. 2017. Future impacts of changing land-use and climate on ecosystem services of mountain grassland and their resilience. Ecosystem Services 26, 79-94.

Schlenker, W. and Lobell, D. B. 2010. Robust negative impacts of climate change on African agriculture. Environmental Research Letters, 5, p.014010.

Schlenker, W. and Roberts, M. J. 2009. Non linear temperature effects indicate severe damages to US crop yields under climate change. Proceedings of the National Academy of Sciences, 106, 15594-15598.

Schmidhuber, J. and Tubiello, F. N. 2007. Global food security under climate change. Proceedings of the National Academy of Sciences, 104, 19703-19708. 
Schmidt,E. and Tadesse, F. 2017. The sustainable land management program in the Ethiopian highlands: An evaluation of its impact on crop production (vol. 103). International Food Policy Research Institute (IFPRI).

Schmidt, E. and Bekele, F. 2016. Rural youth and employment in Ethiopia. ESSP II Working Paper 98. . Washington, D.C. and Addis Ababa, Ethiopia, International Food Policy Research Institute (IFPRI) and Ethiopian Development Research Institute (EDRI).

Schmidt, E. and Tadesse, F. 2014. Sustainable agriculture in the Blue Nile Basin: land and watershed management practices in Ethiopia. Environment and Development Economics, 19, 648-667.

Scholes, R. J. and Biggs, R. 2004. Ecosystem services in southern Africa: a regional assessment Millennium ecosystem assessment.

Seo, N. and Mendelsohn, R. 2008a. Animal husbandry in Africa: climate change impacts and adaptations. African Journal of Agricultural and resource Economics, 2, 65-82.

Seo, S. N. 2010. A microeconometric analysis of adapting portfolios to climate change: Adoption of agricultural systems in Latin America. Applied Economic Perspectives and Policy, 32, 489-514.

Seo, S. N. and Mendelsohn, R. 2008b. An analysis of crop choice: Adapting to climate change in South American farms. Ecological Economics, 67, 109-116.

Seo, S. N. and Mendelsohn, R. 2008c. Measuring impacts and adaptations to climate change: a structural Ricardian model of African livestock management. Agricultural Economics, 38, 151-165.

Seyoum, E. T., Battes, G. E. and Fleming, E. M. 1998. Technical efficiency and productivity of maize producers in eastern Ethiopia: a study of farmers within and outside the Sasakawa-Global 2000 project. Agricultural Economics, 19, 341-348.

Shastri, A. 2014. Gender inequality and women discrimination. Journal of Humanities and Social Science, 19, 27-30.

Sherlund, S. M., Barrett, C. B. and Adesina, A. A. 2002. Smallholder technical efficiency controlling for environmental production conditions Journal of Development Economics, 69, 85-101.

Shiferaw, B. and Holden, S. 1998. Resource degradation and adoption of land conservation technologies in the Ethiopian Highlands: A case study in Andit Tid, North Shewa. Agricultural Economics, 18233 -247.

Shively, E. G. 1999. Risks and returns from soil conservation: evidence from low-income farms in the Philippines. Agricultural Economics 21, 53-67.

Sietz, D. and Van Dijk, H. 2015. Land-based adaptation to global change: What drives soil and water conservation in western Africa? Global Environmental Change, 33, 131-141.

Sikor, T., Müller, D. and Stahl, J. 2009. Land fragmentation and cropland abandonment in Albania: Implications for the roles of state and community in post-socialist land consolidation. World Development, 37, 1411-1423. 
Silvestri, S., Bryan, E., Ringler, C., Herrero, M. and Okoba, B. 2012. Climate change perception and adaptation of agro-pastoral communities in Kenya. Regional Environmental Change, 12, 791-802.

Singh, I., Squire, L. and Strauss, J. 1986. Agricultural household models: Extensions, applications, and policy. Washington DC: The World Bank.

Smucker, A. T. and Wangui, E. E. 2016. Gendered knowledge and adaptive practices: Differentiation and change in Mwanga district, Tanzania. Ambio, 45, 276-286.

Stige, L. C., Stave, J., Chan, K., Ciannelli, L., Pattorelli, N., Glantz, M., Herren, H. and Stenseth, N. 2006. The effect of climate variation on agro-pastoral production in Africa. Proceedings of the National Academy of Sciences of the United States of America, 103, 3049-3053.

Swindale, A. and Bilinsky, P. 2006. Household dietary diversity score (HDDS) for measurement of household food access: Indicator guide. Washington, DC: Food and Nutrition Technical Assistance Project, Academy for Educational Development.

Tan, S., Heerink, N., Kuyvenhoven, A. and Qu, F. 2010. Impact of land fragmentation on rice producers' technical efficiency in South-East China. NJAS -Wageningen Journal of Life Sciences, 57 117-123.

Tana, S., Heerinkb, N. and Qua, F. 2006. Land fragmentation and its driving forces in China. Land Use Policy 23, 272-285.

Tappan, G. and McGahuey, M. 2007. Tracking environmental dynamics and agricultural intensification in southern Mali. Agricultural Systems, 94, 38-51.

Tatlonghari, G. T. and Paris, T. R. 2013. Research, action and policy: Addressing the gendered impacts of climate change. Dordrecht, Springer Science \& Business Media.

Teklewold, H., Kassie, M., Shiferaw, B. and Köhlin, G. 2013. Cropping system diversification, conservation tillage and modern seed adoption in Ethiopia: Impacts on household income, agrochemical use and demand for labor. Ecological Economics, 93, 85-93.

Tennant, C. 2001. Work-related stress and depressive disorders. Journal of Psychosomatic Research, 51, 697-704.

Terry, G. 2009. No climate justice without gender justice: an overview of the issues. Gender \& Development, 17, 5-18.

Tesfaye, A., Bogale, A., Namara, R. E. and Bacha, D. 2008. The impact of small-scale irrigation on household food security: The case of Filtino and Godino irrigation schemes in Ethiopia. Irrigation and Drainage Systems, 22, 145-158.

Teshome, A., Graaff, J. d., Ritsema, C. and Kassie, M. 2014. Farmers' perceptions about the influence of land quality, land fragmentation and tenure systems on sustainable land management in the north western Ethiopian highlands. Land Degradation and Development, 27, 884-898. 
Teshome, A., Rolker, D. and de Graaff, J. 2013. Financial viability of soil and water conservation technologies in northwestern Ethiopian highlands. Applied Geography, 37, 139-149.

Thapa, G. and Paudel, G. 2002. Status of land in the mountain watersheds of Nepal. Land Degradation \& Development, 13, 479-493.

Thapa, G. B. and Niroula, G. S. 2008. Alternative options of land consolidation in the mountains of Nepal: An analysis based on stakeholders' opinions. Land Use Policy, 25, 338-350.

Thomas, S. D. and Twyman, C. 2005. Equity and justice in climate change adaptation amongst natural-resource-dependent societies. Global Environmental Change, 15, 115124.

Tol, R. S. 2011. The economic impact of climate change Perspektiven der Wirtschaftspolitik. 2010 11, 13-37.

Tolessa, T., Senbeta, F. and Kidane, M. 2017. The impact of land use/land cover change on ecosystem services in the central highlands of Ethiopia. Ecosystem Services 23, 47-54.

Tolossa, D. 2003. Issues of land tenure and food security: the case of three communities of Munessa wereda, south central Ethiopia. Norwegian Journal of Geography, 57, 9-19.

Turner, T. and Niemeier, D. 1997. Travel to work and household responsibility: new evidence. Transportation, 24, 397-419.

Udo, R. K. 1965. Disintegration of new cleared settlement in Eastern Nigeria. Geographical Review, 55, 53-67.

United Nations 2005. Guide to producing statistics on time use: Measuring paid and unpaid work. New York: United Nations.

United Nations 2018. World Population Prospects: The 2017 Revision. In: Affairs, U. D. O. E. a. S. (ed.). New York: United Nations Statistics Division.

Van Dijk, T. 2003. Scenarios of central European land fragmentation. Land Use Policy, 20, 149-158.

Vermeulen, S. J., Aggarwal, P. K., Ainslie, A., Angelone, C., Campbell, B. M., Challinor, A. J., Hansen, J. W., Ingram, J. S. I., Jarvis, A., Kristjanson, P., Lau, C., Nelson, G. C., Thornton, P. K. and Wollenberg, E. 2012. Options for support to agriculture and food security under climate change. Environmental Science \& Policy, 15, 136-144.

Von Braun, J. 2009. Chapter Fourteen Famine and Food Insecurity in Ethiopia (7-4) by Joachim von Braun and Tolulope Olofinbiyi. Case Studies in Food Policy for Developing Countries: Domestic policies for markets, production, and environment, 2, 175.

Wadud, M. and White, B. 2000. Farm household efficiency in Bangladesh: a comparison of stochastic frontier and DEA methods. Applied Economics, 32, 1665-1673.

Wan, G. and Cheng, E. 2001. Effects of land fragmentation and returns to scale in the Chinese farming sector. Applied Economics 33, 183-194. 
Wang, H. 2002. Heteroscedasticity and non-monotonic efficiency effects of a stochastic frontier model. Journal of Productivity Analysis, 18, 241-253.

Wang, J., Mendelsohn, R., Dinar, A. and Huang, J. 2010. How Chinese farmers change crop choice to adapt to climate change. Climate Change Economics, 1, 167-185.

Wijeratne, M. A., Anandacoomaraswamy, A., Amarathunga, M. K. S. L. D., Ratnasiri, J., Basnayake, B. R. S. B. and Kalra, N. 2007. Assessment of impact of climate change on productivity of tea (Camellia sinensis L.) plantations in Sri Lanka. The National Science Foundation of Sri Lanka, 35, 119-126.

Williams, R. 2012. Using the margins command to estimate and interpret adjusted predictions and marginal effects. The Stata Journal, 12, 308-331.

World Bank 2016. Ethiopia - Priorities for ending extreme poverty and promoting shared prosperity : systematic country diagnostic. Washington, D.C: World Bank Group.

Wright, P. 2007. Family size and the gendered division of unpaid work: Implications for fertility decisions in Australia. Australian Journal of Social Issues, 42, 513-529.

Wu, J. and Babcock, B. A. 1998. The Choice of Tillage, Rotation, and Soil Testing Practices: Economic and Environmental Implications. American Journal of Agricultural Economics, 80, 494-511.

Zamasiya, B., Nyikahadzoi, K. and Mukamuri, B. B. 2017. Factors influencing smallholder farmers' behavioural intention towards adaptation to climate change in transitional climatic zones: A case study of Hwedza District in Zimbabwe. Journal of Environmental Management, 198, 233-239.

Zellner, A. 1962. An efficient method of estimating seemingly unrelated regressions and tests for aggregation bias. Journal of the American Statistical Association, 57, 348-368.

Zewdie, A. 2014. Impacts of climate change on food security: a literature review in sub Saharan Africa. Earth Science and Climatic Change, 5, 1-4.

Zhang, L., Huang, J. and Rozelle, S. 1996. Land policy and land use in China. OECD Conference on Agricultural Policies in China. Paris. 


\section{English summary}

Smallholder agriculture in Ethiopia is highly vulnerable to the impacts of climate change and variability. Smallholder farmers in the Gamo Highlands of Ethiopia are also facing high levels of land fragmentation (LF). LF, alternatively known as parcelization, refers to a situation in which a farmer cultivates multiple non-contiguous parcels at a distance from home and each other. LF holds back the application of land management practices and, therefore, affects soil fertility improvements. Moreover, LF raises production costs (e.g., increasing the time of travelling and yield loss in the border of fields). However, LF also has production benefits, decreasing the overall risk by spreading plots spatially and production over the seasons. In other words, LF allows farmers to diversify crop production over time and spatially across different agro-ecological zones and hence increases food security. Although many papers have investigated the cost side of LF, its benefits have been largely ignored.

As LF has pros and cons, the challenges and opportunities LF poses for climate change adaptation in the Gamo Highlands are unknown. To explore this, the thesis considers sustainable land management (SLM) practices as a strategy for sustainable adaptation to climate change and assesses the effects of LF on the outcomes of SLM practices. More specifically, the thesis examines the effect of LF on the use of SLM practices and hence how LF and SLM influence food security, technical efficiency and the labour balance between men and women. The objective of the thesis is to explain how LF and SLM practices influence the outcomes of sustainable adaptation to climate change in the Gamo Highlands of Ethiopia.

Chapter 1 introduces the thesis and presents the outline. It comprising a brief explanation of climate change impacts, the options to adapt to the changing climate through SLM practices and the role of LF in adaptation. Chapter 1 also describes the objective, research questions and the methodology of the study.

Chapter 2 examines the effect of LF on the deployment of SLM practices using a multivariate probit model. On average, the farm size of sampled farms in the Gamo Highlands is 1.7 hectares, divided into 21 plots. Smallholders are responding to the climate change they perceived by altering land management practices. The multivariate probit model results indicate that LF indicators have a significant effect on the use of SLM practices. For instance, higher LF promoted crop diversification (to fit different soil types and to stabilize yield), manure application (to increase soil fertility), and terracing (to prevent erosion on mountainous farm fields). The overall results imply that LF has mostly positive effects, related to the number of plots and soil types, and a few negative effects, caused by the 
distance between plots. The contrasts observed between farmers' opinions and inferential results may be attributed to the fact that to simplify the application of effort-intensive SLM practices farmers construct separated multiple homes and use horses and mules to transport farm inputs and outputs to and from distant plots.

Next, the thesis applied both probit and Poisson models to assess the specific and combined effects of LF and SLM practices on food security (set out in Chapter 3). The results show that although farmers are adopting SLM practices to adapt to climate change, the share of food insecure households in the Gamo Highlands remains high during food shortfall seasons, ranging from 93-95\%, depending on the indicator used. The results confirm that LF provides more potential opportunities for improving food security than challenges. Several LF indicators (such as cultivation in distinct agro-ecological zones, the Simpson index and multiple home ownership) increase food security. Furthermore, LF increases farm diversity (including soil types and the microclimates cultivated), leading to diversity in the crops grown and production seasons, allowing farmers to reduce the risks and harvest fresh produce throughout the year, thereby improving food security. Finally, production across different agro-ecological zones helps farmers to cope with price fluctuations and balances intra-annual food supply, thus increasing food security.

The food security effects of the SLM practices employed ranged from negative to positive. The use of quality seed and tree planting are SLM practices that enhance food security. Chemical fertilizer use also enhances food security, although it is not used sustainably because farmers have to pay a mark-up price for fertilizer and are forced to use it. In contrast, terracing, legume-barley rotation and crop diversification have a negative effect on food security, possibly because making terraces from the soil itself and renewing these terraces every production period is not significantly improving soil fertility and successful crop-rotation for food production requires informed decisions. Moreover, SLM practices applied to restore degraded plots take time to repay and the effects depend on weather conditions and the quality, suitability and intensity of the practices applied. LF and SLM practices individually and jointly affect food security and the marginal food security effects of SLM practices change at different values of the Simpson index. Overall, the findings imply that increasing the quality rather than the quantity of SLM practices is important to cope with the adverse impacts of climate change and variability on food security. Farmers' food security can also be enhanced by taking advantage of synergies between SLM and LF and resolving their contrasting effects.

Chapter 4 of the thesis investigates the individual and joint effects of LF and SLM practices on technical efficiency. The stochastic frontier analysis results show that the application of SLM practices, for instance, adding manure to the soil, legume-barley rotation, planting 
indigenous trees and quality seed use increases land productivity in barley production. LF indicators jointly affect technical efficiency. Larger plot size and distance to barley plot are efficiency improving. SLM practices also jointly affect technical efficiency; specifically indigenous tree planting is efficiency improving, but legume and manure application are efficiency impeding as manure use is a demanding activity, and legume application probably lacks quality. The study also reveals a significant joint effect of LF indicators and SLM practices on technical efficiency. However, the efficiency effects of most SLM practices do not depend on distance to the plot or the size of the plot, implying that the SLM practices applied lack quality and intensity. The general implication of the investigation is that SLM practices are not innovative enough to enhance efficiency or that there are constraints (e.g., lack of resources) that hinder their full potential.

The assumption that technical efficiency across multiple separate plots used by the same farmer is equal needs to be reconsidered in efficiency studies. We found that technical efficiency varies across plots for farmers. The mean technical efficiency across plots is $75 \%$ and across farmers $65 \%$. The overall mean technical efficiency is $49 \%$. This indicates that farmers have significant room to increase yield without using additional inputs, offering perspectives for increasing food supply in situations where virgin soil for food production is unavailable and limited. Therefore, farmers can increase technical efficiency and yield if awareness is created about the drawbacks of LF. Moreover, constraints that limit the full potential of existing SLM practices should be lifted (e.g., by providing resources to buy inputs) and new, more innovative SLM practices introduced. Training for farmers and agricultural experts is required to increase the quality and innovativeness of the SLM practices applied. Policy measures that reduce residual and persistent inefficiency are desirable as the magnitude of both inefficiency estimates are considerable.

Furthermore, this thesis examines the existence of gendered adaptation practices (see Chapter 5). To explain the differences in the working hours between men and women in three seasons (i.e., the planting and harvesting seasons or peak seasons and the off-peak seasons), a time allocation model estimated using a seemingly unrelated regression. The study found that the working hours of women are significantly longer in all seasons than those of men because of the gendered division of labor. LF increases the working hours of both men and women during peak seasons. Moreover, during the harvesting season men work longer hours than women. The results can be attributed to a gendered division of labor in Gamo communities. Gamo men travel to faraway plots to harvest crops while women, who are more responsible for domestic chores in the Gamo communities, harvest crops from plots close to home. This result also supports the Household Responsibility Hypothesis $(\mathrm{HRH})$, which says that women commute shorter distances than men to shoulder domestic responsibilities. Applying a large number of SLM practices to deal with climate change in 
fragmented farm fields results in a higher mean working hours for women than men. This implies that the burden of deployment of a large number of SLM practices is biased towards women.

Therefore, although LF is exogenous to farmers, which is why we did not consider endogeneity problems in our estimation of food security effects of SLM practices, it can be deployed in climate change adaptation planning. Moreover, it is clear that the voluntary assembling of plots into larger heterogeneous clusters can help farmers reduce LF and at the same time maximize its benefits. Reducing LF increases the intensity and quality of investment in remote fields and hence the outcomes of adaptation, for instance, supports farmers to become more food secure and reduces work hour wastage, and reduces the gendered effects of adaptation decisions. The thesis does not investigate how land assembling can be done. However, based on the suggestions of farmers during focus group discussions and a mini-workshop held to discuss the overall findings and policy implications of the thesis, promoting the voluntary exchange of plots between farmers or through cooperatives is a possible option.

Chapter 6 is the synthesis of the entire thesis. This chapter discusses and summarizes the main findings, offers critical reflections, suggests further research and provides policy implications. 


\section{Acknowledgements}

I would like to offer special thanks to my promotor Prof. dr. Coen Ritsema for his support throughout this PhD process, having trust in me and giving me the chance to continue my PhD under his supervision. I would like to thank my co-promotors Dr. Luuk Fleskens and Dr. Jack Peerlings for suggesting valuable ideas, insights and comments and for their wonderful multifaceted support, advice and encouragement throughout the PhD process; contact to be continued afterward. You supported me greatly and you were always willing to help me. I will never forget your collaboration, friendly approach, openness, and kindness. Without your great support this PhD would have been impossible. Dr. Diana Sietz, thank you for your valuable and constructive comments.

My gratitude goes to Dr. Bertha Vallejo Carlos, the coordinator of the PhD project, for valuable advice and encouragement and co-workers Kristína Melicherová and E.P.P. Souhail for your kindness and support provided. Moreover, technical assistance provided by Marnella van der Tol, the department secretary, was greatly appreciated. I would like to say thank you Marnella van der Tol for your sincerity and kindness.

I would like to thank my beloved wife Wudinesh Baruda and our children Getayawkal and Beminet for your love, encouragement and patience. My parents, my father Chofana Cholo, my mother Samune Shano and my step-mother Yayote Yage and my beloved brothers and sisters, I am also grateful for your support, mentorship, love, kindness and encouragement.

I would like to express my very great appreciation to Tadesse Chofana, Abraham Chofana and his wife Tabaze Tessema, Hizkel Oke, Melaku Kata, Habte Haile, Birhanu Mancho, Chakiso Chatare, Data Dalake and Tilahun Aba for their commitment and support during field data collection. Moreover, I would like to extend my appreciation to the Dita Woreda Agriculture and Natural Resource Conservation Office for providing Geographic information System (GIS) data. I would also like to appreciate experts and extension workers, farmers and local leaders involved in focus group discussions and mini-workshop for their loyalty and great support provided.

My special thanks are extended to the staff of Ethiopian Civil Service University: Dr. Kassa Teshager, Dr. Terefe Zeleke, Mr. Keokeb G. Giorgis, and Zekarias Minota for your advice, technical support and encouragement. My gratitude goes to my fellow doctoral students Dr. Dessalegn Shamebo, Malebo Mancha, Tegegn Gebeyaw, Samuel A. Heban, Samuel Tesfaye, Célia Bento, Walle Jemberu, Asmare Wubet, Selamwit Damtew and Marcien Ndagijimana: I would like to thank for your kind support and encouragement. Last, but not 
least, my special thanks are extended to Mr. Getachew Wondafrash Negate and Mrs. Claudette Hesselmann for your support, hospitality and encouragement. 


\section{Acknowledgement of financial support}

This project would have been impossible without the financial support of the Netherlands Organization for International Cooperation in Higher Education (Nuffic), under grant no. NICHE/ETH/O20, and coordinated by Tilburg and Wageningen Universities.

Cover design by: Oostindie Klaas

Printed by: Digforce 


\section{About the author}

Tesfaye Chofana Cholo was born on 30 December 1979 in Gamo Gofa, Ethiopia. In 2006, he obtained a BA degree in Economics from Ethiopian Civil Service University (formerly Ethiopian Civil Service College). After graduation, he was employed as a graduate assistant in Ethiopian Civil Service University from 2006 to 2007. In September 2008, he joined Addis Ababa University, Department of Economics to pursue his postgraduate study and received a Master

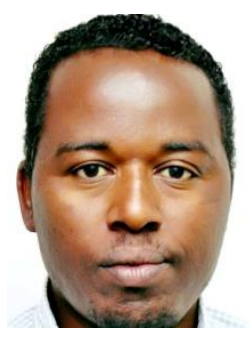
of Science Degree in Economics (under the Natural Resource and Environmental Economics stream) from Addis Ababa University in July 2009. In January 2015, he joined the Soil Physics and Land Management Group of Wageningen University and Research for PhD study. His PhD study was funded by NUFFIC. His future research focus on sustainable development, climate change adaptation, productivity and efficiency, food security, rural job creation and employment. He can be reached at tesfayechofana@yahoo.com; P.O.Box 5648 or Mobile +251912000344.

\section{Publications}

Cholo, T.C., Fleskens, L., Sietz, D. and Peerlings, J., 2018. Is Land Fragmentation Facilitating or Obstructing Adoption of Climate Adaptation Measures in Ethiopia? Sustainability, 10(7), 2120.

Wassie, T.W. and Cholo, T.C. 2012. Youth unemployment trends and its association with education and training in Urban Ethiopia: Evidence using pooled cross-section data from urban employment unemployment surveys. Journal of African Development Studies, 5(1), 88-108.

Submitted papers

Cholo, T.C., Fleskens, L., Sietz, D., and Peerlings, J. Land fragmentation, climate change adaptation, and food security in the Gamo Highlands of Ethiopia. Resubmitted after review to Agricultural Economics

Cholo, T.C., Peerlings, J. and Fleskens, L. Land fragmentation, technical efficiency, and adaptation to climate change by farmers in Ethiopia. Submitted to Journal of Productivity Analysis

Cholo, T.C., Peerlings, J. and Fleskens, L. Gendered climate change adaptation practices in fragmented farm fields of Gamo Highlands, Ethiopia. Submitted to Regional Environmental Change 
Book chapters

Alemu, T. and Cholo, T.C. 2015. Engaging diasporas as development partners in Ethiopia: prospects and challenges. In: Adepoju, A., ed. The diaspora decade Some perspectives on Africa migration-related issues. Nigeria: NOMRA

Cholo, T.C. and Wassie, T. 2014. Socioeconomic Causes of Urban Unemployment in Ethiopia. In: Mihyo, P.B., ed. Employment policies and unemployment in eastern and southern Africa. Ethiopia: OSSREA, 249-294 


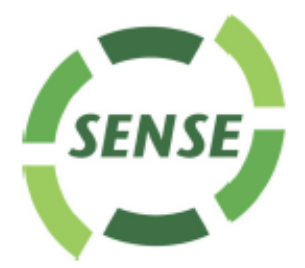

Netherlands Research School for the Socio-Economic and Natural Sciences of the Environment

\section{I P L O M A}

For specialised PhD training

The Netherlands Research School for the Socio-Economic and Natural Sciences of the Environment (SENSE) declares that

\section{Tesfaye Chofana Cholo}

born on 30 December 1979 in Gamogofa, Ethiopia

has successfully fulfilled all requirements of the Educational Programme of SENSE.

Wageningen, 5 September 2018

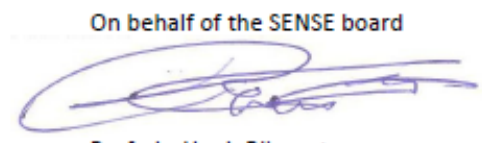

Prof. dr. Huub Rijnaarts

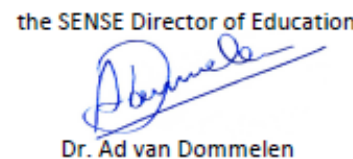

Dr. Ad van Dommelen

The SENSE Research School hes been accredited by the Royal Netherlands Academy of Arts and Sciences (KNAW)

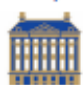

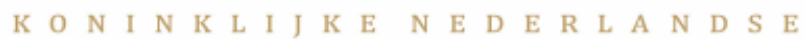

A K A D E M I E V A N W E TE N S C. H A P P E N 


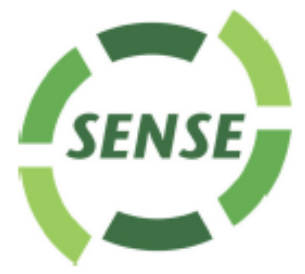

The SENSE Research School declares that Tesfaye Chofana Cholo has successfully fulfilled all requirements of the Educational PhD Programme of SENSE with a work load of $39.0 \mathrm{EC}$, including the following activities:

\section{SENSE PhD Courses}

Grasping Sustainability (2015)

- Environmental research in context (2017)

- Research in context activity: 'Initiating and organizing two workshops with local stakeholders on land fragmentation and sustainable climate change adaptation in Done Kebele and OcholoBadiga Kebele, Ethiopia' (2017)

\section{Other PhD and Advanced MSc Courses}

- Econometrics 1 (CentER), Tilburg University (2014)

- Adaptation to Climate Change in Developing Countries, Wageningen University (2015)

- WASS Summer school on Theory and Practice of Efficiency \& Productivity Measurement: static \& dynamic analysis, Wageningen University (2016)

\section{Management and Didactic Skills Training}

- Supervising four MSc students at the Ethiopian Civil Service University (2015-2016)

- Supervising two MSc students at the Ethiopian Civil Service University (2017-2018)

- Assisting practicals of the BSc course 'Natural Resource and Environmental Economics' (2015-2016)

- Teaching in the MSc course 'Stata Application to Economitrics' (2015-2016)

- Teaching in the MSc course 'Seminar in Development Economics' (2016-2017)

\section{Oral Presentations}

- Is land fragmentation an opportunity or challenge for farmers' climate adaptation in Ethiopia?'. $3^{\text {rd }}$ Wageningen PhD Symposium "Diversity in Science, 26 April 2016, Wageningen, The Netherlands

- Land fragmentation, climate adaptation and food security in the Gamo Highlands of Ethiopia. $18^{\text {th }}$ PhD symposium, Agricultural and Natural Resource Economics, 27 April 2017, Brussels, Belgium

- Land fragmentation, climate adaptation and food security in the Gamo Highlands of Ethiopia. $4^{\text {th }}$ Wageningen PhD Symposium "Science: from local to global", 3 May 2017, Wageningen, The Netherlands

SENSE Coordinator PhD Education<smiles>C1CCC2(CC1)CC1CC3CC(C1)CC2C3</smiles>

Dr. Peter Vermeulen 
